Modelos estocásticos utilizados no planejamento da operação de sistemas hidrotérmicos 



\title{
Modelos estocásticos utilizados no planejamento da operação de sistemas hidrotérmicos
}

\author{
Danilo Alvares da Silva
}

Orientador: Prof. Dr. Marinho Gomes de Andrade Filho

Dissertação apresentada ao Instituto de Ciências Matemáticas e de Computação - ICMC-USP, como parte dos requisitos para obtenção do título de Mestre em Ciências - Ciências de Computação e Matemática Computacional. VERSÃO REVISADA 
Ficha catalográfica elaborada pela Biblioteca Prof. Achille Bassi e Seção Técnica de Informática, ICMC/USP, com os dados fornecidos pelo(a) autor(a)

Alvares da Silva, Danilo

Modelos estocásticos utilizados no planejamento da operação de sistemas hidrotérmicos / Danilo Alvares da Silva; orientador Marinho Gomes de Andrade Filho. -- São Carlos, 2013. $60 \mathrm{p}$.

Dissertação (Mestrado - Programa de Pós-Graduação em Ciências de Computação e Matemática Computacional) -- Instituto de Ciências Matemáticas e de Computação, Universidade de São Paulo, 2013.

1. Planejamento Ótimo da Operação de Sistemas Hidrotérmicos. 2. Programação Dinâmica Estocástica. 3. Modelo de Vazões Log-Normal Truncado. 4. Inferência Bayesiana. 5. Previsão de Vazões. I. Gomes de Andrade Filho, Marinho, orient. II. Título. 
"A arte de sonhar é saber por em prática com as próprias mãos!"

(Danilo Alvares da Silva)

"O importante não é justificar o erro, mas impedir que ele se repita."

(Che Guevara) 



\section{Agradecimentos}

Agradeço à minha família, amigos e namorada pela compreensão nas horas que deixei de estar presente devido a construção dessa dissertação, aos professores Marinho G. Andrade, Eduardo F. Costa e Secundino Soares pela colaboração e elaboração de artigos envolvendo os resultados apresentados nesta dissertação, aos amigos Luiz $H$. B. Bertolucci e Cibele Maria Russo que contribuíram com sugestões no texto, código e interpretações dos resultados e a FAPESP pelo apoio financeiro concedido (Processo no 2011/14585-5). 

Algumas abordagens para o problema de Planejamento Ótimo da Operação de Sistemas Hidrotérmicos (POOSH) utilizam modelos estocásticos para representar as vazões afluentes dos reservatórios do sistema. Essas abordagens utilizam, em geral, técnicas de Programação Dinâmica Estocástica (PDE) para resolver o POOSH. Por outro lado, muitos autores têm defendido o uso dos modelos determinísticos ou, particularmente, a Programação Dinâmica Determinística (PDD) por representar de forma individualizada a interação entre as usinas hidroelétricas do sistema. Nesse contexto, esta dissertação tem por objetivo comparar o desempenho da solução do POOSH obtida via PDD com a solução obtida pela PDE, que emprega um modelo Markoviano periódico, com distribuição condicional Log-Normal Truncada para representar as vazões. Além disso, é realizada a análise com abordagem bayesiana, no modelo de vazões, para estimação dos parâmetros e previsões das vazões afluentes. Comparamos as performances simulando a operação das usinas hidroelétricas de Furnas e Sobradinho, considerando séries de vazões geradas artificialmente. 

Some approaches for problem of Optimal Operation Planning of Hydrothermal Systems (OOPHS) use stochastic models to represent the inflows in the reservoirs that compose the system. These approaches typically use the Stochastic Dynamic Programming (SDP) to solve the OOPHS. On the other hand, many authors defend the use of deterministic models and, particularly, the Deterministic Dynamic Programming (DDP) since it individually represents the interaction between the hydroelectric plants. In this context, this dissertation aims to compare the performance of the OOPHS solution obtained via DDP with the one given by SDP, which employs a periodic Markovian model with conditional Truncated Log-Normal distribution to represent the inflows. Furthermore, it is performed a bayesian approach analysis, in the inflow model, for estimating the parameters and forecasting the inflows. We have compared the performances of the DDP and SDP solutions by simulating the hydroelectric plants of Furnas and Sobradinho, employing artificially generated series. 



\section{Sumário}

1 Introdução 1

1.1 Motivação . . . . . . . . . . . . . . . . . . . . . . . 1

1.2 Problema de Planejamento Ótimo da Operação de Sistemas Hidrotérmicos 2

2 Modelagem do Problema 5

2.1 Programação Dinâmica . . . . . . . . . . . . . . . . . . . . 7

2.2 Modelo de Vazões Log-Normal Truncado . . . . . . . . . . . . . . . . . 8

2.2.1 Algoritmo para Geração de uma Série Sintética . . . . . . . . . 12

2.2.2 Validação da Série Sintética . . . . . . . . . . . . . . . . 12

2.2.3 Validação da Série Sintética via Critério de Kullback-Leibler . . 13

2.3 Análise de Previsões . . . . . . . . . . . . . . . . . . . . . . . . . . . . 14

3 Abordagem Bayesiana para o Modelo PAR(1) 19

3.1 Distribuições a priori e a posteriori . . . . . . . . . . . . . . 20

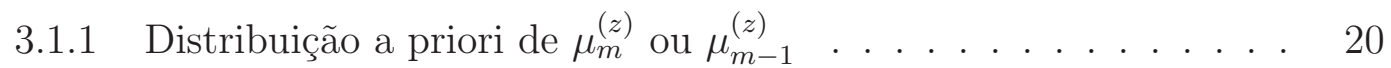

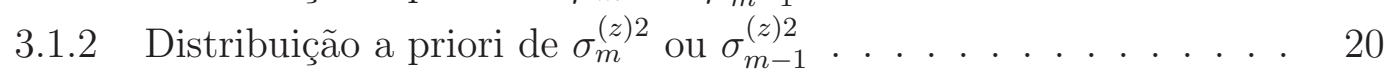

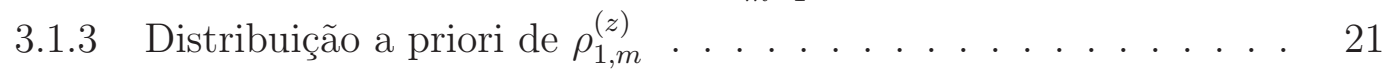

3.2 Métodos de Monte Carlo via cadeias de Markov (MCMC) . . . . . . . . 21

3.2.1 Amostrador de Gibbs . . . . . . . . . . . . . . . . . . 21

3.2.2 Metropolis-Hastings................. 22

3.3 Previsão Bayesiana . . . . . . . . . . . . . . . . . . . 23

4 Estudo de Casos $\quad 25$

4.1 Análise Descritiva dos Dados . . . . . . . . . . . . . . . 27

5 Resultados e Discussões $\quad 29$

5.1 Estimativa dos Parâmetros . . . . . . . . . . . . . . . . . . . . . 29 
5.2 Validação da Previsão . . . . . . . . . . . . . . . . . . . . . . . 32

5.3 Planejamento da Operação do Sistema Hidrotérmico ........ 34

5.4 Estudos de Previsões . . . . . . . . . . . . . . . . . . . . . . . . . . 37

6 Conclusão $\quad 41$

$\begin{array}{lll}7 & \text { Propostas Futuras } & 43\end{array}$

A Gráficos de Convergência $\quad 49$

B Gráficos de Autocorrelação $\quad 55$ 


\section{Lista de Figuras}

1.1 Sistema hidrotérmico com uma usina hidroelétrica e uma termoelétrica.

2.1 Exemplos de funções densidade de probabilidade condicional, utilizando a LN-Truncada, para o primeiro semestre de Furnas.

2.2 Histograma comparativo entre série real e série sintética de (a) Furnas e (b) Sobradinho. . . . . . . . . . . . . . . . . . 12

2.3 QQ-Plot entre série real e série sintética de (a) Furnas e (b) Sobradinho. 13

4.1 Usina hidroelétrica de Furnas. . . . . . . . . . . . . . . . . . . . 25

4.2 Usina hidroelétrica de Sobradinho. . . . . . . . . . . . . . . . 26

4.3 Série real e sintética de (a) Furnas e (b) Sobradinho. . . . . . . . . . . 27

5.1 Comparação entre a previsão e a série real de Furnas para os anos de 2008,2009 e 2010 . . . . . . . . . . . . . . . . . . . .

5.2 Comparação entre a previsão e a série real de Sobradinho para os anos de 2008, 2009 e 2010 . . . . . . . . . . . . . . . . . . . . 34

5.3 Trajetórias médias de volume para (a) Furnas e (b) Sobradinho, obtidas com as técnicas PDD e PDE. . . . . . . . . . . . . . . . 34

5.4 Trajetórias médias das turbinagens e vertimentos para (a) Furnas e (b) Sobradinho, obtidas com as técnicas PDD e PDE. . . . . . . . . . 35

5.5 Geração hidroelétrica média e complementação térmica média para as usinas de (a) Furnas e (b) Sobradinho, obtidas com as técnicas PDD e

5.6 Trajetória dos valores preditos e MLT em 2011, 2012 e 2013 para Furnas. 38

5.7 Trajetória dos valores preditos e MLT em 2011, 2012 e 2013 para Sobradinho. 
5.8 Trajetórias médias de volume para (a) Furnas e (b) Sobradinho, obtidas com as técnicas PDD e PDE no período de 2011 a 2013.

5.9 Trajetórias médias das turbinagens e vertimentos para (a) Furnas e (b) Sobradinho, obtidas com as técnicas PDD e PDE no período de 2011 a

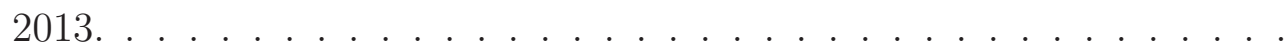

5.10 Geração hidroelétrica média e complementação térmica média para as usinas de (a) Furnas e (b) Sobradinho, obtidas com as técnicas PDD e PDE no período de 2011 a $2013 . \ldots$. . . . . . . . . . . . . . . . 40

A.1 Convergência de $\mu_{m}, m=1, \ldots, 12$, da usina hidroelétrica de Furnas. . 49

A.2 Convergência de $\mu_{m}, m=1, \ldots, 12$, da usina hidroelétrica de Sobradinho. 50

A.3 Convergência de $\sigma_{m}^{2}, m=1, \ldots, 12$, da usina hidroelétrica de Furnas. . $\quad 51$

A.4 Convergência de $\sigma_{m}^{2}, m=1, \ldots, 12$, da usina hidroelétrica de Sobradinho. 52

A.5 Convergência de $\rho_{m}, m=1, \ldots, 12$, da usina hidroelétrica de Furnas. . 53

A.6 Convergência de $\rho_{m}, m=1, \ldots, 12$, da usina hidroelétrica de Sobradinho. 54

B.1 Autocorrelação de $\mu_{m}, m=1, \ldots, 12$, da usina hidroelétrica de Furnas. $\quad 55$

B.2 Autocorrelação de $\mu_{m}, m=1, \ldots, 12$, da usina hidroelétrica de Sobradinho. . . . . . . . . . . . . . . . 56

B.3 Autocorrelação de $\sigma_{m}^{2}, m=1, \ldots, 12$, da usina hidroelétrica de Furnas. $\quad 57$

B.4 Autocorrelação de $\sigma_{m}^{2}, m=1, \ldots, 12$, da usina hidroelétrica de Sobradinho. . . . . . . . . . . . . . . . . 5 58

B.5 Autocorrelação de $\rho_{m}, m=1, \ldots, 12$, da usina hidroelétrica de Furnas. $\quad 59$

B.6 Autocorrelação de $\rho_{m}, m=1, \ldots, 12$, da usina hidroelétrica de Sobradinho. 60 


\section{Lista de Tabelas}

4.1 Média e desvio-padrão das séries históricas e sintéticas de Furnas e Sobradinho.

5.1 Sumários a posteriori dos parâmetros para a usina hidroelétrica de Furnas. 30

5.2 Sumários a posteriori dos parâmetros para a usina hidroelétrica de Sobradinho. . . . . . . . . . . . . . . . . . 31

5.3 Valores reais, previsões, REQM e EAP para os anos de 2008, 2009 e 2010 das usinas hidroelétricas de Furnas e Sobradinho. . . . . . . . . . 33

5.4 Resultados para a operação de Furnas e Sobradinho (GH = Geração Hidráulica Média; GT = Geração Térmica Média). . . . . . . . . . . 36

5.5 Resultados para o período crítico de Furnas e Sobradinho (GH = Geração Hidráulica Média; GT = Geração Térmica Média). . . . . . . . . . .

5.6 Valores preditos de vazões afluentes para os anos de 2011, 2012 e 2013 das usinas hidroelétricas de Furnas e Sobradinho. . . . . . . . . . . . 37

5.7 Resultado da operação de Furnas e Sobradinho para os anos de 2011, 2012 e 2013 (GH = Geração Hidráulica Média; GT = Geração Térmica Média). 



\section{Lista de Abreviações}

CCEE - câmara de comercialização de energia elétrica

DDP - deterministic dynamic programming

EAP - erro absoluto percentual

GH - geração hidráulica média

GT - geração térmica média

$\mathbf{h m}^{3}$ - hectômetro cúbico

iid - independentes identicamente distribuídos

LN - log-normal

$\mathbf{m}^{3} / \mathbf{s}$ - metro cúbico por segundo

MCMC - Monte Carlo via cadeias de Markov

MLT - média de longo termo

MW - megawatts

ONS - operador nacional do sistema elétrico

OOPHS - optimal operation planning of hydrothermal systems

PAR - periódico autorregressivo

PDD - programação dinâmica determinística

PDE - programação dinâmica estocástica

POOSH - planejamento ótimo da operação de sistemas hidrotérmicos

REQM - raiz quadrada do erro quadrático médio

SDP - stochastic dynamic programming

SIN - sistema interligado nacional 



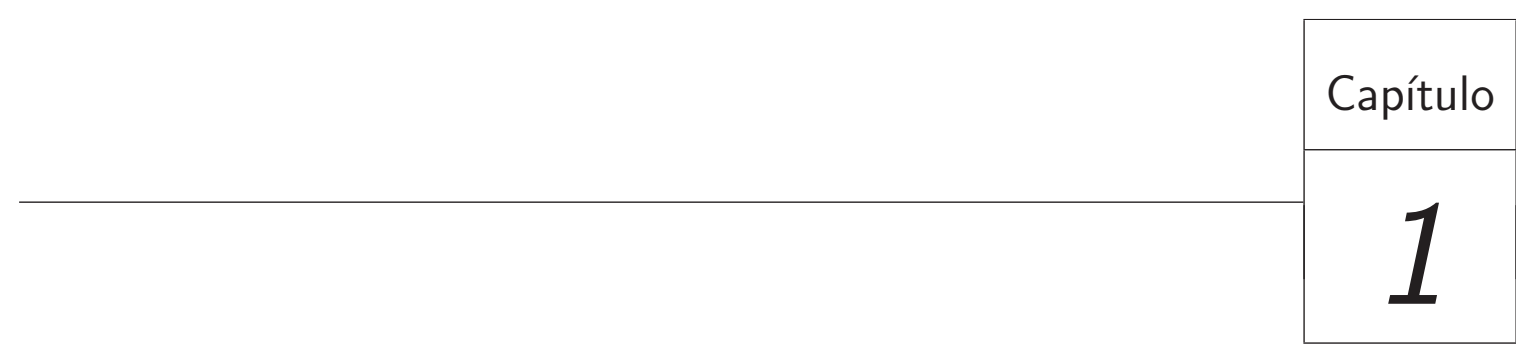

Introdução

\subsection{Motivação}

Para a sociedade moderna, os avanços tecnológicos se mostraram de extrema importância. Uma das principais contribuições nesse setor foi a descoberta da energia elétrica, pois a partir dela diversos equipamentos elétricos foram desenvolvidos e o padrão de vida foi melhorado.

A partir de 1889, o Brasil deu início a utilização de usinas hidroelétricas para a produção de energia elétrica. Atualmente, há aproximadamente 120 hidroelétricas em operação, sendo responsáveis por mais de $90 \%$ da energia elétrica consumida pelo país.

Na maioria das vezes, a demanda supera a quantidade de energia elétrica produzida nas usinas hidroelétrica, assim, é necessário a complementação de energia através de usinas nucleares, termoelétricas e algumas fontes de energia renováveis, como eólica e solar.

No caso de usinas térmicas a carvão, óleo e gás natural, há um agravante ambiental, pois ocorre a emissão de gases poluentes, como dióxido e monóxido de carbono, óxidos de enxofre e nitrogênio, que intensificam o efeito estufa e dá origem as chuvas ácidas, prejudicando a agricultura, florestas, monumentos urbanos e causando doenças respiratórias, além de ser um recurso com valor monetário mais elevado. 
Nas últimas décadas, o uso dessas fontes não renováveis tem aumentado, não somente pelo crescimento natural da população, mas devido ao planejamento ineficiente da produção de energia elétrica e, consequentemente, desperdício, que, segundo a Eletrobrás, trata-se de $12 \%$ da produção total, equivalente a 7500 megawatts (MW), ou ainda, o consumo de 40\% das residências brasileiras. Na verdade, desde 1995 o consumo de energia elétrica vem crescendo mais do que a capacidade de geração das fontes de energia.

Para não ocorrer blecautes de energia, os chamados "apagões", em períodos que a demanda não é atingida, a produção de energia deve ser uma estratégia que visa economia, planejamento e poucos impactos ambientais.

É fato que o processamento de energia implica, necessariamente, na exploração de recursos naturais e/ou na emissão de rejeitos no meio ambiente. Quando essa visão ambiental é somada ao fato de que os combustíveis fósseis são fontes de energia não renováveis e prejudiciais ao meio ambiente, fica evidente a necessidade da utilização de fontes alternativas para a geração de energia. Entre essas fontes, no Brasil, as usinas hidroelétricas são as que possuem maior produção com menor custo.

Nesse contexto, esse projeto visa explorar a capacidade produtiva de uma usina hidroelétrica através de uma política ótima da operação do sistema hidrotérmico, isto é, objetiva-se em maximizar a produção de energia elétrica advinda da usina hidroelétrica e, consequentemente, reduzir o uso das termoelétricas.

\subsection{Problema de Planejamento Ótimo da Operação de Sistemas Hidrotérmicos}

O problema do planejamento da operação de um conjunto de usinas hidroelétricas visa estabelecer regras que determinam a turbinagem de cada reservatório de acordo com o volume de água presente no sistema e com os valores observados para as vazões afluentes. Esta é uma tarefa de alta complexidade, uma vez que envolve inúmeras restrições, relacionadas à capacidade de armazenamento e turbinagem dos reservatórios; dependência de variáveis estocásticas, considerando principalmente a aleatoriedade das vazões afluentes; e utilização de equações não lineares, como, por exemplo, para o cálculo da potência gerada pelas usinas.

Para a otimização do problema, podemos adotar diversas funções objetivo, tais como, minimização da perda de energia potencial armazenada, maximização da energia total produzida, minimização da quantidade de água vertida, dentre outros Wurbs 
(1996); Yeh (1985). Neste trabalho consideramos uma função objetivo relacionada com a minimização dos custos de produção de energia em um sistema hidrotérmico Pereira (1985); Soares and Carneiro (1991), ou seja, constituído de usinas hidroelétricas e termoelétricas.

A produção de energia hidroelétrica, além de menos poluente, apresenta um custo muitas vezes menor que a termoelétrica, uma vez que a primeira utiliza-se da energia potencial gravitacional da água em um reservatório para geração de energia elétrica, enquanto uma usina termoelétrica utiliza-se de combustíveis como carvão, óleo, gás ou combustíveis nucleares.

Assim, uma boa estratégia é utilizar prioritariamente hidroelétricas, enquanto termoelétricas devem cumprir um papel de complementação para garantir o atendimento à demanda energética. No Brasil, a criação do Sistema Interligado Nacional (SIN) facilitou o intercâmbio de energia elétrica entre as regiões geográficas brasileiras, favorecendo a implementação desta estratégia, comumente denominada minimização da energia complementar Barros et al. (2003). Com isso, passamos a denominar este problema como planejamento da operação de um sistema hidrotérmico, cuja solução consiste em definir regras para a turbinagem de um sistema de usinas hidroelétricas que promovam o menor custo de complementação energética por termoelétricas.

Os modelos matemáticos utilizados para representar o Planejamento Ótimo da Operação de Sistemas Hidrotérmicos (POOSH) têm como uma de suas principais características a modelagem da natureza estocástica das vazões que chegam aos reservatórios, na qual algumas dessas modelagens podem ser vistas em Thomas and Fiering (1962); Todorovic and Zelenhasic (1970); Vicens et al. (1975); Lawrence and Kottegoda (1977); Hippel et al. (1979); Stedinger and Taylor (1982); Pereira et al. (1984); Jardim et al. (2001); Mondal and Wasimib (2006); Salas et al. (2006). Em decorrência disso, muitos autores têm utilizado técnicas de Programação Dinâmica Estocástica (PDE) para resolver o POOSH, como Stedinger et al. (1984) e Maceira et al. (2002). No entanto, em todos estes trabalhos, com o intuito de contornar o problema de dimensionalidade da PDE, esta técnica é empregada considerando-se um modelo agregado das usinas hidroelétricas, ou seja, as usinas hidroelétricas que compõem o sistema não são representadas de forma individualizada, o que acarreta um certo grau de subotimalidade na solução do problema. Por outro lado, ao abrir mão da representação estocástica das vazões empregando-se a Programação Dinâmica Determinística (PDD), é possível tratar de forma mais coerente a interação individualizada entre as usinas hidroelétricas do sistema. 
Assim, a PDD por um lado diminui a subotimalidade introduzida pelo modelo agregado de usinas da PDE, mas por outro introduz outro tipo de perda de otimalidade ao não considerar a estocasticidade das vazões afluentes. Neste contexto, torna-se imprescindível fazer uma comparação entre estas duas técnicas para avaliar a subotimalidade provocada pela representação determinística das vazões.

Considerando o exposto nesse trabalho, temos por objetivo fazer comparações entre as soluções da PDE e a PDD para o problema de POOSH, considerando um sistema compostos por uma usina hidroelétrica e uma termoelétrica, Figura 1.1, em um cenário com demanda de potência conhecida. É importante apresentar os custos relativos à PDE pois, desconsiderando a necessária discretização das variáveis, a solução dada por esta técnica em um sistema com uma única usina pode ser considerada como ótima para o problema Ouarda and Labadie (2001).

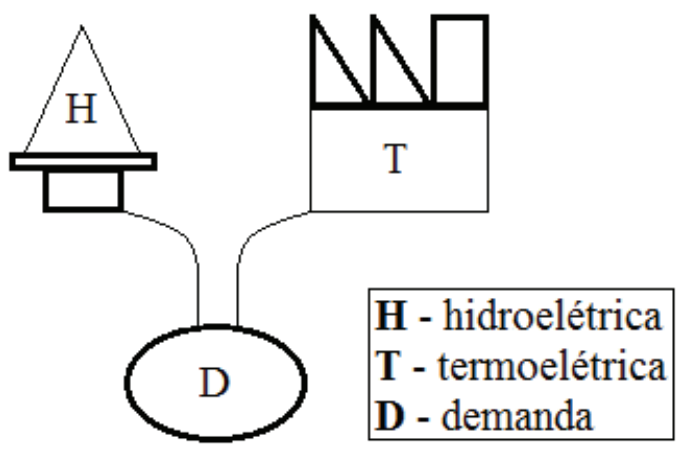

Figura 1.1: Sistema hidrotérmico com uma usina hidroelétrica e uma termoelétrica.

Na PDE, o modelo proposto para as vazões afluentes ao reservatório, é um processo de Markov periódico (modelo periódico autorregressivo, PAR(1)) com distribuição condicional Log-Normal Truncada. Além disso, é introduzida uma abordagem bayesiana para estimação dos parâmetros e previsão das vazões afluentes. Para avaliar o grau de subotimalidade da solução obtida via PDD em relação à PDE, são feitas simulações da operação do sistema considerando séries de vazões geradas artificialmente com o modelo PAR(1). Nos estudos realizados neste trabalho foram considerados dados reais das usinas hidroelétricas de Furnas e Sobradinho. 


\begin{tabular}{|c|c|}
\hline & Capítulo \\
\hline & 2 \\
\hline
\end{tabular}

\section{Modelagem do Problema}

O problema de Planejamento Ótimo da Operação de Sistemas Hidrotérmicos (POOSH) é formulado aqui para um horizonte de tempo finito $T$, definido em meses, considerando apenas uma usina hidroelétrica, visando atender a uma demanda de energia elétrica conhecida (capacidade máxima de geração da usina hidroelétrica). Quando esta demanda não pode ser atendida inteiramente pela usina hidroelétrica, utiliza-se dos recursos de uma usina termoelétrica para complementar o atendimento a demanda.

$\mathrm{Na}$ formulação deste problema são consideradas as seguintes variáveis:

- $x_{t}$ : volume de água $\left(h m^{3}\right)$ armazenado no reservatório, $t=0, \ldots, T$. Em geral, estes volumes devem atender às restrições físicas da capacidade de armazenamento do reservatório, tal que, $x_{\min } \leq x_{t} \leq x_{\max }$.

- $y_{t}$ : vazão afluente $\left(\mathrm{m}^{3} / \mathrm{s}\right)$ ao reservatório, $t=0, \ldots, T-1$. Esta vazão é de natureza aleatória e modelada como um processo de Markov com função densidade de probabilidade condicional, $f\left(y_{t} \mid y_{t-1}\right)$, definida para todo $t=0, \ldots, T-1 \mathrm{com}$ $y_{-1}$ conhecido.

- $u_{t}$ : vazão turbinada $\left(m^{3} / s\right), t=0, \ldots, T-1$. A vazão $u_{t}$ é a variável de decisão do problema de POOSH e, em geral, deve atender às restrições físicas da turbina, tal que, $u_{\min } \leq u_{t} \leq u_{\max }$. 
- $v_{t}$ : vazão vertida $\left(m^{3} / s\right), t=0, \ldots, T-1$. O vertimento ocorre para manter o volume do reservatório abaixo do volume máximo de operação, ou seja, $x_{t} \leq x_{\max }$. Em geral, as vazões vertidas devem atender as restrições físicas do vertedouro, tal que, $0 \leq v_{t} \leq v_{\max }$.

- $q_{t}$ : vazão defluente $\left(m^{3} / s\right) t=0, \ldots, T-1$. A vazão $q_{t}$ corresponde a soma das vazões turbinadas $u_{t}$ e vertidas $v_{t}$, ou seja, $q_{t}=u_{t}+v_{t}$.

Estas variáveis definem a equação dinâmica do reservatório, também chamada de equação de balanço hídrico, em $t=0, \ldots, T-1$, dada por

$$
x_{t+1}=x_{t}+\alpha\left(y_{t}-q_{t}\right),
$$

em que $\alpha$ é uma constante que converte unidades de vazão $\left(m^{3} / s\right)$ em unidades de volume $\left(h m^{3}\right)$.

Como veremos abaixo, um fator importante a ser considerado no cálculo da potência hidroelétrica gerada, é a altura de queda bruta, pois é com o uso desta que se obtém a capacidade de produção da usina hidroelétrica. Esta variável é definida como a diferença entre os níveis de água do reservatório (cota de montante) e do canal de fuga (cota jusante). A cota de montante é uma função do volume armazenado no reservatório $x_{t}$. Costumam-se utilizar polinômios para representar esta função. A obtenção desses polinômios é feita a partir de estudos topográficos da região alagada pela construção da barragem. Neste trabalho, denotaremos o polinômio de cota de montante por $h_{1}\left(x_{t}\right)$. Assim como a cota de montante do reservatório, a cota do canal de fuga também é representada por um polinômio. O polinômio de cota do canal de fuga depende da defluência $q_{t}$ e será representado por $h_{2}\left(q_{t}\right)$. Desta forma, a altura de queda bruta da usina pode ser calculada como

$$
h\left(x_{t}, q_{t}\right)=h_{1}\left(x_{t}\right)-h_{2}\left(q_{t}\right) .
$$

A função de geração da usina hidroelétrica, denotada por $H_{t}\left(x_{t}, u_{t}, v_{t}\right)$, representa a quantidade de energia gerada pela hidroelétrica (em MW-mês) em cada mês $t=$ $0, \ldots, T-1$, em função do volume de água armazenado no reservatório, da vazão turbinada e da vazão vertida. Após algumas simplificações, representamos esta função por

$$
H_{t}\left(x_{t}, u_{t}, v_{t}\right)=\rho h\left(x_{t}, q_{t}\right) u_{t},
$$


em que $\rho$ representa a produtividade específica da usina, que corresponde ao produto da aceleração da gravidade pela densidade da água e pelo rendimento médio do conjunto turbina-gerador, neste trabalho considerada constante.

\subsection{Programação Dinâmica}

Denota-se por $D_{t}$ a demanda de energia elétrica (em MW-mês) a ser atendida pelo sistema a cada mês $t=0, \ldots, T-1$ e denota-se por $G_{t}$ a geração térmica complementar, necessária para o atendimento da demanda $D_{t}$, tal que $G_{t}=D_{t}-H_{t}\left(x_{t}, u_{t}, v_{t}\right)$. Associada a estas variáveis define-se uma função, que representa o custo da geração térmica em um horizonte $T$, dada por

$$
V_{u}=\sum_{t=0}^{T-1}\left\{D_{t}-H_{t}\left(x_{t}, u_{t}, v_{t}\right)\right\}^{2}+\Psi\left(x_{T}\right),
$$

em que $\Psi\left(x_{T}\right)$ representa o custo terminal, com $x_{T}=x_{\max }$.

Com isso, temos a formulação do POOSH como um problema de otimização estocástico, considerando $x_{0}$ e $y_{-1}$ conhecidos e as equações (2.1)-(2.4), para $t=0, \ldots, T-1$. A modelagem desse problema é dada por

$$
V_{0}\left(x_{0}, y_{-1}\right)=\operatorname{Min}_{u_{0}, \ldots, u_{T}} E\left\{\sum_{t=0}^{T-1}\left[D_{t}-H_{t}\left(x_{t}, u_{t}, v_{t}\right)\right]^{2}\right\}
$$

sujeito a:

$$
\begin{array}{r}
x_{t+1}=x_{t}+\alpha\left(y_{t}-q_{t}\right), \\
H_{t}\left(x_{t}, u_{t}, v_{t}\right)=\rho h\left(x_{t}, q_{t}\right) u_{t}, \\
v_{t}=\max \left(0, x_{t}+\alpha\left(y_{t}-u_{t}\right)-x_{\max }\right), \\
q_{t}=u_{t}+v_{t}, \\
x_{\min } \leq x_{t} \leq x_{\max }, \\
u_{\min } \leq u_{t} \leq u_{\max }, \\
0 \leq v_{t} \leq v_{\max } \\
x_{T}=x_{\max }
\end{array}
$$

em que o valor esperado em (2.5) é calculado com relação as densidades de probabilidade condicional das vazões $f\left(y_{t} \mid y_{t-1}\right)$ para $t=0, \ldots, T-1$. 
Basicamente, a proposta da Programação Dinâmica é fragmentar o problema original em sub-problemas cujas soluções podem ser obtidas mais facilmente. Para detalhes sobre o método e discussão sobre diferentes formas de implementação da programação dinâmica no gerenciamento de reservatórios, consulte Nandalal and Bogardi (2007), e, para excelente revisão sobre o tema, consulte Yakowitz (1982). Para resolver o problema (2.5)-(2.12) usando o algoritmo da PDE, é necessário obter a equação de Bellman, ou seja, calcular a função recursiva definida por

$$
\begin{gathered}
V_{t}\left(x_{t}, y_{t-1}\right)=\operatorname{Min}_{u_{t}} E\left\{\left[D_{t}-H_{t}\left(x_{t}, u_{t}, v_{t}\right)\right]^{2}+V_{t+1}\left(x_{t+1}, y_{t}\right) \mid x_{t}, y_{t-1}\right\} \\
\text { sujeito as restrições }(2.5)-(2.12), \\
\text { para } t=0, \ldots, T-1, \text { com } V_{T}\left(x_{T}, y_{T-1}\right)=\Psi\left(x_{T}\right) .
\end{gathered}
$$

A formulação do problema de PDE exige a determinação de um modelo estocástico para a série de vazões, que consiste na escolha e ajuste das funções densidade de probabilidade condicional $f\left(y_{t} \mid y_{t-1}\right)$ para $t=0, \ldots, T-1$. Para obter o controlador da PDD, emprega-se a mesma formulação que a PDE, no entanto, admite-se que a vazão $y_{t}$ seja conhecida, de modo que é possível suprimir o valor esperado da equação acima.

\subsection{Modelo de Vazões Log-Normal Truncado}

Seja $\left\{y_{t}\right\}$, onde $t=t(r, m)=s(r-1)+m, s=12, m=1, \ldots, 12$ e $r=1,2, \ldots, n$, na qual $r$ refere-se aos anos e $n$ o número de anos a ser considerado, uma série de vazões médias mensais, assim, para desenvolver o modelo de vazões Log-Normal Truncado (LN-Truncado), algumas considerações devem ser feitas:

i) $y_{t} \in\left(y_{m}^{\min }, y_{m}^{\max }\right)$, em que $y_{m}^{\min }$ e $y_{m}^{\max }$ são os valores mínimo e máximo de vazões médias em cada mês $m$, respectivamente;

ii) Seja $z_{t} \in \mathbb{R}$, então $z_{t}=\ln \left(\frac{y_{t}-y_{m}^{\min }}{y_{m}^{\max }-y_{t}}\right)$;

iii) $z_{t} \sim N\left(\mu_{m}^{(z)}, \sigma_{m}^{(z) 2}\right)$.

Além disso, é razoável supor que $z_{t}$ e as observações anteriores, $z_{t-1}, z_{t-2}, \ldots, z_{t-k}$, estejam relacionadas por um modelo periódico autorregressivo de ordem $p_{m}=k$, ver Anderson and Vecchia (1993). No entanto, a utilização desse modelo terá forte impacto na distribuição condicional utilizada na PDE, tornando o problema intratável quanto ao tempo computacional, este fenômeno é conhecido como "maldição da dimensionalidade". Sendo assim, é necessário utilizar-se de um modelo de baixa ordem, nesse caso, será adotado um modelo periódico autorregressivo de ordem $p_{m}=1, \operatorname{PAR}(1)$, dado por 


$$
\left(\frac{z_{t}-\mu_{m}^{(z)}}{\sigma_{m}^{(z)}}\right)=\phi_{m}\left(\frac{z_{t-1}-\mu_{m-1}^{(z)}}{\sigma_{m-1}^{(z)}}\right)+a_{t}
$$

em que $a_{t}$ são ruídos independentes identicamente distribuídos (iid) com distribuição Normal $N\left(0, \sigma_{m}^{(a) 2}\right)$ e $\left|\phi_{m}\right|<1$, para cada $m$.

A partir do modelo PAR(1), temos que

$$
a_{t}=\left(\frac{z_{t}-\mu_{m}^{(z)}}{\sigma_{m}^{(z)}}\right)-\phi_{m}\left(\frac{z_{t-1}-\mu_{m-1}^{(z)}}{\sigma_{m-1}^{(z)}}\right)
$$

e

$$
\sigma_{m}^{(z)} a_{t}=z_{t}-\mu_{m}^{(z)}-\phi_{m} \frac{\sigma_{m}^{(z)}}{\sigma_{m-1}^{(z)}}\left(z_{t-1}-\mu_{m-1}^{(z)}\right),
$$

então

$$
\sigma_{m}^{(z) 2} E\left(a_{t}^{2}\right)=E\left\{z_{t}-\mu_{m}^{(z)}-\phi_{m} \frac{\sigma_{m}^{(z)}}{\sigma_{m-1}^{(z)}}\left(z_{t-1}-\mu_{m-1}^{(z)}\right)\right\}^{2}
$$

portanto, definindo $\mu_{m \mid m-1}^{(z)}=E\left(Z_{m} \mid Z_{m-1}\right)$,

$$
\mu_{m \mid m-1}^{(z)}=\mu_{m}^{(z)}+\phi_{m} \frac{\sigma_{m}^{(z)}}{\sigma_{m-1}^{(z)}}\left(z_{t-1}-\mu_{m-1}^{(z)}\right)
$$

e, definindo $\sigma_{m \mid m-1}^{(z) 2}=\operatorname{Var}\left(Z_{m} \mid Z_{m-1}\right)$,

$$
\sigma_{m \mid m-1}^{(z) 2}=\sigma_{m}^{(z) 2} E\left(a_{t}^{2}\right)=\sigma_{m}^{(z) 2} \sigma_{m}^{(a) 2} .
$$

Seja $w_{t}=\left(\frac{z_{t}-\mu_{m}^{(z)}}{\sigma_{m}^{(z)}}\right)$, então $E\left(w_{t}\right)=0$ e $\operatorname{Var}\left(w_{t}\right)=1$. Portanto, do modelo $\operatorname{PAR}(1)$, temos que

$$
w_{t}=\phi_{m} w_{t-1}+a_{t} \quad \Rightarrow \quad E\left(w_{t}^{2}\right)=\phi_{m} E\left(w_{t} w_{t-1}\right)+E\left(w_{t} a_{t}\right),
$$

além disso,

$$
\rho_{1, m}^{(z)}=E\left(w_{t} w_{t-1}\right)=E\left\{\left(\frac{z_{t}-\mu_{m}^{(z)}}{\sigma_{m}^{(z)}}\right)\left(\frac{z_{t-1}-\mu_{m-1}^{(z)}}{\sigma_{m-1}^{(z)}}\right)\right\}
$$

e

$$
E\left(w_{t} a_{t}\right)=E\left\{\left(\phi_{m} w_{t-1}+a_{t}\right) a_{t}\right\}=E\left(a_{t}^{2}\right)=\sigma_{m}^{(a) 2},
$$


então

$$
E\left(w_{t}^{2}\right)=\phi_{m} \rho_{1, m}^{(z)}+\sigma_{m}^{(a) 2}=1,
$$

ou seja,

$$
\sigma_{m}^{(a) 2}=1-\phi_{m} \rho_{1, m}^{(z)}
$$

Utilizando a equação de Yule-Walke para o modelo PAR(1), temos

$$
\begin{gathered}
\rho_{1, m}^{(z)}=E\left(w_{t} w_{t-1}\right)=E\left\{\left(\phi_{m} w_{t-1}+a_{t}\right) w_{t-1}\right\} \\
\rho_{1, m}^{(z)}=\phi_{m} E\left(w_{t-1}^{2}\right)+E\left(a_{t} w_{t-1}\right) \\
\rho_{1, m}^{(z)} \\
=\phi_{m}
\end{gathered}
$$

Portanto, em (2.15), temos

$$
\sigma_{m}^{(a) 2}=1-\rho_{1, m}^{(z) 2}
$$

Substituindo (2.17) em (2.14), temos

$$
\sigma_{m \mid m-1}^{(z) 2}=\sigma_{m}^{(z) 2} \sigma_{m}^{(a) 2}=\sigma_{m}^{(z) 2}\left(1-\rho_{1, m}^{(z) 2}\right)
$$

Como $z_{t} \sim N\left(\mu_{m}^{(z)}, \sigma_{m}^{(z) 2}\right)$, a densidade de probabilidade condicional $f\left(z_{t} \mid z_{t-1}\right)$ é dada por

$$
f\left(z_{t} \mid z_{t-1}\right)=\frac{1}{\sqrt{2 \pi} \sigma_{m \mid m-1}^{(z)}} \exp \left\{-\frac{1}{2 \sigma_{m \mid m-1}^{(z) 2}}\left(z_{t}-\mu_{m \mid m-1}^{(z)}\right)^{2}\right\},
$$

substituindo as equações (2.13) e (2.18) em (2.19), temos

$$
\begin{gathered}
f\left(z_{t} \mid z_{t-1}\right)= \\
\frac{1}{\sqrt{2 \pi} \sigma_{m}^{(z)}\left(1-\rho_{1, m}^{(z) 2}\right)^{1 / 2}} \exp \left\{-\frac{1}{2 \sigma_{m}^{(z) 2}\left(1-\rho_{1, m}^{(z) 2}\right)}\left[z_{t}-\mu_{m}^{(z)}-\rho_{1, m}^{(z)} \frac{\sigma_{m}^{(z)}}{\sigma_{m-1}^{(z)}}\left(z_{t-1}-\mu_{m-1}^{(z)}\right)\right]^{2}\right\} .
\end{gathered}
$$

Com isso, usando a relação $z_{t}=\ln \left(\frac{y_{t}-y_{m}^{\min }}{y_{m}^{\max }-y_{t}}\right)$, podemos obter a densidade de probabilidade condicional $f\left(y_{t} \mid y_{t-1}\right)$ da seguinte forma

$$
f\left(y_{t} \mid y_{t-1}\right)=\frac{1}{\sqrt{2 \pi} \sigma_{m}^{(z)}\left(1-\rho_{1, m}^{(z) 2}\right)^{1 / 2}} \exp \left\{-\frac{1}{2 \sigma_{m}^{(z) 2}\left(1-\rho_{1, m}^{(z) 2}\right)} \times\right.
$$




$$
\left.\times\left[\ln \left(\frac{y_{t}-y_{m}^{\min }}{y_{m}^{\max }-y_{t}}\right)-\mu_{m}^{(z)}-\rho_{1, m}^{(z)} \frac{\sigma_{m}^{(z)}}{\sigma_{m-1}^{(z)}}\left(\ln \left(\frac{y_{t-1}-y_{m-1}^{\min }}{y_{m-1}^{\max }-y_{t-1}}\right)-\mu_{m-1}^{(z)}\right)\right]^{2}\right\} J\left(z_{t}, y_{t}\right)
$$

onde o termo $J\left(z_{t}, y_{t}\right)$ refere-se ao jacobiano da transformação e é dado por

$$
J\left(z_{t}, y_{t}\right)=\left|\frac{d z_{t}}{d y_{t}}\right|=\frac{\left(y_{m}^{\max }-y_{m}^{\min }\right)}{\left(y_{t}-y_{m}^{\min }\right)\left(y_{m}^{\max }-y_{t}\right)} .
$$

Portanto, temos a densidade de probabilidade condicional $f\left(y_{t} \mid y_{t-1}\right)$ dada por

$$
\begin{gathered}
f\left(y_{t} \mid y_{t-1}\right)=\frac{\left(y_{m}^{\max }-y_{m}^{\min }\right)}{\sqrt{2 \pi} \sigma_{m}^{(z)}\left(1-\rho_{1, m}^{(z) 2}\right)^{1 / 2}\left(y_{t}-y_{m}^{\min }\right)\left(y_{m}^{\max }-y_{t}\right)} \exp \left\{-\frac{1}{2 \sigma_{m}^{(z) 2}\left(1-\rho_{1, m}^{(z) 2}\right)} \times\right. \\
\left.\times\left[\ln \left(\frac{y_{t}-y_{m}^{\min }}{y_{m}^{\max }-y_{t}}\right)-\mu_{m}^{(z)}-\rho_{1, m}^{(z)} \frac{\sigma_{m}^{(z)}}{\sigma_{m-1}^{(z)}}\left(\ln \left(\frac{y_{t-1}-y_{m-1}^{\min }}{y_{m-1}^{\max }-y_{t-1}}\right)-\mu_{m-1}^{(z)}\right)\right]^{2}\right\} .
\end{gathered}
$$

Para ilustrar a densidade de probabilidade condicional de cada mês, apresentamos, na Figura 2.1, as densidades dos meses de janeiro, fevereiro, março, abril, maio e junho de Furnas, condicionados ao mês anterior, respectivamente. Para isto, fez-se uso da equação (2.16) e para estimar os parâmetros foi utilizado o método dos momentos.
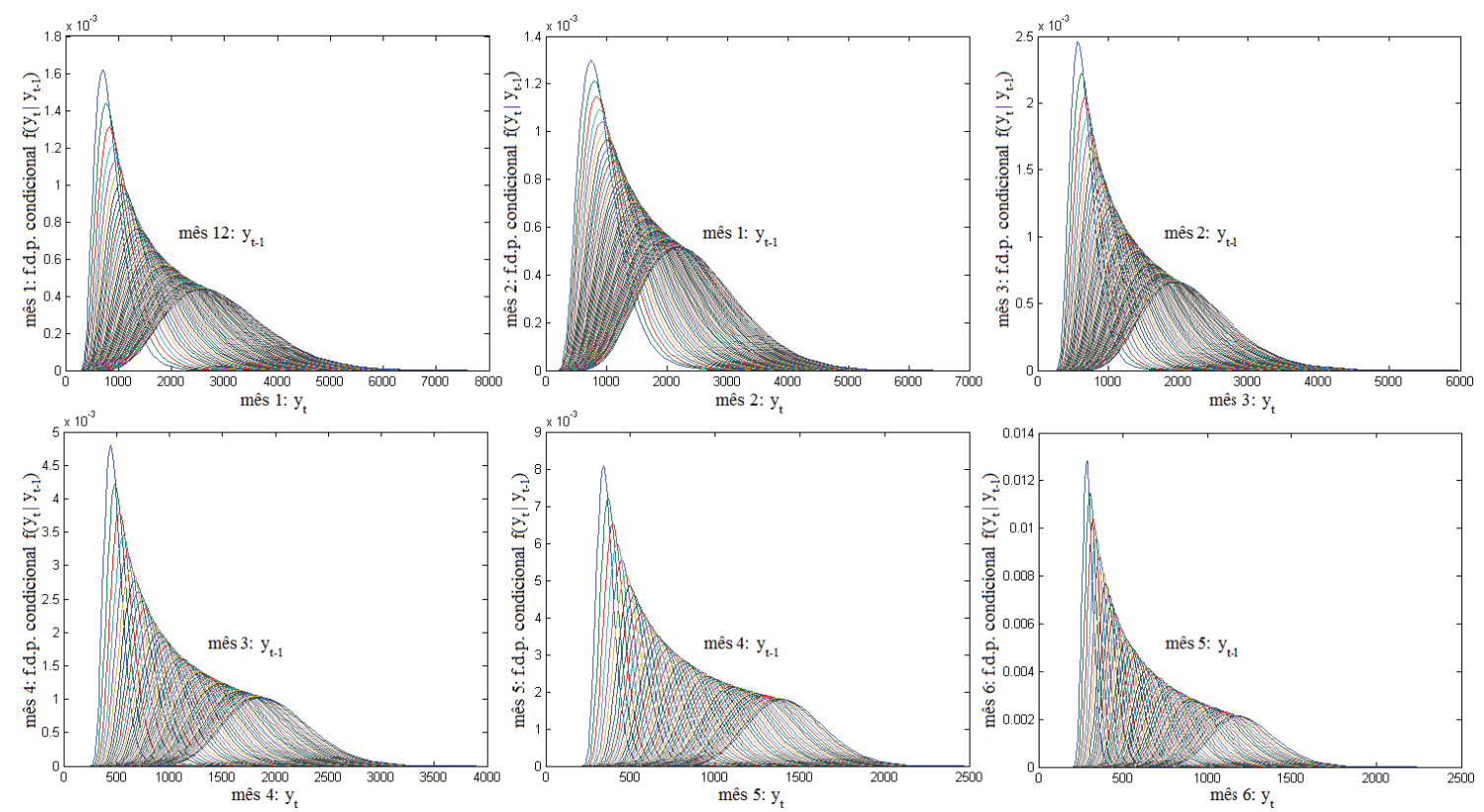

Figura 2.1: Exemplos de funções densidade de probabilidade condicional, utilizando a LN-Truncada, para o primeiro semestre de Furnas.

Note que para cada valor de afluência no mês anterior $\left(y_{t-1}\right)$, temos uma função distribuição de probabilidade no mês atual $\left(f\left(y_{t} \mid y_{t-1}\right)\right)$ diferente. Considerar estas funções densidade de probabilidade variando em função de $y_{t-1}$ na PDE deve reproduzir adequadamente a estocasticidade das vazões. 


\subsubsection{Algoritmo para Geração de uma Série Sintética}

A partir do modelo apresentado anteriormente, é possível gerar séries sintéticas com distribuição LN-Truncada considerando o seguinte algoritmo:

Passo 1: Estimam-se com os dados históricos os parâmetros:

$$
\mu_{m}^{(z)}, \mu_{m-1}^{(z)}, \sigma_{m}^{(z)}, \sigma_{m-1}^{(z)}, \rho_{1, m}^{(z)}, y_{m-1}^{\min }, y_{m-1}^{\max }
$$

Passo 2: Dado um valor de $y_{t-1}$, calculam-se:

$$
\begin{gathered}
\mu_{m \mid m-1}^{(z)}=\mu_{m}^{(z)}+\rho_{1, m}^{(z)} \frac{\sigma_{m}^{(z)}}{\sigma_{m-1}^{(z)}}\left[\ln \left(\frac{y_{t-1}-y_{m-1}^{\min }}{y_{m-1}^{\max }-y_{t-1}}\right)-\mu_{m-1}^{(z)}\right] \\
\sigma_{m \mid m-1}^{(z) 2}=\sigma_{m}^{(z) 2}\left(1-\rho_{1, m}^{(z) 2}\right)
\end{gathered}
$$

Passo 3: Gera-se um valor de $z_{t}$ da distribuição Normal $N\left(\mu_{m \mid m-1}^{(z)}, \sigma_{m \mid m-1}^{(z) 2}\right)$.

Passo 4: A vazão gerada $y_{t}$ é obtida da relação:

$$
y_{t}=\frac{y_{m}^{\max } \exp \left\{z_{t}\right\}+y_{m}^{\min }}{1+\exp \left\{z_{t}\right\}}
$$

\subsubsection{Validação da Série Sintética}

Para validação da série sintética gerada com o algoritmo apresentado na seção (2.2.1), vamos considerar a análise gráfica, que consiste em comparar o histograma da série real com o da série sintética. Esta comparação é apresentada na Figura 2.2.

(a)

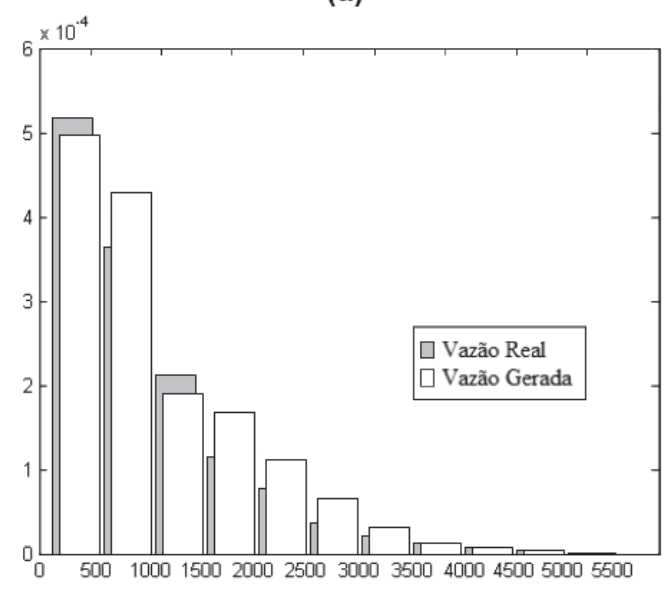

(b)

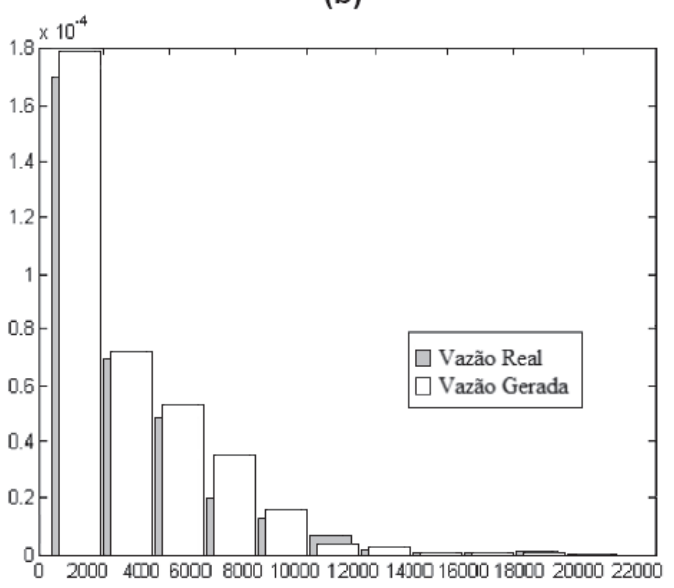

Figura 2.2: Histograma comparativo entre série real e série sintética de (a) Furnas e (b) Sobradinho. 
Uma outra análise pode ser feita a partir do gráfico QQ-Plot (Figura 2.3) para as duas séries.

(a)

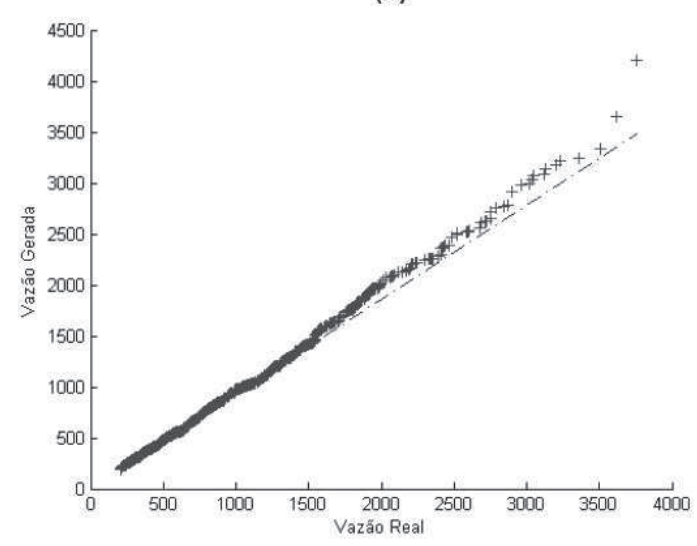

(b)

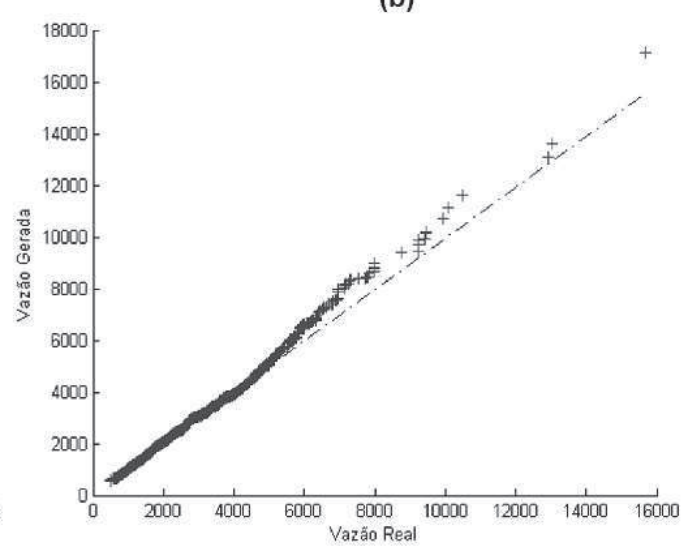

Figura 2.3: QQ-Plot entre série real e série sintética de (a) Furnas e (b) Sobradinho.

A partir da Figura 2.3, podemos inferir que a série sintética representa, satisfatoriamente, os dados reais, já que os pontos se aproximam da reta. Entretanto, a análise gráfica é sempre intuitiva, portanto será apresentado uma análise mais precisa, através do critério de Kullback-Leibler.

\subsubsection{Validação da Série Sintética via Critério de Kullback-Leibler}

Uma série de vazões gerada de uma distribuição de probabilidade ajustada pode não representar adequadamente as características estatísticas da série real. Isso devese, principalmente, às limitações dos modelos propostos e à qualidade dos ajustes destes modelos. Para avaliar se uma série de vazões gerada da distribuição de probabilidade ajustada representa uma série de vazão plausível, uma alternativa é comparar a densidade da série gerada $f_{\hat{y}}$ e a densidade da série real $f_{y}$, com ambas calculadas de forma não paramétrica. Considera-se que as densidades são avaliadas em $M$ pontos de forma que tem-se, para ambas, os pares $\left(\hat{y}_{1}, f_{\hat{y}}^{1}\right), \ldots,\left(\hat{y}_{M}, f_{\hat{y}}^{M}\right)$ e $\left(y_{1}, f_{y}^{1}\right), \ldots,\left(y_{M}, f_{y}^{M}\right)$. Estes pontos podem ser avaliados construindo um histograma das séries e adotando cada ponto como o ponto médio de cada classe do histograma. A comparação é feita calculando a divergência de Kullback-Leibler Kullback and Leibler (1951)), que mede a distância entre duas densidades de probabilidade, dada por

$$
K L\left(f_{y}(y), f_{\hat{y}}(\hat{y})\right)=\int \log \left(\frac{f_{y}(y)}{f_{\hat{y}}(\hat{y})}\right) f_{y}(y) d y
$$


de tal forma que para se mensurar a divergência $K L\left(f_{y}(y), f_{\hat{y}}(\hat{y})\right)$ considerando-se os pontos avaliados, utiliza-se um método de integração numérica, tal como o método dos trapézios. Nesse caso, tem-se que

$$
K L\left(f_{y}(y), f_{\hat{y}}(\hat{y})\right)=\left\{\frac{f_{y}^{1}}{2} \log \left(\frac{f_{y}^{1}}{f_{\hat{y}}^{1}}\right)+\sum_{i=2}^{M-1} f_{y}^{i} \log \left(\frac{f_{y}^{i}}{f_{\hat{y}}^{i}}\right)+\frac{f_{y}^{M}}{2} \log \left(\frac{f_{y}^{M}}{f_{\hat{y}}^{M}}\right)\right\} \delta_{y},
$$

em que $\delta_{y}$ representa a amplitude das classes do histograma.

Uma medida de calibração para a divergência $K L\left(f_{y}(y), f_{\hat{y}}(\hat{y})\right)$ dada por McCulloch (1989), denotada aqui por $p$, é obtida resolvendo-se a equação

$$
K L\left(f_{y}(y), f_{\hat{y}}(\hat{y})\right)=K L(B(0,5), B(p))=-\log 4 p(1-p) / 2,
$$

em que $B(p)$ denota a distribuição de Bernoulli com probabilidade de sucesso $p$. Isso significa aceitar a série gerada com a densidade de probabilidade $f_{\hat{y}}(\hat{y})$ como vinda da distribuição de probabilidade $f_{y}(y)$ e é equivalente a descrever um evento não observado como tendo probabilidade $p$, quando a probabilidade correta é 0,5. Resolvendo-se a equação para $p$, tem-se que

$$
p=\frac{1}{2}\left\{1+\sqrt{1-\exp \left[-2 K L\left(f_{y}(y), f_{\hat{y}}(\hat{y})\right)\right]}\right\}
$$

Isso implica que $0,5 \leq p \leq 1$. Portanto, quanto menor a divergência entre as densidades $f_{y}(y)$ e $f_{\hat{y}}(\hat{y})$, tem-se $p$ mais próximo do valor verdadeiro $(p \approx 0,5)$. Para $p \gg 0,5$ tem-se que a divergência entre as densidades $f_{y}(y)$ e $f_{\hat{y}}(\hat{y})$ é grande e, consequentemente, a série gerada, provavelmente, não tem a mesma distribuição da série real. Recomenda-se a rejeição da série gerada para $p \geq 0,95$.

Para avaliar a distância entre a série sintética e a série real, foram geradas 1000 séries a partir do algoritmo mostrado anteriormente, e ao utilizar a divergência de Kullback-Leibler, verificou-se que os valores para $p$ estão entre 0,65 e 0,85 para Furnas e entre 0,63 e 0,92 para Sobradinho, portanto, pode-se considerar que a série sintética está, relativamente, próxima da série real em ambos os casos.

\subsection{Análise de Previsões}

Uma das definições de previsão de séries temporais, dada por Barbancho (1970), é a manifestação relativa a sucessos desconhecidos em um futuro determinado. Para Morettin and Toloi (1981) a previsão visa atingir objetivos na tomada de decisões 
através de informações e subsídios. As previsões dos valores futuros de uma série temporal são classificadas por Souza (1989) e Makridakis and Wheelwright (1985) como de curto, médio ou longo prazo. Com isso, há diferentes técnicas para predizer valores futuros, em que Refenes et al. (1993) destaca duas possíveis abordagens:

- Passos simples: a previsão é feita apenas para o período de tempo imediatamente posterior ao atual, a partir das observações da série temporal. Não há incorporação de previsões aos dados utilizados para encontrar a próxima previsão, sendo esta, independente dos valores anteriormente previstos.

- Passos múltiplos: esta abordagem, adotada para longos horizontes de previsão, procura identificar as tendências gerais e os pontos de inflexão mais relevantes na série temporal. Na previsão múltiplos passos, o conjunto de valores correntes é empregado na realização da previsão para determinado instante; esta previsão é, então, introduzida entre as observações passadas, compondo, desta forma, um novo conjunto de dados, sobre o qual será obtida a previsão do tempo subsequente.

Alguns autores, como Souza (1989), defendem que a otimalidade das previsões somente é atingida quando o instante predito é imediatamente após o tempo atual.

Para Barbancho (1970), o modelo com o poder preditivo mais adequado para explicar o mecanismo gerador da série temporal é escolhido através de processos empíricos de verificação, na qual são feitas comparações entre as observações reais e as previsões, a fim de confirmar a habilidade do modelo matemático em descrever a estrutura definida pelos dados da série temporal analisada.

Os métodos quantitativos para previsões tomam como informações preliminares as observações passadas, assim, tentam retirar características importantes da série temporal e utilizar de indícios de interrelação dos dados. Com isso, se o futuro apresentar comportamento similar ao passado, as previsões tornam-se mais acuradas. Segundo Makridakis and Wheelwright (1985), o propósito dos métodos de previsão consiste em distinguir o padrão de qualquer ruído que possa estar contido nas observações e então usar esse padrão para prever os valores futuros da série temporal. Assim, pela identificação dessa componente, a previsão para períodos de tempo subsequentes ao observado pode ser desenvolvida.

Embora a maioria dos métodos de previsão de séries temporais se baseiam apenas na análise das observações da série de interesse para a elaboração de algum modelo que descreva essas observações, algumas metodologias de previsão tentam explicar o comportamento de uma série temporal pela evolução dos fenômenos observacionais de 
outras séries. Assim, Souza (1989) classifica os métodos de previsão em univariados, funções de transferência e multivariados, dependendo do número de séries temporais envolvidas na modelagem.

- Métodos univariados: compreendem a maior parte dos métodos de previsão de séries temporais, consideram somente uma única série para a realização das previsões. As previsões decorrentes da aplicação de métodos univariados podem estar relacionadas apenas com as informações contidas na série histórica de interesse (métodos baseados na estatística clássica) ou também, além de incorporarem essas informações, consideram outras supostamente relevantes e que não estão contidas na série analisada (métodos baseados na estatística bayesiana).

- Funções de transferência: são metodologias nas quais a série de interesse é explicada não só pelo seu passado histórico, como também por outras séries temporais não correlacionadas. Esta classe de métodos de previsão envolve, portanto, mais de uma série temporal, com a ressalva de que a relação de causalidade entre estas séries é perfeitamente conhecida.

- Métodos multivariados: abrangem os procedimentos de previsão que associam mais de uma série temporal sem, no entanto, qualquer imposição com relação à causalidade entre essas séries.

Diante disso, para Makridakis and Wheelwright (1985), há uma vasta variedade de métodos de previsão de séries temporais, cada qual com suas capacidades e limitações. Qualquer que seja a classificação desses métodos, é possível utilizar um número muito grande de métodos diferentes para descrever o comportamento de uma série particular. A seleção do método de previsão adequado depende de vários fatores, tais como o comportamento do fenômeno observável ou o conhecimento a priori que se tenha sobre a sua natureza e do objetivo da análise.

Para efetuar a previsão utilizando a Inferência Clássica com o método de passo simples univariado é necessário a utilização do método de Monte Carlo (Robert and Casella (2005)), pois a integração numérica para obter as estimativas dos parâmetros tem uma estrutura complexa. Com as estimativas dos parâmetros, $\left(\hat{\mu}_{m}^{(z)}, \hat{\mu}_{m-1}^{(z)}, \hat{\sigma}_{m}^{(z)}, \hat{\sigma}_{m-1}^{(z)}, \hat{\rho}_{1, m}^{(z)}\right)$, calculadas, estas são utilizadas na equação (2.21).

$$
z_{t}^{p r e d}=\hat{\mu}_{m}^{(z)}+\hat{\rho}_{1, m}^{(z)} \frac{\hat{\sigma}_{m}^{(z)}}{\hat{\sigma}_{m-1}^{(z)}}\left[\ln \left(\frac{y_{t-1}-y_{m-1}^{\min }}{y_{m-1}^{\max }-y_{t-1}}\right)-\hat{\mu}_{m-1}^{(z)}\right]
$$


Com isso, é feita a substituição de $z_{t}^{\text {pred }}$ na equação $(2.22)$ e, então, obtém-se a previsão de um passo a frente.

$$
y_{t}=\frac{y_{m}^{\max } \exp \left\{z_{t}^{\text {pred }}\right\}+y_{m}^{\min }}{1+\exp \left\{z_{t}^{\text {pred }}\right\}}
$$

Esse procedimento é repetido até se obter o número de previsões desejado, incluindo em cada iteração da simulação a previsão obtida no período anterior. No entanto, a previsão via inferência clássica possui algumas limitações para a obtenção dos intervalos de confiança, pois é necessário a utilização de teoria assintótica, que nem sempre produz resultados satisfatórios. 



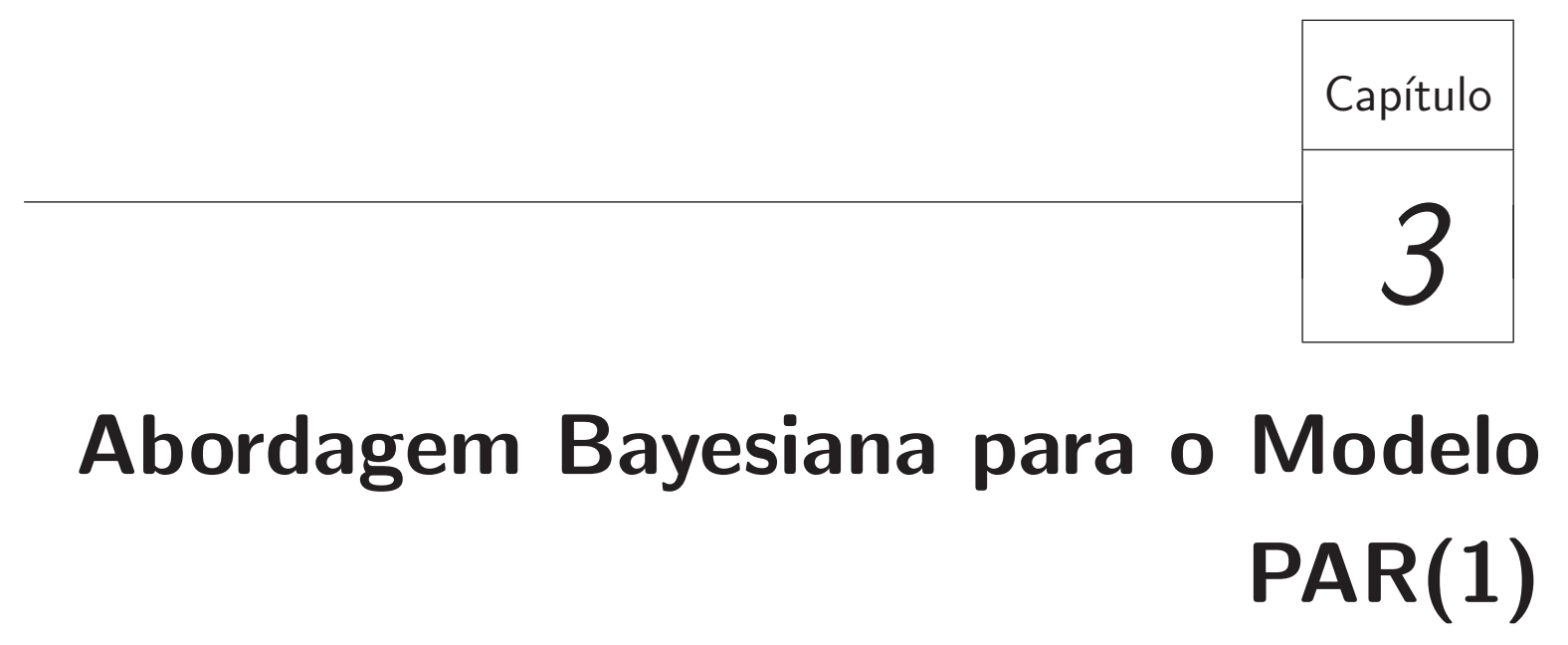

Na inferência bayesiana tem-se a composição da distribuição a posteriori, $p(\theta \mid y)$, dada pela função de verossimilhança, $L(\theta \mid y)$, e uma distribuição a priori, $p(\theta)$, para o parâmetro $\theta$.

Neste enfoque, os parâmetros são interpretados como variáveis aleatórias, ao invés de constantes, como é feito na abordagem clássica. Assim, temos que a distribuição a posteriori é dada por

$$
p(\theta \mid y)=\frac{L(\theta \mid y) p(\theta)}{\int_{\Theta} p(y \mid \theta) p(\theta) d \theta}
$$

ou, na forma proporcional,

$$
p(\theta \mid y) \propto L(\theta \mid y) p(\theta)
$$

Na maioria dos casos, o cálculo da distribuição a posteriori é complicado de se obter analiticamente, então utiliza-se algoritmos de simulação para gerar amostras desta distribuição, com isso, os métodos mais utilizados na literatura são os de Monte Carlo via cadeias de Markov (MCMC), ver Robert and Casella (2011). 


\subsection{Distribuições a priori e a posteriori}

A partir dos dados, temos que $y_{m}^{\min }$ e $y_{m}^{\max }$ são conhecidos, assim, os parâmetros da equação (2.20) são $\boldsymbol{\theta}=\left(\mu_{m}^{(z)}, \mu_{m-1}^{(z)}, \sigma_{m}^{(z) 2}, \sigma_{m-1}^{(z) 2}, \rho_{1, m}^{(z)}\right)$. Assumindo independência entre as prioris, a partir de (3.2), temos

$$
p\left(\boldsymbol{\theta} \mid H_{t}\right) \propto L\left(\boldsymbol{\theta} \mid H_{t}\right) p\left(\mu_{m}^{(z)}\right) p\left(\mu_{m-1}^{(z)}\right) p\left(\sigma_{m}^{(z) 2}\right) p\left(\sigma_{m-1}^{(z) 2}\right) p\left(\rho_{1, m}^{(z)}\right)
$$

em que $L\left(\boldsymbol{\theta} \mid H_{t}\right)=\left[\prod_{t=2}^{n} f\left(y_{t} \mid y_{t-1}, \boldsymbol{\theta}\right)\right] f\left(y_{1} \mid y_{0}, \boldsymbol{\theta}\right)$, com $f\left(y_{t} \mid y_{t-1}, \boldsymbol{\theta}\right)$ dada por (2.20), define-se $f\left(y_{1} \mid y_{0}, \boldsymbol{\theta}\right)=1, H_{t}=\left(y_{1}, y_{2}, \ldots, y_{t}\right)$ é o histórico de vazões afluentes até o período $t$ e as prioris $p\left(\mu_{m}^{(z)}\right), p\left(\mu_{m-1}^{(z)}\right), p\left(\sigma_{m}^{(z) 2}\right)$ ou $p\left(\sigma_{m-1}^{(z) 2}\right)$ e $p\left(\rho_{1, m}^{(z)}\right)$ são dadas por (3.4), (3.5) e (3.6), respectivamente.

\subsubsection{Distribuição a priori de $\mu_{m}^{(z)}$ ou $\mu_{m-1}^{(z)}$}

Como $\mu_{m}^{(z)}$ denota a média da variável aleatória $z_{t}$ para o mês $m$, onde essa quantidade aleatória assume valores reais, assim, podemos assumir $\mu_{m}^{(z)} \equiv \theta \sim N\left(a_{m}, b_{m}^{2}\right)$, com hiperparâmetros $a_{m} \in \mathbb{R}$ e $b_{m}^{2}>0$, ou seja,

$$
p\left(\theta \mid a, b^{2}\right)=\left(2 \pi b^{2}\right)^{-1 / 2} \exp \left[-\frac{1}{2 b^{2}}(\theta-a)^{2}\right]
$$

em que $a=a_{m}, b^{2}=b_{m}^{2}, \operatorname{com} m=1, \ldots, 12$.

\subsubsection{Distribuição a priori de $\sigma_{m}^{(z) 2}$ ou $\sigma_{m-1}^{(z) 2}$}

Como $\sigma_{m}^{(z) 2}$ denota a variância da variável aleatória $z_{t}$ para o mês $m$, onde essa quantidade aleatória assume apenas valores positivos, assim, podemos assumir $\sigma_{m}^{(z) 2} \equiv$ $\phi \sim \operatorname{Gama}\left(c_{m}, d_{m}\right)$, com hiperparâmetros $c_{m}>0$ e $d_{m}>0$, ou seja,

$$
p(\phi \mid c, d)=\frac{d^{c}}{\Gamma(c)} \phi^{c-1} e^{-d \phi}
$$

em que $c=c_{m}, d=d_{m}$, com $m=1, \ldots, 12$. 


\subsubsection{Distribuição a priori de $\rho_{1, m}^{(z)}$}

Como $\rho_{1, m}^{(z)} \in(-1,1)$, será utilizado uma variável aleatória auxiliar com distribuição normal para reparametrizar esse intervalo. Assim, seja $x_{m} \in \mathbb{R}$, então $x_{m}=$ $\ln \left(\frac{\rho_{1, m}^{(z)}+1}{1-\rho_{1, m}^{(z)}}\right)$, com isso, assumindo $x_{m} \sim N\left(k_{m}, v_{m}^{2}\right)$, encontramos a distribuição a priori para $\rho_{1, m}^{(z)}$ dada por

$$
p\left(\rho_{1, m}^{(z)} \mid k, v^{2}\right)=\frac{2}{\sqrt{2 \pi v^{2}}\left(1-\rho_{1, m}^{(z) 2}\right)} \exp \left\{-\frac{1}{2 v^{2}}\left[\ln \left(\frac{\rho_{1, m}^{(z)}+1}{1-\rho_{1, m}^{(z)}}\right)-k\right]^{2}\right\}
$$

em que $k=k_{m}, v^{2}=v_{m}^{2}, \operatorname{com} m=1, \ldots, 12$.

\subsection{Métodos de Monte Carlo via cadeias de Markov (MCMC)}

Suponha que temos interesse em gerar uma amostra da distribuição a posteriori $p(\boldsymbol{\theta} \mid y), \boldsymbol{\theta} \in R^{k}$, mas os cálculos são complicados de se obter diretamente. Entretanto, podemos construir uma cadeia de Markov com espaço de estados no espaço paramétrico $\Theta$ (conjunto de todos os possíveis valores de $\boldsymbol{\theta}$ ) que é simples para simular e cuja distribuição de equilíbrio seja dada por $p(\boldsymbol{\theta} \mid y)$. Se temos muitas simulações dessa cadeia, os valores simulados da cadeia podem ser usados como uma base para sumarizar características da posteriori $p(\boldsymbol{\theta} \mid y)$. Os métodos de construção da cadeia de Markov cuja distribuição de equilíbrio seja $p(\boldsymbol{\theta} \mid y)$, denominados métodos MCMC, mais utilizados são o amostrador de Gibbs (Geman and Geman (1984)) e o Metropolis-Hastings (Metropolis et al. (1953) e Hastings (1970)). Os algoritmos desse métodos são apresentados na seção (3.2.1) e (3.2.2), porém, para mais detalhes consulte Gamerman and Lopes (2006).

\subsubsection{Amostrador de Gibbs}

Suponha uma distribuição conjunta a posteriori $p(\boldsymbol{\theta} \mid y)$, com $\boldsymbol{\theta}=\left(\theta_{1}, \theta_{2}, \ldots, \theta_{k}\right)$, conhecida a menos de uma constante de proporcionalidade e que se tem interesse na obtenção de resumos estatísticos das densidades marginais a posteriori desses parâmetros. 
O amostrador de Gibbs faz a construção de uma amostra da distribuição a posteriori $p(\boldsymbol{\theta} \mid y)$ supondo que as distribuições condicionais completas a posteriori de $p\left(\theta_{1} \mid \boldsymbol{\theta}_{(1)}, y\right)$, $p\left(\theta_{2} \mid \boldsymbol{\theta}_{(2)}, y\right), \ldots, p\left(\theta_{k} \mid \boldsymbol{\theta}_{(k)}, y\right)$, em que $\boldsymbol{\theta}_{(i)}$ denota todos os elementos do vetor $\boldsymbol{\theta}$ com exceção de $i$, são conhecidas, ou seja, possuem forma fechada. Com isso, o algoritmo gera uma sequência $\left(\theta_{1}^{(1)}, \theta_{2}^{(1)}, \ldots, \theta_{k}^{(1)}\right),\left(\theta_{1}^{(2)}, \theta_{2}^{(2)}, \ldots, \theta_{k}^{(2)}\right), \ldots,\left(\theta_{1}^{(m)}, \theta_{2}^{(m)}, \ldots, \theta_{k}^{(m)}\right)$ de tamanho $m$, a partir de um valor inicial $\left(\theta_{1}^{(0)}, \theta_{2}^{(0)}, \ldots, \theta_{k}^{(0)}\right)$ arbitrário. Essa sequência é obtida iterativamente, através de gerações alternadas de valores, como descrito no algoritmo abaixo:

Passo 1: Inicialize o contador de iterações da cadeia, $j=1$, e escolha valores iniciais para $\boldsymbol{\theta}^{(0)}=\left(\theta_{1}^{(0)}, \theta_{2}^{(0)}, \ldots, \theta_{k}^{(0)}\right)$.

Passo 2: Obtenha um novo vetor $\boldsymbol{\theta}^{(j)}=\left(\theta_{1}^{(j)}, \theta_{2}^{(j)}, \ldots, \theta_{k}^{(j)}\right)$ a partir de $\boldsymbol{\theta}^{(j-1)}$, através de sucessivas gerações de valores com $p\left(\theta_{i} \mid \boldsymbol{\theta}_{(i)}^{(j-1)}, y\right)$, para $i=1, \ldots, k$.

Passo 3: Repita o Passo 2 para $j=2,3, \ldots, m$.

Se a convergência é atingida na iteração $w$ (período de aquecimento, em inglês "burn-in"), as $M=m-w$ iterações restantes representam uma amostra da cadeia em equilíbrio, ou seja, uma amostra de tamanho $M$ da distribuição conjunta a posteriori $p(\boldsymbol{\theta} \mid y)$.

\subsubsection{Metropolis-Hastings}

Conhecendo as distribuições condicionais completas a posteriori dos parâmetros, o amostrador de Gibbs é ideal para amostrar da distribuição a posteriori $p(\boldsymbol{\theta} \mid y)$. Porém, na prática, dificilmente as distribuições condicionais completas dos parâmetros possuem forma fechada, assim, surge a necessidade de utilizar o algoritmo de MetropolisHastings.

Seja $V_{t}$ o estado atual da cadeia de Markov, o algoritmo de Metropolis-Hastings propõe um valor para o próximo estado da cadeia, $V_{t+1}^{*}$, utilizando uma distribuição proposta $q\left(V_{t+1}^{*} \mid V_{t}\right)$. Então, o novo estado $V_{t+1}$ será igual a $V_{t+1}^{*}$ com probabilidade $\alpha\left(V_{t}, V_{t+1}^{*}\right)$ ou igual a $V_{t}$ com probabilidade $1-\alpha\left(V_{t}, V_{t+1}^{*}\right)$, em que

$$
\alpha\left(V_{t}, V_{t+1}^{*}\right)=\min \left\{1, \frac{p\left(V_{t+1}^{*} \mid h\right) q\left(V_{t} \mid V_{t+1}^{*}\right)}{p\left(V_{t} \mid h\right) q\left(V_{t+1}^{*} \mid V_{t}\right)}\right\}
$$

O procedimento completo é descrito no algoritmo abaixo:

Passo 1: Escolha um valor inicial $V_{0}$. 
Passo 2: Gere $V_{t+1}^{*} \sim q\left(V_{t+1}^{*} \mid V_{t}\right)$.

Passo 3: Calcule $\alpha\left(V_{t}, V_{t+1}^{*}\right)$, conforme descrito na equação (3.7), e gere uma variável aleatória $U$ de uma distribuição uniforme $(0,1)$, então, o novo estado da cadeia será

$$
V_{t+1}=\left\{\begin{array}{l}
V_{t+1}^{*}, \text { se } U \leq \alpha\left(V_{t}, V_{t+1}^{*}\right) \\
V_{t}, \text { caso contrário. }
\end{array}\right.
$$

Passo 4: Repita o Passo 2 e Passo 3 para $t=1, \ldots, m$ vezes.

A densidade proposta, $q\left(V_{t+1}^{*} \mid V_{t}\right)$, deve ser definida no domínio da densidade alvo, $p\left(V_{t+1}^{*} \mid h\right)$. Na prática, o algoritmo de Metropolis-Hastings é de fácil implementação se a distribuição proposta é simples de ser simulada.

Note que o algoritmo do Amostrador de Gibbs é um caso particular do MetropolisHastings, onde a distribuição proposta é dada por $q\left(V_{t+1}^{*} \mid V_{t}\right)=p\left(V_{t+1}^{*} \mid h\right)$, assim, tem-se que $\alpha\left(V_{t}, V_{t+1}^{*}\right)=1$ e a proposta, (3.8), é sempre aceita.

\subsection{Previsão Bayesiana}

A abordagem bayesiana para previsão permite que informações não contidas nos dados históricos sejam incorporadas ao modelo, isso através das prioris. Com a distribuição a posteriori (3.3), considerando a previsão como $\hat{z}_{t+1}$ e $H_{t}=\left(y_{1}, y_{2}, \ldots, y_{t}\right)$, temos que

$$
f\left(z_{t+1}, \boldsymbol{\theta} \mid H_{t}\right)=\underbrace{f\left(z_{t+1} \mid \boldsymbol{\theta}, H_{t}\right)}_{\text {Preditiva }} \underbrace{p\left(\boldsymbol{\theta} \mid H_{t}\right)}_{\text {Posteriori }}
$$

Assim,

$$
\hat{z}_{t+1}=E\left(z_{t+1} \mid H_{t}\right)=\int_{z} z_{t+1} f\left(z_{t+1} \mid H_{t}\right) d z
$$

A partir da equação (3.9), tem-se que

$$
\hat{z}_{t+1}=\int_{z} z_{t+1}\left[\int_{\boldsymbol{\theta}} f\left(z_{t+1} \mid \boldsymbol{\theta}, H_{t}\right) p\left(\boldsymbol{\theta} \mid H_{t}\right) d \boldsymbol{\theta}\right] d z
$$

Permutando as integrais da equação (3.11), tem-se que

$$
\hat{z}_{t+1}=\int_{\boldsymbol{\theta}} \underbrace{\left[\int_{z} z_{t+1} f\left(z_{t+1} \mid \boldsymbol{\theta}, H_{t}\right) d z\right]}_{E\left(z_{t+1} \mid \boldsymbol{\theta}, H_{t}\right)} p\left(\boldsymbol{\theta} \mid H_{t}\right) d \boldsymbol{\theta}
$$


Portanto, temos a previsão $\hat{z}_{t+1}$ dada por

$$
\hat{z}_{t+1}=\int_{\boldsymbol{\theta}} E\left(z_{t+1} \mid \boldsymbol{\theta}, H_{t}\right) p\left(\boldsymbol{\theta} \mid H_{t}\right) d \boldsymbol{\theta}
$$

Utilizando simulações de MCMC, é possível obter amostras dos parâmetros, representadas pelo vetor $\boldsymbol{\theta}^{j}=\left(\mu_{m}^{(z)(j)}, \sigma_{m}^{(z)(j) 2}, \sigma_{m-1}^{(z)(j) 2}, \rho_{1, m}^{(z)(j)}\right)$, com $j=1, \ldots, M$, em que $M$ é o número de simulações. Com isso, calcula-se

$$
\hat{z}_{t+1}=\frac{1}{M} \sum_{j=1}^{M} z_{t+1}^{j}
$$

em que $z_{t+1}^{j}=\mu_{m+1}^{(z)(j)}+\rho_{1, m+1}^{(z)(j)} \frac{\sigma_{m+1}^{(z)(j)}}{\sigma_{m}^{(z)(j)}}\left[\ln \left(\frac{y_{t}-y_{m}^{\min }}{y_{m}^{\max }-y_{t}}\right)-\mu_{m}^{(z)(j)}\right], \operatorname{com} j=1, \ldots, M$. No entanto, a relação $z_{t}=\ln \left(\frac{y_{t}-y_{m}^{\min }}{y_{m}^{\max }-y_{t}}\right)$ pode ser utilizada para calcular a previsão da vazão afluente $\hat{y}_{t+1}$, dada por

$$
\hat{y}_{t+1}=\frac{1}{M} \sum_{j=1}^{M} y_{t+1}^{j}
$$

em que $y_{t+1}^{j}=\frac{y_{m+1}^{\max } \exp \left\{z_{t+1}^{j}\right\}+y_{m+1}^{\min }}{1+\exp \left\{z_{t+1}^{j}\right\}}, \operatorname{com} j=1, \ldots, M$.

Nesse ponto, a inferência bayesiana possui vantagens nos cálculos e interpretações para o intervalo de credibilidade de $100(1-\alpha) \%$, pois basta ordenar os $y_{t+1}^{j}$, para cada período $t+1$ predito, com $j=1, \ldots, M$, e calcular os percentis conforme o nível de significância $\alpha$ estabelecido. 


\begin{tabular}{|c|c|}
\hline & Capítulo \\
\hline & 4 \\
\hline
\end{tabular}

\section{Estudo de Casos}

Para cumprir o objetivo desta dissertação, foram utilizados os dados da usina hidroelétrica de Furnas, localizada no curso médio do rio Grande, no trecho denominado "Corredeiras das Furnas", entre os municípios de São José da Barra e São João Batista do Glória, em Minas Gerais (Figura 4.1); e da usina hidroelétrica de Sobradinho, localizada no município de Sobradinho, Bahia, no curso médio do rio São Francisco (Figura 4.2). Os parâmetros necessário para construir os modelos destes reservatório foram obtidos diretamente do endereço eletrônico da Câmara de Comercialização de Energia Elétrica (CCEE).

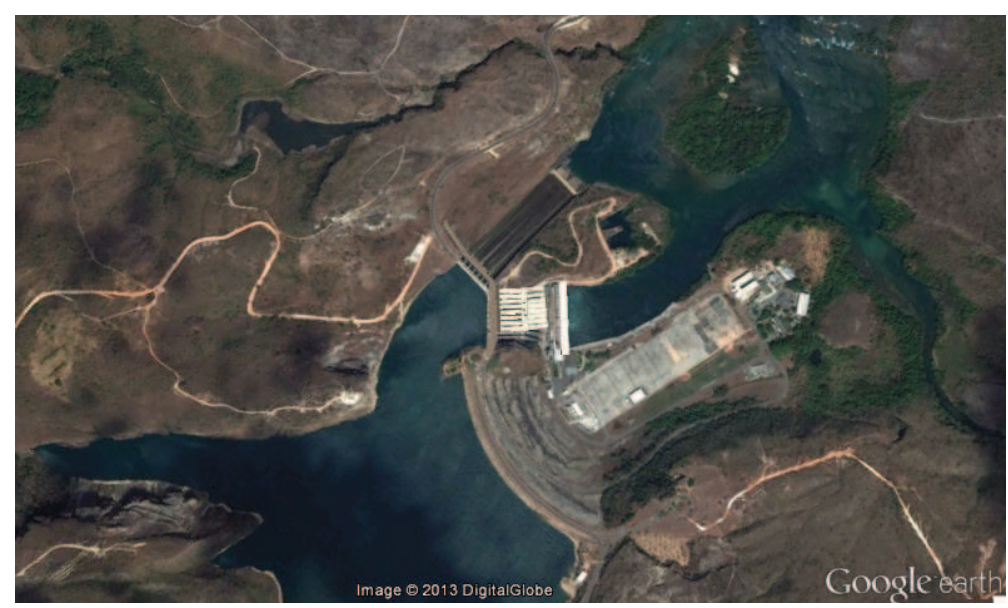

Figura 4.1: Usina hidroelétrica de Furnas. 


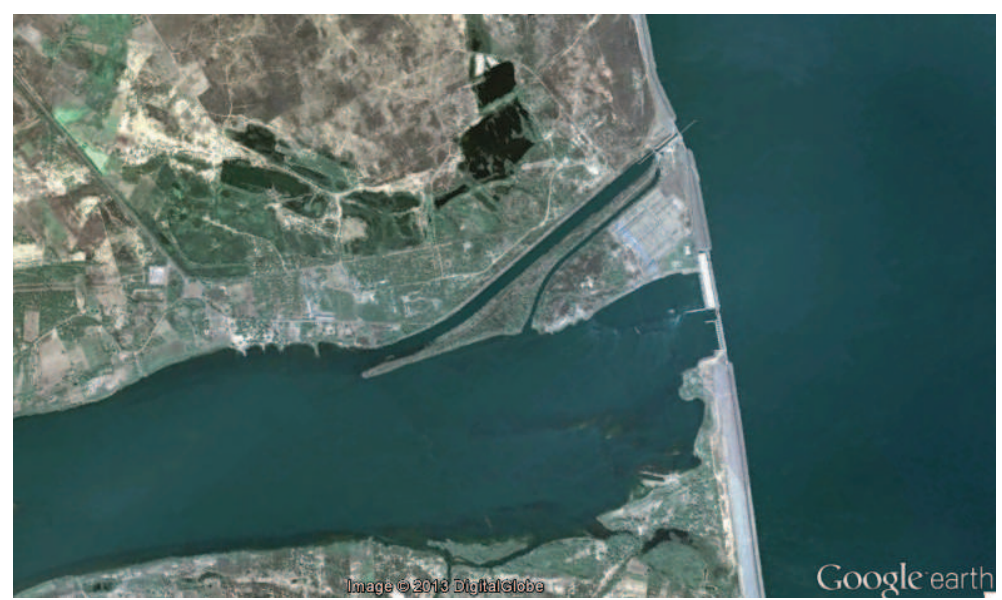

Figura 4.2: Usina hidroelétrica de Sobradinho.

Para fins de comparação, nessa modelagem será utilizado o sistema hidrotérmico com apenas uma usina hidroelétrica. Para avaliar o modelo estocástico utilizado na solução do problema POOSH, foi comparado via simulação o uso das tabelas de decisão obtidas com a PDE e PDD. Para modelar as vazões, foram utilizadas as séries históricas obtidas no endereço eletrônico do Operador Nacional do Sistema Elétrico (ONS) que se estendem de janeiro de 1931 a dezembro de 2010. Nos experimentos, foram consideradas as vazões mínimas e máximas do histórico como limitantes para truncar as funções densidade de probabilidade dos modelos de vazões. Com isso, para as duas usinas em questão, foram estimados os 12 modelos LN-Truncada e foi gerada uma série sintética de 4000 anos. Cabe destacar que foram empregados esses mesmos modelos com distribuição condicional para as vazões no cálculo da PDE. Em seguida, foi utilizada a primeira metade da série como um pseudo-histórico de vazões e empregou-se sua média como o modelo de vazões para PDD. Vale ressaltar que não foram constatadas diferenças significativas entre as médias obtidas dos históricos de vazões e as do pseudo-histórico.

Em seguida, utilizou-se a segunda metade da série, com 2000 anos de vazões, para comparar os modelos determinístico e estocástico, ou seja, o desempenho da PDE em relação à PDD. Para o cálculo dos controladores via PDD e PDE, foi fixado um horizonte de tempo de 45 meses, suficientes para a convergência das tabelas da programação dinâmica. É interessante notar que estes resultados estão de acordo com, por exemplo, Archibald et al. (1997), em que obteve-se convergência da programação dinâmica após 30 meses. Para obter estes controladores, empregaram-se ainda 100 pontos para discretizar a variável de estado $\left(x_{t}\right)$ e 50 pontos para discretizar a variável de controle $\left(u_{t}\right)$. Especificamente para a PDE, foram utilizados 50 pontos para discretizar a variável de 
vazão no período anterior $\left(y_{t-1}\right)$ e, para o cálculo do valor esperado, 100 pontos para discretizar a variável de vazão no período atual $\left(y_{t}\right)$.

No primeiro caso de estudos, foi considerado que a demanda de energia a ser atendida pela usina de Furnas é de $D_{t}=2100 \mathrm{MW}$-mês, para $t=0, \ldots, T-1$, já para o sistema hidrotérmico de Sobradinho foi estabelecido $D_{t}=1650$ MW-mês. É importante mencionar que foi considerado como nulo o limite inferior para a turbinagem, ou seja, $u_{\text {min }}=0$.

\subsection{Análise Descritiva dos Dados}

Para ilustrar o comportamento das séries, na Figura 4.3, temos a série real e sintética de Furnas e Sobradinho, respectivamente.

(a)

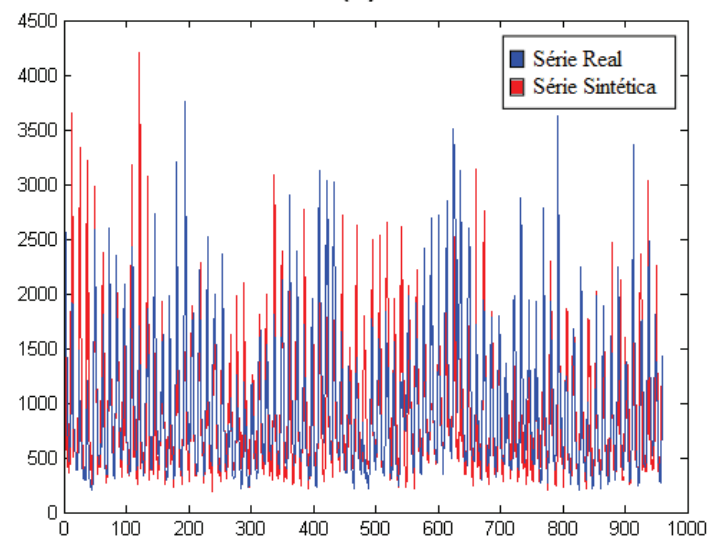

(b)

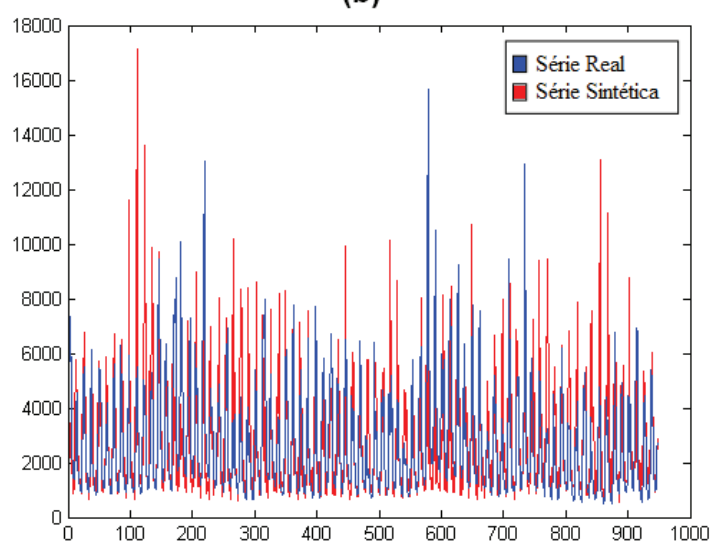

Figura 4.3: Série real e sintética de (a) Furnas e (b) Sobradinho.

Além disso, para descrever e interpretar os dados coletados e gerados, temos, na Tabela 4.1, as médias e desvios-padrões mensais para essas séries. O procedimento utilizado para estimar esses valores nas séries sintéticas foi o método de simulação de Monte Carlo via cadeias de Markov (MCMC). 
Tabela 4.1: Média e desvio-padrão das séries históricas e sintéticas de Furnas e Sobradinho.

\begin{tabular}{c|c|c|c|c}
\hline Furnas & \multicolumn{2}{|c|}{ Média $\left(\mathrm{km}^{3} / \mathrm{s}\right)$} & \multicolumn{2}{c}{ D.P. $\left(\mathrm{km}^{3} / \mathrm{s}\right)$} \\
\hline Meses & Histórica & Sintética & Histórica & Sintética \\
\hline 1 & 1,7551 & 1,7846 & 0,6890 & 0,6069 \\
2 & 1,6656 & 1,6935 & 0,6248 & 0,6860 \\
3 & 1,4741 & 1,4190 & 0,5833 & 0,5254 \\
4 & 1,0134 & 1,0042 & 0,3484 & 0,3306 \\
5 & 0,7410 & 0,7522 & 0,2274 & 0,2221 \\
6 & 0,6138 & 0,6326 & 0,2413 & 0,1973 \\
7 & 0,5061 & 0,5207 & 0,1514 & 0,1462 \\
8 & 0,4175 & 0,4266 & 0,1202 & 0,1259 \\
9 & 0,4381 & 0,4428 & 0,2249 & 0,1891 \\
10 & 0,5150 & 0,5458 & 0,2206 & 0,2093 \\
11 & 0,7303 & 0,7480 & 0,3027 & 0,3170 \\
12 & 1,2490 & 1,2601 & 0,4544 & 0,5221 \\
\hline Sobradinho & Média & $(\mathrm{km} / \mathrm{s})$ & \multicolumn{2}{|c}{ D.P. } \\
\hline Meses & Histórica & Sintética & Histórica & Sintética \\
\hline 1 & 4,7303 & 5,0276 & 1,4045 & 1,6708 \\
2 & 4,9780 & 5,2972 & 2,0244 & 2,3524 \\
3 & 4,8506 & 4,9731 & 2,5019 & 2,5388 \\
4 & 3,7863 & 4,0527 & 1,6973 & 1,8826 \\
5 & 2,3157 & 2,3861 & 1,1530 & 0,9069 \\
6 & 1,5759 & 1,6102 & 0,5426 & 0,4806 \\
7 & 1,3176 & 1,3429 & 0,3897 & 0,3471 \\
8 & 1,1417 & 1,1800 & 0,3195 & 0,2935 \\
9 & 1,0222 & 1,0261 & 0,2864 & 0,2454 \\
10 & 1,1475 & 1,1664 & 0,3624 & 0,3282 \\
11 & 1,8894 & 1,9703 & 0,7751 & 0,8068 \\
12 & 3,3804 & 3,4078 & 1,2016 & 1,2585 \\
\hline
\end{tabular}

Com isso, é possível notar que a média e o desvio-padrão do histórico e da série sintética se assemelham, para ambas as usinas, reafirmando que o modelo é adequado. 


\begin{tabular}{|c|c|}
\hline & Capítulo \\
\hline 5 \\
\hline
\end{tabular}

\section{Resultados e Discussões}

Para a etapa de simulação e previsão foram utilizados os softwares R (versão 2.15.1) e OpenBUGS (versão 3.2.2), com a verossimilhança dada a partir da função densidade de probabilidade (2.20) e as distribuições a priori (3.4), (3.5) e (3.6).

As especificações de simulação são: 50000 iterações, com saltos de tamanho 50 e um "período de aquecimento" (burn-in) de 10000 iterações.

\subsection{Estimativa dos Parâmetros}

As Tabelas 5.1 e 5.2 apresentam os estimadores de Monte Carlo das médias a posteriori baseadas nas amostras geradas de Gibbs dos parâmetros, assim, como algumas medidas descritivas e os intervalos de credibilidade de $95 \%$ para cada parâmetro para as usinas hidroelétrica de Furnas e Sobradinho, respectivamente. 
Tabela 5.1: Sumários a posteriori dos parâmetros para a usina hidroelétrica de Furnas.

\begin{tabular}{|c|c|c|c|c|c|c|}
\hline Parâmetro & Estimativa & Desvio Padrão & Erro de Monte Carlo & $2,5 \%$ & Mediana & $97,5 \%$ \\
\hline$\mu_{1}^{(z)}$ & $-1,888$ & 0,075 & $5,85 \times 10^{-4}$ & $-2,036$ & $-1,889$ & $-1,741$ \\
\hline$\mu_{2}^{(z)}$ & $-1,679$ & 0,072 & $6,58 \times 10^{-4}$ & $-1,821$ & $-1,678$ & $-1,539$ \\
\hline$\mu_{3}^{(z)}$ & $-2,282$ & 0,063 & $6,59 \times 10^{-4}$ & $-2,404$ & $-2,282$ & $-2,158$ \\
\hline$\mu_{4}^{(z)}$ & $-2,128$ & 0,059 & $6,51 \times 10^{-4}$ & $-2,244$ & $-2,128$ & $-2,013$ \\
\hline$\mu_{5}^{(z)}$ & $-1,985$ & 0,056 & $6,55 \times 10^{-4}$ & $-2,096$ & $-1,985$ & $-1,876$ \\
\hline$\mu_{6}^{(z)}$ & $-3,127$ & 0,052 & $6,35 \times 10^{-4}$ & $-3,230$ & $-3,127$ & $-3,025$ \\
\hline$\mu_{7}^{(z)}$ & $-2,429$ & 0,051 & $6,22 \times 10^{-4}$ & $-2,530$ & $-2,429$ & $-2,331$ \\
\hline$\mu_{8}^{(z)}$ & $-2,143$ & 0,055 & $6,5 \times 10^{-4}$ & $-2,250$ & $-2,143$ & $-2,036$ \\
\hline$\mu_{9}^{(z)}$ & $-3,501$ & 0,069 & $7,45 \times 10^{-4}$ & $-3,637$ & $-3,500$ & $-3,365$ \\
\hline$\mu_{10}^{(z)}$ & $-2,992$ & 0,062 & $5,90 \times 10^{-4}$ & $-3,113$ & $-2,992$ & $-2,870$ \\
\hline$\mu_{11}^{(z)}$ & $-2,501$ & 0,070 & $6,19 \times 10^{-4}$ & $-2,638$ & $-2,502$ & $-2,363$ \\
\hline$\mu_{12}^{(z)}$ & $-2,198$ & 0,061 & $4,89 \times 10^{-4}$ & $-2,319$ & $-2,197$ & $-2,076$ \\
\hline$\sigma_{1}^{(z) 2}$ & 0,427 & 0,074 & $4,01 \times 10^{-4}$ & 0,304 & 0,420 & 0,592 \\
\hline$\sigma_{2}^{(z) 2}$ & 0,403 & 0,068 & $3,96 \times 10^{-4}$ & 0,289 & 0,396 & 0,554 \\
\hline$\sigma_{3}^{(z) 2}$ & 0,313 & 0,050 & $3,14 \times 10^{-4}$ & 0,229 & 0,308 & 0,425 \\
\hline$\sigma_{4}^{(z) 2}$ & 0,277 & 0,042 & $3,30 \times 10^{-4}$ & 0,205 & 0,273 & 0,369 \\
\hline$\sigma_{5}^{(z) 2}$ & 0,255 & 0,037 & $3,22 \times 10^{-4}$ & 0,191 & 0,251 & 0,336 \\
\hline$\sigma_{6}^{(z) 2}$ & 0,219 & 0,031 & $2,77 \times 10^{-4}$ & 0,165 & 0,216 & 0,287 \\
\hline$\sigma_{7}^{(z) 2}$ & 0,208 & 0,030 & $2,55 \times 10^{-4}$ & 0,156 & 0,205 & 0,274 \\
\hline$\sigma_{8}^{(z) 2}$ & 0,240 & 0,036 & $2,56 \times 10^{-4}$ & 0,178 & 0,237 & 0,319 \\
\hline$\sigma_{9}^{(z) 2}$ & 0,383 & 0,060 & $3,68 \times 10^{-4}$ & 0,281 & 0,377 & 0,516 \\
\hline$\sigma_{10}^{(z) 2}$ & 0,302 & 0,050 & $2,75 \times 10^{-4}$ & 0,217 & 0,297 & 0,414 \\
\hline$\sigma_{11}^{(z) 2}$ & 0,387 & 0,065 & $3,78 \times 10^{-4}$ & 0,279 & 0,380 & 0,532 \\
\hline$\sigma_{12}^{(z) 2}$ & 0,294 & 0,051 & $3,14 \times 10^{-4}$ & 0,210 & 0,288 & 0,409 \\
\hline$\rho_{1,1}^{(z)}$ & 0,654 & 0,055 & $3,00 \times 10^{-4}$ & 0,536 & 0,657 & 0,753 \\
\hline$\rho_{1,2}^{(z)}$ & 0,670 & 0,053 & $2,99 \times 10^{-4}$ & 0,557 & 0,674 & 0,766 \\
\hline$\rho_{1,3}^{(z)}$ & 0,732 & 0,045 & $2,44 \times 10^{-4}$ & 0,635 & 0,735 & 0,811 \\
\hline$\rho_{1,4}^{(z)}$ & 0,830 & 0,030 & $1,87 \times 10^{-4}$ & 0,764 & 0,833 & 0,883 \\
\hline$\rho_{1,5}^{(z)}$ & 0,883 & 0,021 & $1,61 \times 10^{-4}$ & 0,835 & 0,884 & 0,919 \\
\hline$\rho_{1,6}^{(z)}$ & 0,914 & 0,016 & $1,17 \times 10^{-4}$ & 0,878 & 0,916 & 0,941 \\
\hline$\rho_{1,7}^{(z)}$ & 0,933 & 0,013 & $8,61 \times 10^{-4}$ & 0,905 & 0,934 & 0,955 \\
\hline$\rho_{1,8}^{(z)}$ & 0,930 & 0,013 & $9,49 \times 10^{-4}$ & 0,900 & 0,931 & 0,952 \\
\hline$\rho_{1,9}^{(z)}$ & 0,831 & 0,030 & $1,82 \times 10^{-4}$ & 0,765 & 0,833 & 0,882 \\
\hline$\rho_{1,10}^{(z)}$ & 0,699 & 0,049 & $2,63 \times 10^{-4}$ & 0,594 & 0,702 & 0,785 \\
\hline$\rho_{1,11}^{(z)}$ & 0,750 & 0,043 & $2,39 \times 10^{-4}$ & 0,657 & 0,754 & 0,825 \\
\hline$\rho_{1,12}^{(z)}$ & 0,694 & 0,050 & $2,93 \times 10^{-4}$ & 0,587 & 0,697 & 0,784 \\
\hline
\end{tabular}


Tabela 5.2: Sumários a posteriori dos parâmetros para a usina hidroelétrica de Sobradinho.

\begin{tabular}{|c|c|c|c|c|c|c|}
\hline Parâmetro & Estimativa & Desvio Padrão & Erro de Monte Carlo & $2,5 \%$ & Mediana & $97,5 \%$ \\
\hline$\mu_{1}^{(z)}$ & $-1,794$ & 0,060 & $7,14 \times 10^{-4}$ & $-1,912$ & $-1,795$ & $-1,676$ \\
\hline$\mu_{2}^{(m)}$ & $-1,830$ & 0,078 & $1,07 \times 10^{-4}$ & $-1,984$ & $-1,829$ & $-1,674$ \\
\hline$\mu_{3}^{(m)}$ & $-2,814$ & 0,075 & $1,15 \times 10^{-4}$ & $-2,962$ & $-2,815$ & $-2,667$ \\
\hline$\mu_{4}^{(z)}$ & $-1,917$ & 0,076 & $1,35 \times 10^{-4}$ & $-2,064$ & $-1,917$ & $-1,768$ \\
\hline$\mu_{5}^{(z)}$ & $-3,096$ & 0,063 & $1,20 \times 10^{-4}$ & $-3,218$ & $-3,097$ & $-2,971$ \\
\hline$\mu_{6}^{(z)}$ & $-2,455$ & 0,060 & $1,17 \times 10^{-3}$ & $-2,571$ & $-2,455$ & $-2,336$ \\
\hline$\mu_{7}^{(z)}$ & $-1,905$ & 0,054 & $1,06 \times 10^{-3}$ & $-2,010$ & $-1,906$ & $-1,799$ \\
\hline$\mu_{8}^{(z)}$ & $-1,849$ & 0,058 & $1,13 \times 10^{-3}$ & $-1,962$ & $-1,850$ & $-1,734$ \\
\hline$\mu_{9}^{(z)}$ & $-1,929$ & 0,052 & $9,75 \times 10^{-4}$ & $-2,029$ & $-1,929$ & $-1,826$ \\
\hline$\mu_{10}^{(z)}$ & $-1,657$ & 0,063 & $1,05 \times 10^{-3}$ & $-1,779$ & $-1,657$ & $-1,534$ \\
\hline$\mu_{11}^{(z)}$ & $-2,120$ & 0,068 & $9,69 \times 10^{-4}$ & $-2,253$ & $-2,120$ & $-1,986$ \\
\hline$\mu_{12}^{(z)}$ & $-1,681$ & 0,072 & $9,09 \times 10^{-4}$ & $-1,823$ & $-1,682$ & $-1,539$ \\
\hline$\overline{\sigma_{1}^{(z) 2}}$ & 0,256 & 0,045 & $2,45 \times 10^{-4}$ & 0,182 & 0,251 & 0,356 \\
\hline$\sigma_{2}^{(z) 2}$ & 0,445 & 0,074 & $5,12 \times 10^{-4}$ & 0,321 & 0,437 & 0,611 \\
\hline$\sigma_{3}^{(z) 2}$ & 0,419 & 0,066 & $5,10 \times 10^{-4}$ & 0,308 & 0,413 & 0,567 \\
\hline$\sigma_{4}^{(z) 2}$ & 0,445 & 0,064 & $6,79 \times 10^{-4}$ & 0,335 & 0,440 & 0,585 \\
\hline$\sigma_{5}^{(z) 2}$ & 0,316 & 0,042 & $5,41 \times 10^{-4}$ & 0,241 & 0,313 & 0,407 \\
\hline$\sigma_{6}^{(z) 2}$ & 0,285 & 0,037 & $5,18 \times 10^{-4}$ & 0,219 & 0,282 & 0,365 \\
\hline$\sigma_{7}^{(z) 2}$ & 0,229 & 0,030 & $4,15 \times 10^{-4}$ & 0,176 & 0,227 & 0,292 \\
\hline$\sigma_{8}^{(z) 2}$ & 0,267 & 0,035 & $4,86 \times 10^{-4}$ & 0,205 & 0,264 & 0,342 \\
\hline$\sigma_{9}^{(z) 2}$ & 0,208 & 0,029 & $3,52 \times 10^{-4}$ & 0,159 & 0,206 & 0,271 \\
\hline$\sigma_{10}^{(z) 2}$ & 0,295 & 0,045 & $3,65 \times 10^{-4}$ & 0,219 & 0,291 & 0,394 \\
\hline$\sigma_{11}^{(z) 2}$ & 0,335 & 0,055 & $3,66 \times 10^{-4}$ & 0,242 & 0,330 & 0,460 \\
\hline$\sigma_{12}^{(z) 2}$ & 0,376 & 0,064 & $3,94 \times 10^{-4}$ & 0,268 & 0,370 & 0,521 \\
\hline$\rho_{1,1}^{(z)}$ & 0,639 & 0,058 & $3,39 \times 10^{-4}$ & 0,517 & 0,642 & 0,742 \\
\hline$\rho_{1,2}^{(z)}$ & 0,683 & 0,052 & $2,72 \times 10^{-4}$ & 0,572 & 0,687 & 0,776 \\
\hline$\rho_{1,3}^{(z)}$ & 0,802 & 0,035 & $2,40 \times 10^{-4}$ & 0,727 & 0,805 & 0,863 \\
\hline$\rho_{1,4}^{(z)}$ & 0,790 & 0,036 & $2,43 \times 10^{-4}$ & 0,713 & 0,793 & 0,852 \\
\hline$\rho_{1,5}^{(z)}$ & 0,912 & 0,016 & $1,52 \times 10^{-4}$ & 0,876 & 0,913 & 0,940 \\
\hline$\rho_{1,6}^{(z)}$ & 0,956 & 0,008 & $8,56 \times 10^{-5}$ & 0,937 & 0,956 & 0,970 \\
\hline$\rho_{1,7}^{(z)}$ & 0,977 & 0,004 & $4,89 \times 10^{-4}$ & 0,966 & 0,977 & 0,984 \\
\hline$\rho_{1,8}^{(z)}$ & 0,976 & 0,004 & $4,58 \times 10^{-4}$ & 0,966 & 0,977 & 0,984 \\
\hline$\rho_{1,9}^{(z)}$ & 0,940 & 0,011 & $1,01 \times 10^{-4}$ & 0,914 & 0,941 & 0,959 \\
\hline$\rho_{1,10}^{(z)}$ & 0,845 & 0,027 & $2,09 \times 10^{-4}$ & 0,785 & 0,847 & 0,892 \\
\hline$\rho_{1,11}^{(z)}$ & 0,733 & 0,044 & $2,70 \times 10^{-4}$ & 0,639 & 0,736 & 0,811 \\
\hline$\rho_{1,12}^{(z)}$ & 0,755 & 0,043 & $2,42 \times 10^{-4}$ & 0,662 & 0,758 & 0,830 \\
\hline
\end{tabular}

Além desses resultados, no Apêndice A são apresentados os gráficos de convergência para todos os parâmetros nos estudos de Furnas e Sobradinho. 
Embora seja da natureza do problema a sazonalidade e dependência entre os períodos, foi constatado um baixo nível de autocorrelação para a maioria dos parâmetros, provavelmente por consequência da escolha do tamanho dos saltos. Esses resultados também podem ser vistos no Apêndice B.

\subsection{Validação da Previsão}

Como procedimento de validação da previsão, foi utilizado no ajuste do modelo apenas o histórico de vazões no período de 1931 a 2007. Assim, a previsão de três anos pode ser comparada com as afluências obtidas nos anos de 2008, 2009 e 2010, isso para ambas as usinas hidroelétricas.

Para avaliar a qualidade das previsões são utilizadas as medidas de raiz quadrada do erro quadrático médio (REQM) e erro absoluto percentual (EAP), expressas em (5.1).

$$
R E Q M=\sqrt{\frac{1}{N} \sum_{i=1}^{N}\left(y_{i}-\hat{y}_{i}\right)^{2}}, \quad E A P=\frac{100}{N} \sum_{i=1}^{N}\left|\frac{y_{i}-\hat{y}_{i}}{y_{i}}\right|
$$

em que $N$ é o número de anos de previsão, $y_{i}$ é o valor real da vazão afluente no período $i$ e $\hat{y}_{i}$ é o valor predito da vazão afluente no período $i$. A Tabela 5.3 apresenta os valores reais e preditos no período de três anos após 2007.

Note que a REQM e o EAP, que são medidas de discrepância entre valores, resultam valores satisfatórios em ambos os casos, principalmente o EAP que apresenta valores percentuais entre $14 \%$ e $35 \%$ para Furnas e entre $6 \%$ e $32 \%$ para Sobradinho, o que é adequado e dentro da faixa esperada nesse contexto. As trajetórias entre as previsões e os valores reais, para Furnas e Sobradinho, podem ser vistas nas Figuras 5.1 e 5.2, respectivamente.

Com isso, o modelo apresentado utilizando a abordagem bayesiana mostrou-se coerente com a realidade e útil para o planejamento da operação de sistemas hidrotérmicos, principalmente na adequabilidade quanto a previsões de vazões afluentes. 
Tabela 5.3: Valores reais, previsões, REQM e EAP para os anos de 2008, 2009 e 2010 das usinas hidroelétricas de Furnas e Sobradinho.

\begin{tabular}{c|cc|cc|cc|cc}
\hline Furnas & \multicolumn{2}{|c|}{2008} & \multicolumn{2}{|c|}{2009} & \multicolumn{2}{|c|}{2010} & \multicolumn{2}{c}{$2008-2009-2010$} \\
\hline Mês & Real & Previsão & Real & Previsão & Real & Previsão & REQM & EAP \\
\hline Janeiro & 1092 & 1245,101 & 2028 & 1630,703 & 1741 & 1948,974 & 273,581 & 14,19 \\
Fevereiro & 1737 & 1962,231 & 2485 & 2051,806 & 1018 & 2116,960 & 694,253 & 26,94 \\
Março & 1758 & 1427,411 & 1619 & 1087,541 & 1251 & 951,466 & 400,754 & 25,20 \\
Abril & 1448 & 1522,002 & 1643 & 1165,936 & 812 & 1035,992 & 307,292 & 18,51 \\
Maio & 771 & 590,034 & 843 & 653,744 & 581 & 697,413 & 165,406 & 20,87 \\
Junho & 624 & 963,713 & 566 & 433,982 & 452 & 264,978 & 236,305 & 33,31 \\
Julho & 460 & 443,432 & 630 & 660,541 & 424 & 915,837 & 284,673 & 20,65 \\
Agosto & 433 & 380,901 & 525 & 453,886 & 301 & 540,711 & 147,607 & 23,40 \\
Setembro & 518 & 687,114 & 395 & 262,022 & 276 & 148,179 & 144,340 & 34,85 \\
Outubro & 477 & 413,071 & 828 & 536,918 & 452 & 624,227 & 198,772 & 25,41 \\
Novembro & 866 & 564,507 & 658 & 770,752 & 870 & 996,817 & 200,180 & 20,76 \\
Dezembro & 1558 & 1154,009 & 1813 & 1293,803 & 1434 & 1367,291 & 381,624 & 19,73 \\
\hline Sobradinho & & 2008 & & 2009 & & 2010 & $2008-2009-2010$ \\
\hline Mês & Real & Previsão & Real & Previsão & Real & Previsão & REQM & EAP \\
\hline Janeiro & 5905 & 5401,561 & 1933 & 4762,998 & 5409 & 4455,438 & 1748,487 & 28,52 \\
Fevereiro & 6947 & 5423,779 & 4021 & 4326,461 & 5072 & 4240,482 & 1017,338 & 15,13 \\
Março & 6765 & 4629,619 & 4465 & 4705,087 & 3542 & 4186,326 & 1295,203 & 17,35 \\
Abril & 2547 & 2991,427 & 3964 & 3415,469 & 4254 & 3762,232 & 496,735 & 13,42 \\
Maio & 1482 & 2442,369 & 1901 & 1163,002 & 2410 & 2725,701 & 722,638 & 29,91 \\
Junho & 1302 & 1548,629 & 1127 & 1298,023 & 1492 & 3305,292 & 1061,148 & 27,99 \\
Julho & 995 & 1125,547 & 928 & 1566,677 & 1236 & 2093,036 & 621,681 & 31,10 \\
Agosto & 996 & 936,658 & 843 & 960,100 & 976 & 985,699 & 76,000 & 6,38 \\
Setembro & 727 & 926,207 & 669 & 897,467 & 1019 & 874,410 & 193,896 & 20,38 \\
Outubro & 573 & 786,140 & 729 & 804,209 & 1393 & 1563,175 & 163,345 & 15,78 \\
Novembro & 614 & 890,910 & 945 & 1071,975 & 2534 & 2214,706 & 254,788 & 18,51 \\
Dezembro & 1588 & 1800,920 & 2303 & 2297,593 & 2730 & 2098,637 & 384,700 & 11,73 \\
\hline
\end{tabular}

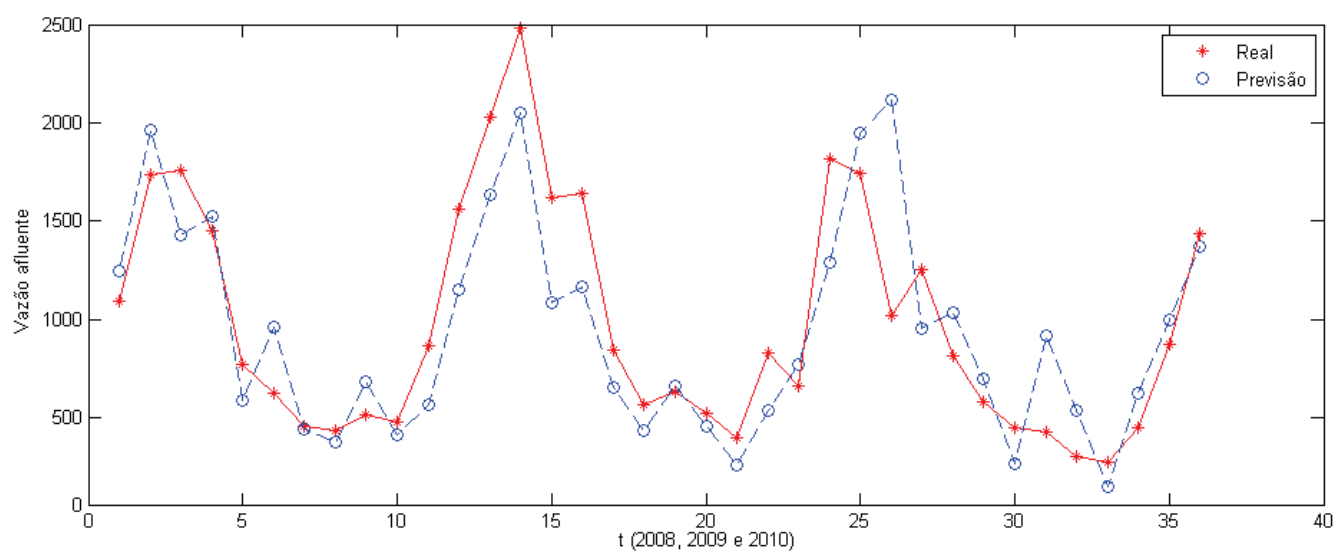

Figura 5.1: Comparação entre a previsão e a série real de Furnas para os anos de 2008, 2009 e 2010. 


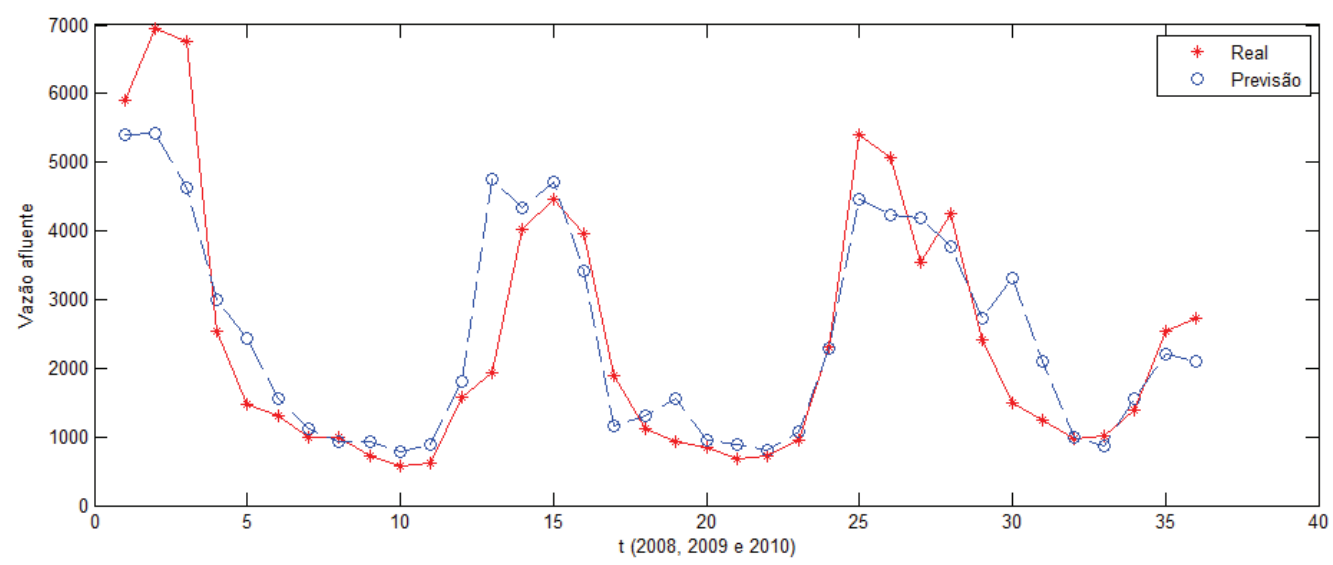

Figura 5.2: Comparação entre a previsão e a série real de Sobradinho para os anos de 2008,2009 e 2010.

\subsection{Planejamento da Operação do Sistema Hidrotér- mico}

A Figura 5.3 apresenta as trajetórias do volume médio dos dois reservatórios. Notase que para o reservatório de Furnas, a PDE apresenta uma operação com níveis de reservatório mais baixo do que a PDD em todo período.

(a)

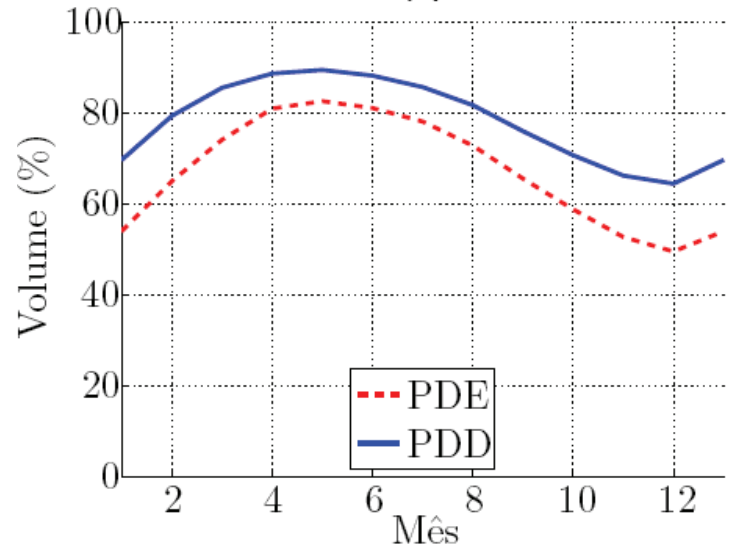

(b)

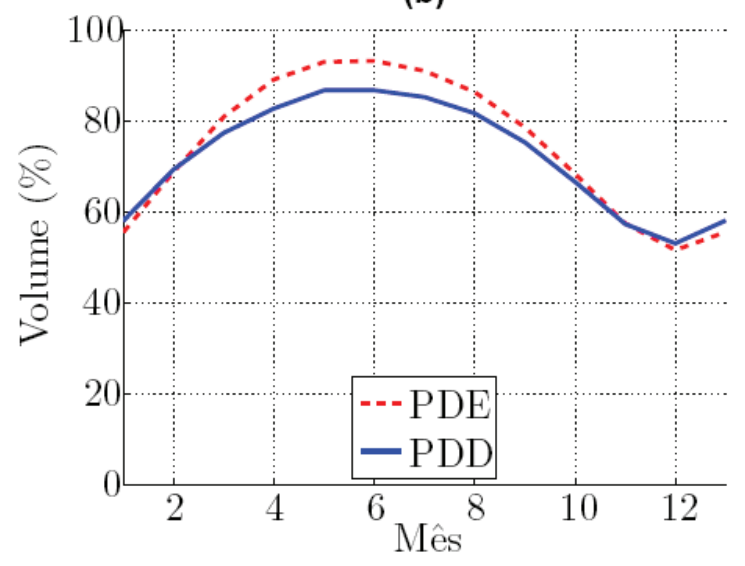

Figura 5.3: Trajetórias médias de volume para (a) Furnas e (b) Sobradinho, obtidas com as técnicas PDD e PDE.

Como consequência, a PDD apresenta maior vertimento do que a PDE, como pode ser observado na Figura 5.4. Uma situação parcialmente oposta pode ser observada para o reservatório de Sobradinho. Nesse caso, a PDE apresenta uma trajetória média do volume acima da PDD na maior parte do tempo. Porém, essa situação não leva 
esta técnica a verter mais que a PDD, como se pode notar na Figura 5.4, o vertimento médio entre ambas é semelhante.

(a)

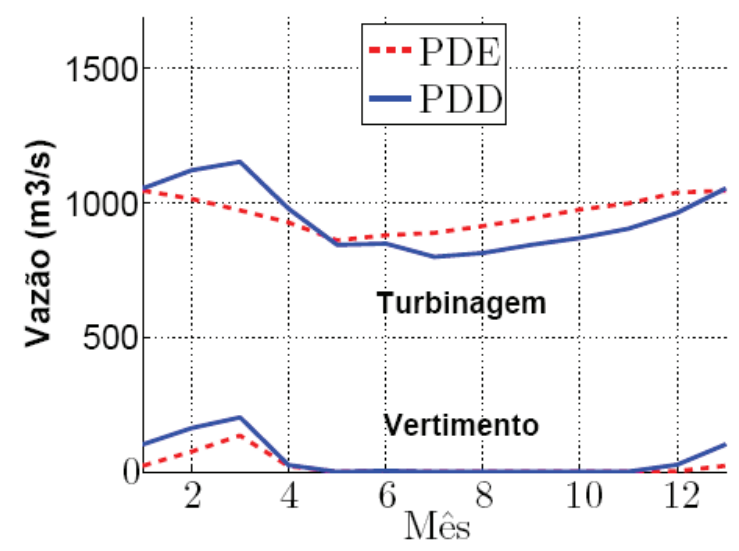

(b)

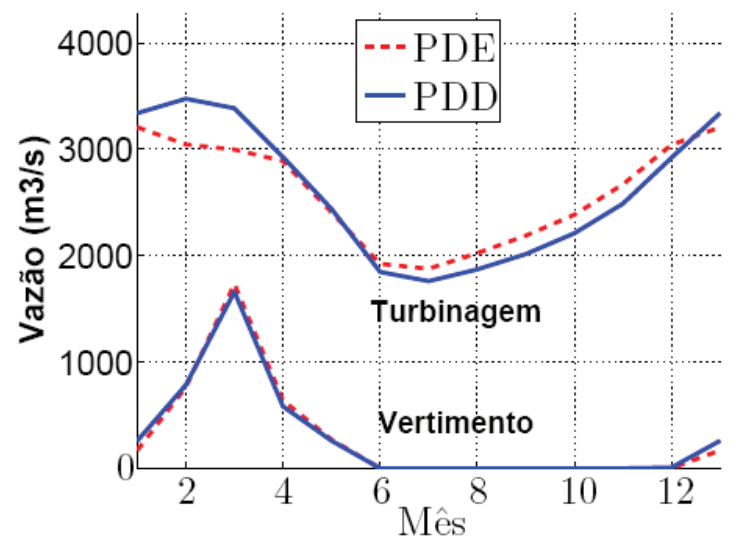

Figura 5.4: Trajetórias médias das turbinagens e vertimentos para (a) Furnas e (b) Sobradinho, obtidas com as técnicas PDD e PDE.

A Figura 5.4 também ilustra as trajetórias médias de turbinagens obtidas com as duas técnicas. Destaca-se que apesar da operação feita com o uso da PDD resultar em mais vertimento, isto não afeta de forma significativa o rendimento das usinas, como pode ser observado pelas trajetórias de geração hidroelétrica (e complementação térmica) na Figura 5.5.

(a)

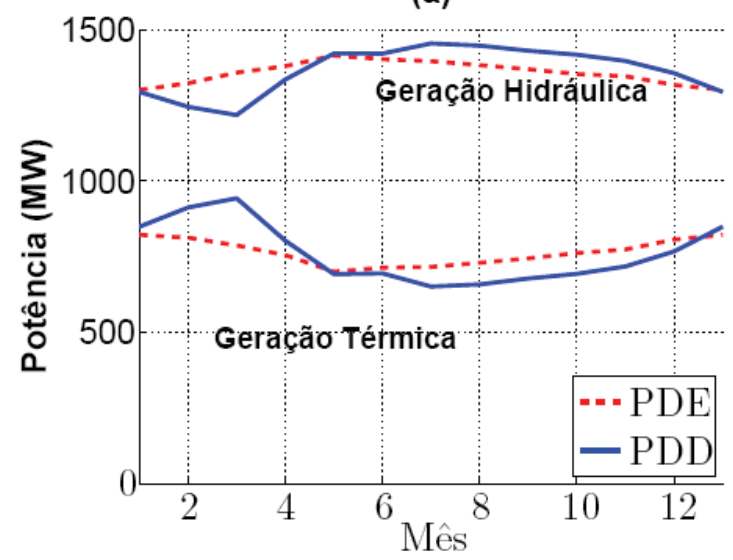

(b)

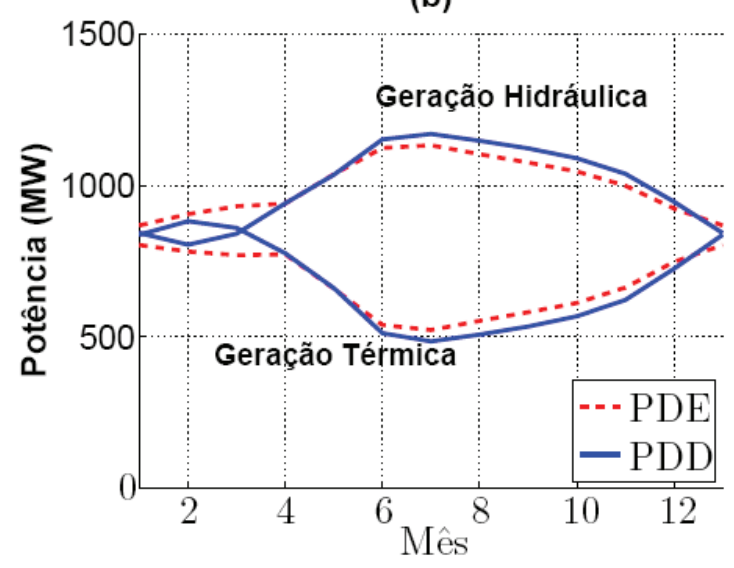

Figura 5.5: Geração hidroelétrica média e complementação térmica média para as usinas de (a) Furnas e (b) Sobradinho, obtidas com as técnicas PDD e PDE.

A Tabela 5.4 apresenta os valores totais de geração e custo de operação para os dois reservatórios considerados. 
Tabela 5.4: Resultados para a operação de Furnas e Sobradinho (GH = Geração Hidráulica Média; GT = Geração Térmica Média).

\begin{tabular}{c|c|c|c}
\hline Furnas & PDD & PDE & PDD/PDE \\
\hline GH (MW-mês) & 754,2752 & 759,5221 & 0,9930 \\
GT (MW-mês) & 1345,6373 & 1340,3904 & 1,0039 \\
Custo (Milhões) & 1,8802 & 1,8539 & 1,0142 \\
\hline Sobradinho & PDD & PDE & PDD/PDE \\
\hline GH (MW-mês) & 663,4995 & 666,3106 & 0,9957 \\
GT (MW-mês) & 986,4318 & 983,6207 & 1,0029 \\
Custo (Milhões) & 1,0369 & 1,0209 & 1,0157 \\
\hline
\end{tabular}

Analisando esses resultados, constata-se que a PDE apresenta uma vantagem de aproximadamente 1,5\% em relação a PDD no tocante aos custos, e de 0,7\% e 0,4\%, respectivamente para Furnas e Sobradinho, em termos de geração hidroelétrica.

Uma análise semelhante foi feita para os períodos de maior escassez hídrica, que denominamos períodos críticos, identificados na série de vazões empregada nas simulações. Para o reservatório de Furnas foram identificados 8 períodos críticos que tiveram em média uma janela de aproximadamente 39 meses, enquanto que no reservatório de Sobradinho foram obtidos 12 períodos críticos com extensão de aproximadamente 22 meses. Nesses períodos, em média, a PDE mantém uma margem significativa de ganho em relação à PDD, como podemos observar na Tabela 5.5, com destaque para o custo no reservatório de Sobradinho em que a PDD obteve um valor de 2,6\% maior que a PDE.

Tabela 5.5: Resultados para o período crítico de Furnas e Sobradinho (GH = Geração Hidráulica Média; GT = Geração Térmica Média).

\begin{tabular}{c|c|c|c}
\hline Furnas & PDD & PDE & PDD/PDE \\
\hline GH (MW-mês) & 457,6976 & 464,4562 & 0,9855 \\
GT (MW-mês) & 1644,0116 & 1638,9058 & 1,0031 \\
Custo (Milhões) & 2,7034 & 2,6867 & 1,0062 \\
\hline Sobradinho & PDD & PDE & PDD/PDE \\
\hline GH (MW-mês) & 363,1436 & 380,0843 & 0,9554 \\
GT (MW-mês) & 1291,8626 & 1274,8805 & 1,0133 \\
Custo (Milhões) & 1,6694 & 1,6258 & 1,0268 \\
\hline
\end{tabular}

A análise dos resultados apresentados nesta seção revelam que a vantagem da PDE em frente a PDD é em torno de 1,5\% em termos de custo e que uma margem positiva de ganho mantém-se nos períodos críticos. Devido ao grande porte do sistema de energia 
elétrica brasileiro, essa vantagem pode representar um ganho significativo na operação do sistema.

\subsection{Estudos de Previsões}

Nesta última seção será utilizada a metodologia bayesiana para previsões apresentada no capítulo 3 e validada na seção 5.2 para prever as vazões afluentes de 2011, 2012 e 2013, assim como, compará-las com a média de longo termo (MLT) do histórico de Furnas e Sobradinho, e utilizar as tabelas de decisões da PDE e PDD para obter o planejamento da operação. Além disso, será comparado os resultados entre a abordagem estocástica e determinística. Essas previsões serão mensuradas EAP das previsões em relação a MLT, esses resultados são apresentados na Tabela 5.6.

Tabela 5.6: Valores preditos de vazões afluentes para os anos de 2011, 2012 e 2013 das usinas hidroelétricas de Furnas e Sobradinho.

\begin{tabular}{c|c|c|c|c}
\hline Furnas & 2011 & 2012 & 2013 & EAP \\
\hline Janeiro & 2236,966 & 2397,451 & 2509,123 & 35,68 \\
Fevereiro & 1627,112 & 1801,898 & 1933,905 & 8,66 \\
Março & 1049,479 & 934,9204 & 883,068 & 35,29 \\
Abril & 893,941 & 921,9163 & 934,5076 & 9,76 \\
Maio & 617,0353 & 672,4468 & 709,9023 & 10,30 \\
Junho & 486,976 & 283,4657 & 208,1933 & 46,96 \\
Julho & 413,9941 & 623,0663 & 874,1112 & 37,88 \\
Agosto & 351,7061 & 420,6642 & 502,0841 & 12,10 \\
Setembro & 290,6505 & 155,8544 & 119,3366 & 57,13 \\
Outubro & 368,6793 & 502,5981 & 601,2929 & 15,89 \\
Novembro & 642,0561 & 858,7322 & 1087,559 & 26,30 \\
Dezembro & 1390,881 & 1416,181 & 1428,651 & 13,22 \\
\hline Sobradinho & 2011 & 2012 & 2013 & $\mathrm{EAP}$ \\
\hline Janeiro & 3770,279 & 3938,779 & 4030,611 & 17,27 \\
Fevereiro & 5391,368 & 5173,590 & 4984,005 & 4,12 \\
Março & 4698,185 & 2531,971 & 1663,017 & 38,89 \\
Abril & 2923,151 & 5320,874 & 8258,857 & 60,49 \\
Maio & 2487,354 & 1177,264 & 731,099 & 41,67 \\
Junho & 1635,536 & 2420,835 & 3460,698 & 58,99 \\
Julho & 1270,501 & 1745,804 & 2292,976 & 36,68 \\
Agosto & 1071,754 & 1108,080 & 1148,030 & 3,22 \\
Setembro & 883,805 & 863,400 & 846,893 & 15,39 \\
Outubro & 1133,717 & 1361,214 & 1629,901 & 20,60 \\
Novembro & 2215,141 & 1585,649 & 1222,814 & 22,86 \\
Dezembro & 4152,072 & 5067,988 & 5897,001 & 49,08 \\
\hline
\end{tabular}

Note que o EAP tem uma grande variação mensal para o período predito em ambas as usinas, na qual temos meses com muita similaridade entre as previsões e a MLT, mas 
também temos meses que a diferença chegou em aproximadamente $60 \%$. Para facilitar a visualização dos valores preditos comparados com a MLT, seguem, nas Figuras 5.6 e 5.7, os gráficos com as trajetórias obtidas na Tabela 5.6 para Furnas e Sobradinho, respectivamente.

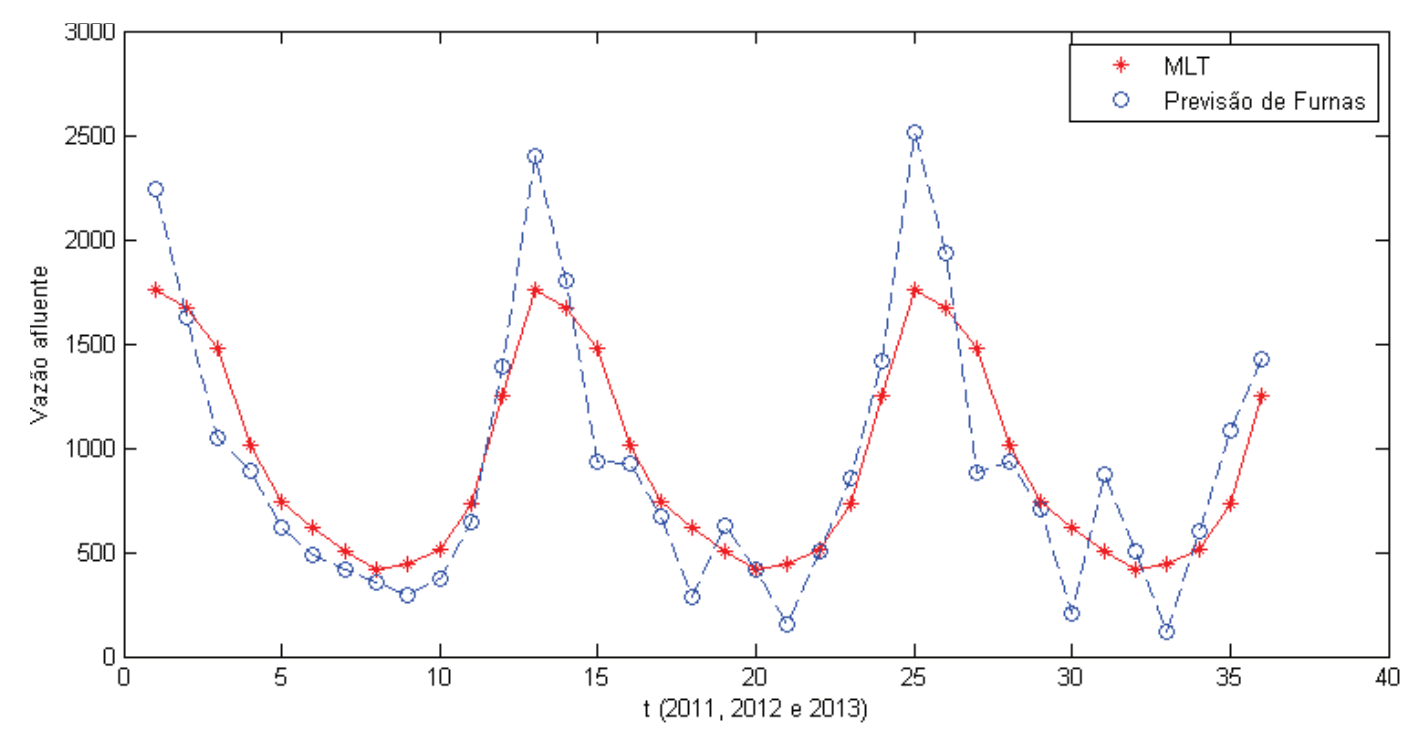

Figura 5.6: Trajetória dos valores preditos e MLT em 2011, 2012 e 2013 para Furnas.

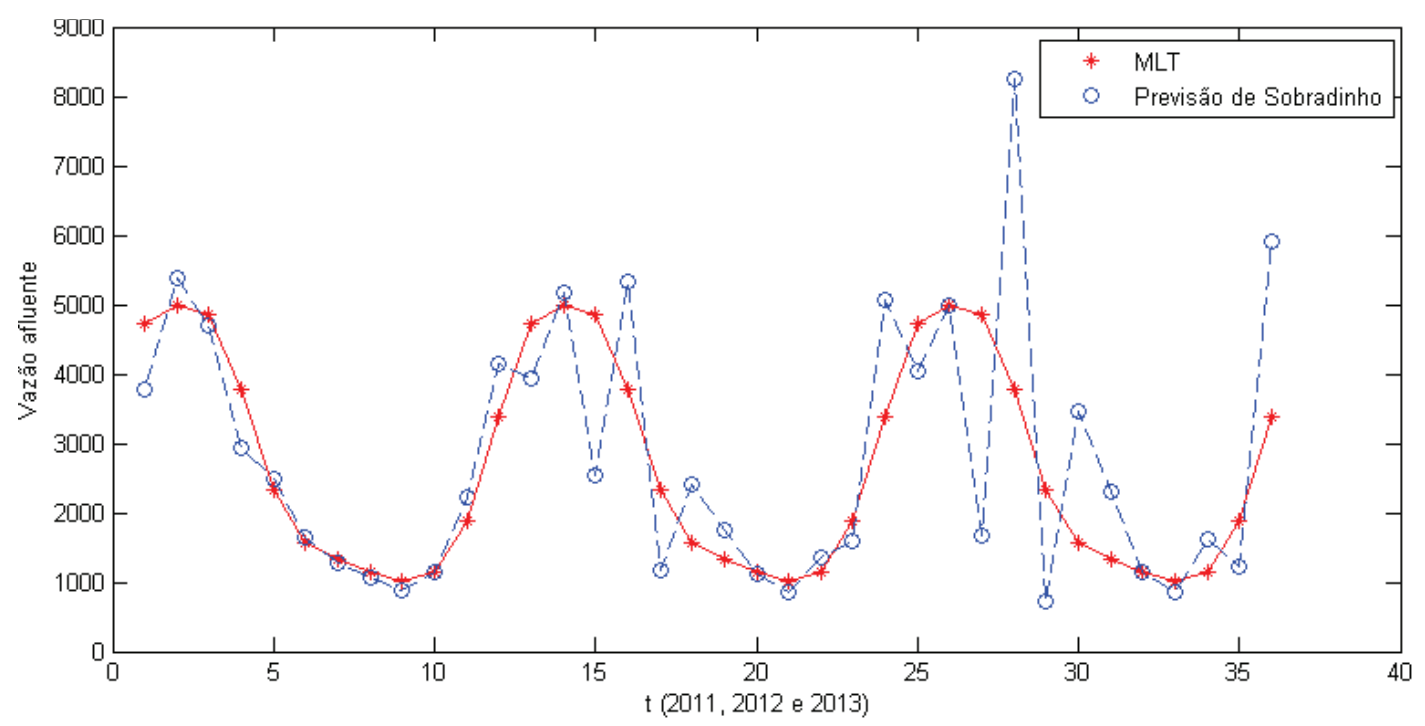

Figura 5.7: Trajetória dos valores preditos e MLT em 2011, 2012 e 2013 para Sobradinho.

As trajetórias do volume médio dos dois reservatórios são apresentadas na Figura 5.8. Nota-se que para o reservatório de Furnas, a PDE apresenta uma operação com níveis de reservatório mais baixo do que a PDD em todo período. 
(a)

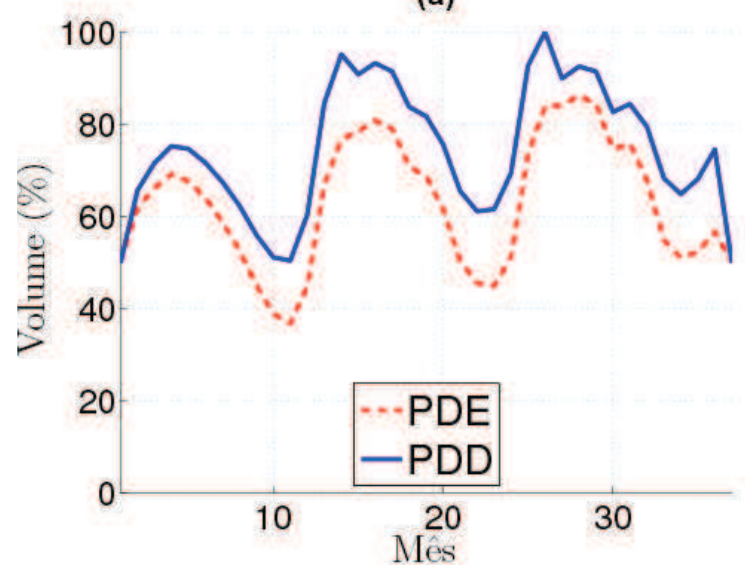

(b)

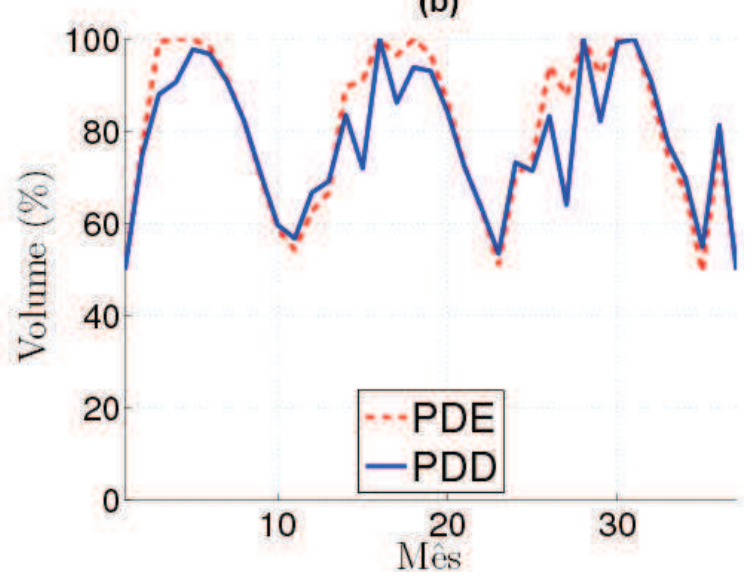

Figura 5.8: Trajetórias médias de volume para (a) Furnas e (b) Sobradinho, obtidas com as técnicas PDD e PDE no período de 2011 a 2013.

No entanto, o vertimento em ambas as técnicas para Furnas é nulo, como pode ser observado na Figura 5.9. Uma situação parcialmente oposta pode ser observada para o reservatório de Sobradinho. Neste caso, a PDE apresenta uma trajetória média do volume acima da PDD na maior parte do tempo.

(a)

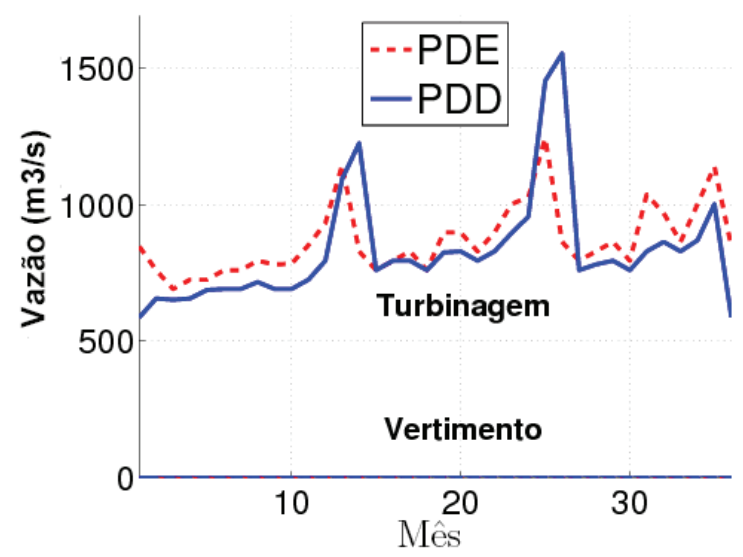

(b)

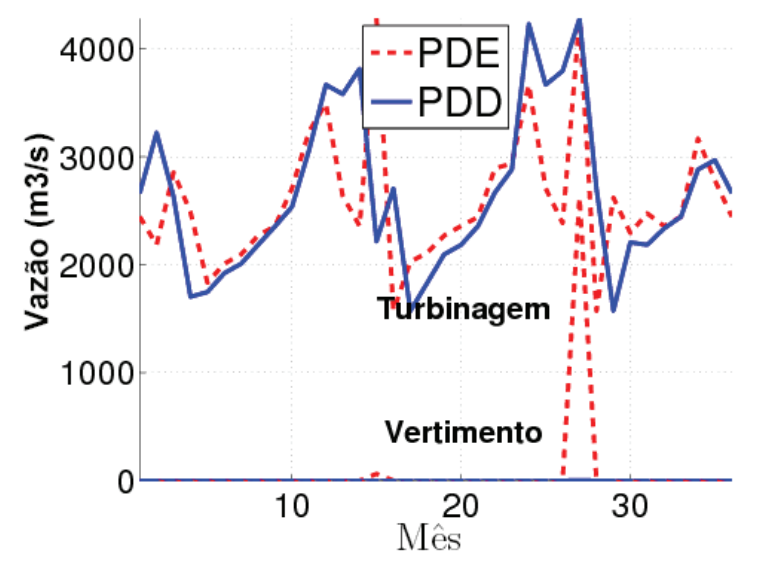

Figura 5.9: Trajetórias médias das turbinagens e vertimentos para (a) Furnas e (b) Sobradinho, obtidas com as técnicas PDD e PDE no período de 2011 a 2013.

A Figura 5.9 ilustra as trajetórias médias de turbinagens e vertimentos obtidos com as duas técnicas. Destaca-se o pico de vertimento para Sobradinho com a PDE, provavelmente ocorrido devido ao valor elevado da vazão afluente predita nesse mesmo período, porém, isto não afeta de forma significativa o rendimento da usina de Sobradinho, como pode ser observado pelas trajetórias de geração hidroelétrica (e complementação térmica) na Figura 5.10. 
(a)

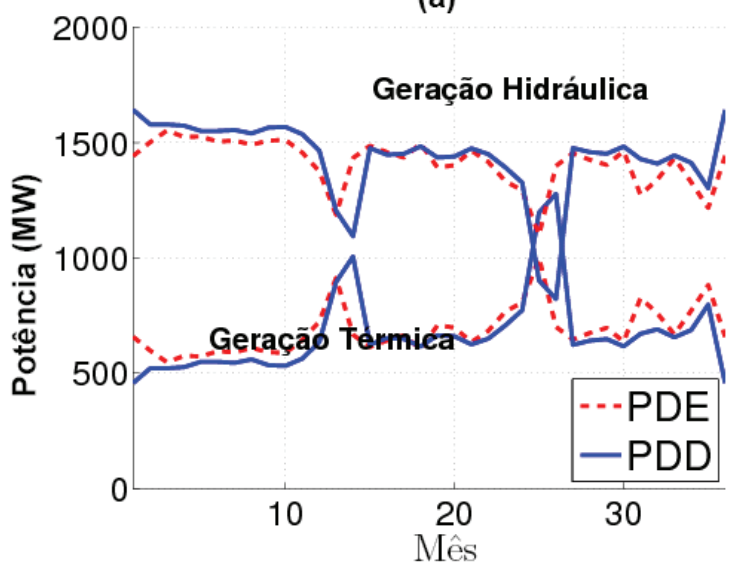

(b)

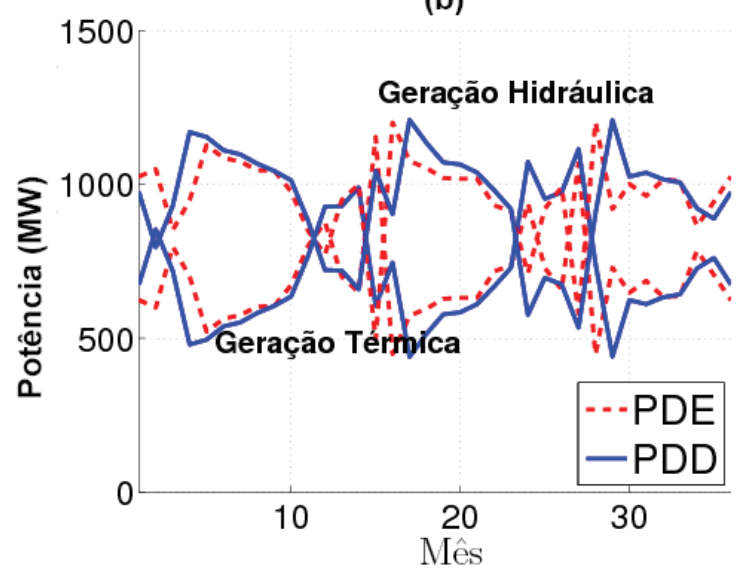

Figura 5.10: Geração hidroelétrica média e complementação térmica média para as usinas de (a) Furnas e (b) Sobradinho, obtidas com as técnicas PDD e PDE no período de 2011 a 2013.

A Tabela 5.7 apresenta os valores totais de geração e custo de operação para os reservatórios de Furnas e Sobradinho.

Tabela 5.7: Resultado da operação de Furnas e Sobradinho para os anos de 2011, 2012 e 2013 (GH = Geração Hidráulica Média; GT = Geração Térmica Média).

\begin{tabular}{c|c|c|c}
\hline Furnas & PDD & PDE & PDD/PDE \\
\hline GH (MW-mês) & 672,2707 & 684,7818 & 0,9817 \\
GT (MW-mês) & 1427,7293 & 1415,2182 & 1,0088 \\
Custo (Milhões) & 2,0690 & 2,0132 & 1,0277 \\
\hline Sobradinho & PDD & PDE & PDD/PDE \\
\hline GH (MW-mês) & 700,9641 & 688,1215 & 1,0187 \\
GT (MW-mês) & 949,0359 & 961,8785 & 0,9866 \\
Custo (Milhões) & 0,9316 & 0,9464 & 0,9843 \\
\hline
\end{tabular}

Com esses resultados, verificou-se que a PDE apresenta vantagens de custo médio em Furnas de, aproximadamente, 2, 8\%, enquanto que a PDD se mostrou mais econômica para Sobradinho com, aproximadamente, 1,6\% abaixo da PDE. Em termos de geração hidroelétrica, em Furnas é produzido, aproximadamente, 1,8\% a mais com a PDE e em Sobradinho há uma redução em torno 1,9\% com essa mesma técnica. 


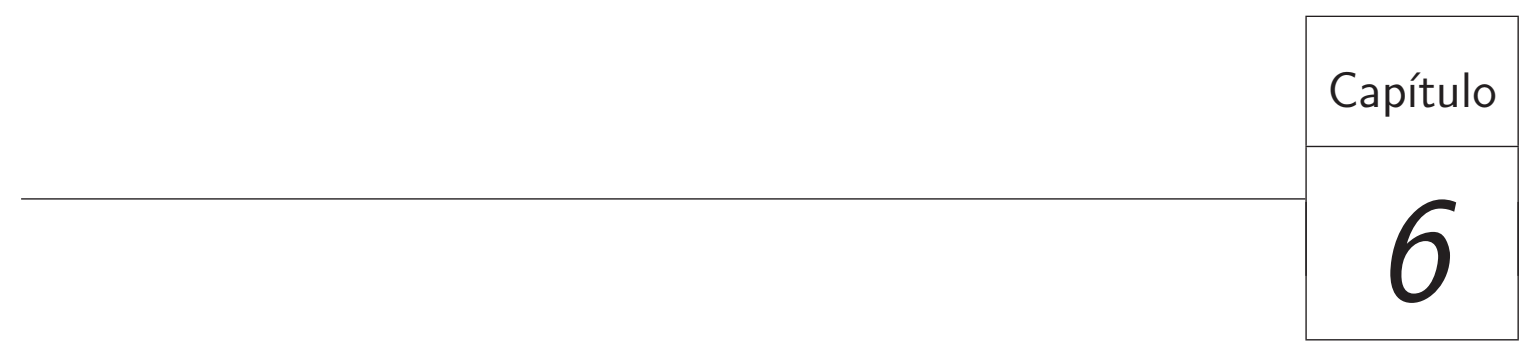

\section{Conclusão}

A proposta dessa dissertação foi apresentar a modelagem do problema de Planejamento Ótimo da Operação de Sistemas Hidrotérmicos (POOSH) através da programação dinâmica, na qual, a abordagem estocástica utilizou-se de um modelo de vazões Log-Normal Truncado (LN-Truncado) na perspectiva bayesiana. Essa metodologia foi aplicada no contexto das usinas hidroelétricas de Furnas e Sobradinho.

A combinação do modelo Markoviano periódico com a abordagem bayesiana se mostrou de grande valia para obtenção das estimativas dos parâmetros e previsões afluentes. A boa qualidade das previsões é evidenciada a partir do erro absoluto percentual (EAP) com valor entre 14\% e 35\% para Furnas e entre 6\% e 32\% para Sobradinho.

Com isso, foi comparado o desempenho da solução do POOSH obtida via Programação Dinâmica Determinística (PDD) com a solução obtida pela Programação Dinâmica Estocástica (PDE). Assim, foram apresentados resultados no sentido de avaliar o ganho com a utilização de um modelo estocástico na formulação do problema de POOSH.

A partir dos resultados obtidos foi observado que a PDE pode apresentar vantagens significativas em relação à PDD, com uma diferença de custo médio em torno de 1,5\% nos casos de estudo avaliados, além disso, a PDE possui vantagens nos períodos críticos simulados, no entanto, mais testes devem ser realizados para uma conclusão mais afirmativa. 
Após as análises e comparações do planejamento médio anual com a PDE e a PDD, utilizou-se a metodologia apresentada para previsões com o intuito de prever as vazões afluentes de 2011, 2012 e 2013. Nesses resultados foi constatado uma redução de custo da PDE, em relação a PDD, de aproximadamente 2, 8\% para Furnas e um aumento de $1,6 \%$ para Sobradinho.

Com isso, as principais contribuições desse trabalho foram a revisão literária da modelagem do problema e a incorporação do modelo de vazões LN-Truncado na abordagem bayesiana para calcular as estimativas dos parâmetros e previsões afluentes. 


\begin{tabular}{|l|l|}
\hline & Capítulo \\
\hline
\end{tabular}

\section{Propostas Futuras}

Como proposta de complementação dessa dissertação, temos a aplicação da Programação Dinâmica Estocástica, com a metodologia apresentada, para outras usinas hidroelétrica do sistema brasileiro. Além disso, é fundamental a elaboração de outros critérios de validação da série sintética.

Com o mesmo enfoque abordado nesse trabalho, um fator relevante é a escolha das prioris, na qual, informações de especialistas da área podem tornar essas prioris mais informativas, fornecendo melhores estimativas e previsões.

Para expandir a modelagem do problema pode ser utilizado a metodologia de sistemas equivalente, assim, incorpora-se múltiplos reservatórios ao modelo, o que torna os resultados mais realistas e coerentes com a atual situação do sistema hidroelétrico brasileiro. 



\section{Referências Bibliográficas}

Anderson, P. L. and Vecchia, A. V. (1993). Asymptotic results for periodic autoregressive moving average processes. Time Series Analyses, 14:1-18.

Archibald, T., McKinnon, K., and Thomas, L. (1997). An aggregate stochastic dynamic programming model of multireservoir systems. Water Resources Research, 33(2):333340.

Barbancho, A. G. (1970). Fundamentos e Possibilidades da Econometria. Estante de Economia e Finanças. Forum, Rio de Janeiro.

Barros, M. T. L., Tsai, F. T.-C., Yang, S., Lopes, J. E. G., and Yeh, W. W.-G. (2003). Optimization of large-scale hydropower system operations. Journal of Water Resources Planning and Management, 129(3):178-188.

Gamerman, D. and Lopes, H. F. (2006). Markov Chain Monte Carlo: Stochastic Simulation for Bayesian Inference. Chapman \& Hall/CRC Texts in Statistical Science, second edition.

Geman, S. and Geman, D. (1984). Stochastic relaxation, gibbs distributions, and the bayesian restoration of images. IEEE Transactions on Pattern Analysis and Machine Intelligence, 6(6):721 - 741 .

Hastings, W. K. (1970). Monte carlo sampling methods using markov chains and their applications. Biometrika, 57(1):97 - 109.

Hippel, K. W., McBean, A., and McLeod, A. I. (1979). Hydrologic generating model selection. J. Water Resour. Plann. Manege. Div. Am. Soc. Civ. Eng., 105-WR2:223242. 
Jardim, D. L. D. D., Maceira, M. E. P., and Falcão, D. M. (2001). Stochastic streamflow model for hydroelectric systems using clustering techniques. In IEEE Porto Power Tech Conference, pages 1-6, Porto, Portugal.

Kullback, S. and Leibler, R. (1951). On information and sufficiency. Annals of Mathematical Statistics, 22-1:79-86.

Lawrence, A. J. and Kottegoda, N. T. (1977). Stochastic modelling of riverflow time series. J. R. Statist. Soc. Serie A, 150-1:1-47.

Maceira, M. E. P., Terry, L., Costa, F. S., Damázio, J. M., and Melo, A. C. G. (2002). Chain of optimization models for setting the energy dispatch and spot price in the brazilian system. In 14 th Power Systems Computation Conference, Sevilla, Spanish.

Makridakis, S. G. and Wheelwright, S. C. (1985). Forecasting Methods for Management. John Wiley \& Sons Inc, New York, 4th edition edition.

McCulloch, R. E. (1989). Local model influence. Journal of the American Statistical Association, 84-406:473-478.

Metropolis, N., Rosenbluth, A. W., Rosenbluth, M. N., Teller, A. H., and Teller, E. (1953). Equation of state calculations by fast computing machines. The Journal of Chemical Physics, 21(6):1087 - 1092.

Mondal, M. S. and Wasimib, S. A. (2006). Generating and forecasting monthly flows of the ganges river with par model. Journal of Hydrology, 323:41-56.

Morettin, P. A. and Toloi, C. M. C. (1981). Modelos para Previsão de Séries Temporais. $13^{\circ}$ Colóquio Brasileiro de Matemática (IMPA), Rio de Janeiro.

Nandalal, K. D. W. and Bogardi, J. J. (2007). Dynamic programming based operation of reservoirs: applicability and limits. Cambridge University Press.

Ouarda, T. and Labadie, J. (2001). Chance-constrained optimal control for multireservoir system optimization and risk analysis. Stochastic Environmental Research and Risk Assessment, 15(3):185-204.

Pereira, M. (1985). Optimal Scheduling of Hydrothermal Systems - An Overview. IFAC - Symposium on Planning and Operation of Electric Energy System, pages 1-9.

Pereira, M. V. F., Oliveira, G. C., Costa, C. C. G., and Kelman, J. (1984). Stochastic streamflow models for hydroelectric systems (brazil). Water Resources Research, 20-3:379-390. 
Refenes, A. N., Barac, A. M., and Treleaven, P. C. (1993). Financial modeling using neural networks. In Liddell, H., editor, Commercial Applications of Parallel Computing. UNICOM.

Robert, C. P. and Casella, G. (2005). Monte Carlo Statistical Methods (Springer Texts in Statistics). Springer-Verlag New York, Inc., Secaucus, NJ, USA.

Robert, C. P. and Casella, G. (2011). A short history of markov chain monte carlo: Subjective recollections from incomplete data. Statistical Science, 26(1):102 - 115.

Salas, J. D., Sveinsson, O. G., Lane, W. L., and Frevert, D. K. (2006). Stochastic streamflow simulation using sams-2003. Journal of Irrigation and Drainage Engineering, 132-2:112-122.

Soares, S. and Carneiro, A. (1991). Optimal Operation of Reservoirs for Electric Generation. Power Delivery, IEEE Transactions on, 6(3):1101 -1107.

Souza, R. C. (1989). Modelos Estruturais para Previsão de Séries Temporais : Abordagens Clássica e Bayesiana. $17^{\circ}$ Colóquio Brasileiro de Matemática (IMPA), Rio de Janeiro.

Stedinger, J. R., Sule, B. F., and Loucks, D. P. (1984). Stochastic dynamic programming models for reservoir operation optimization. Water Resources Research, 20-11:1499-1505.

Stedinger, J. R. and Taylor, M. R. (1982). Synthetic streamflow generation. 1. model verification and validation (delaware river, new york state). Water Resources Research, 18-4:909-918.

Thomas, Jr., H. A. and Fiering, M. B. (1962). Design of Water Resources Systems. Number 12 in Cambridge, Mass. Mathematical synthesis of streamflow sequences for the analysis of river basins by simulation, harvard university press edition.

Todorovic, P. and Zelenhasic, E. (1970). A stochastic model for flood analysis. Water Resources Research, 6-6:1641-1648.

Vicens, G. J., Rodriguez-Iturbe, I., and Schaake Jr., J. C. (1975). Bayesian generation of synthetic streamflows. Water Resources Management, 11-6:827-838.

Wurbs, R. (1996). Modeling and Analysis of Reservoir System Operations. PrenticeHall. 
Yakowitz, S. (1982). Dynamic-Programming Applications in Water-Resources. Water Resources Research, 18(4):673-696.

Yeh, W. W. G. (1985). Reservoir Management and Operations Models: A State-ofthe-Art Review. Water Resources Research, 21(12):1797-1818. 


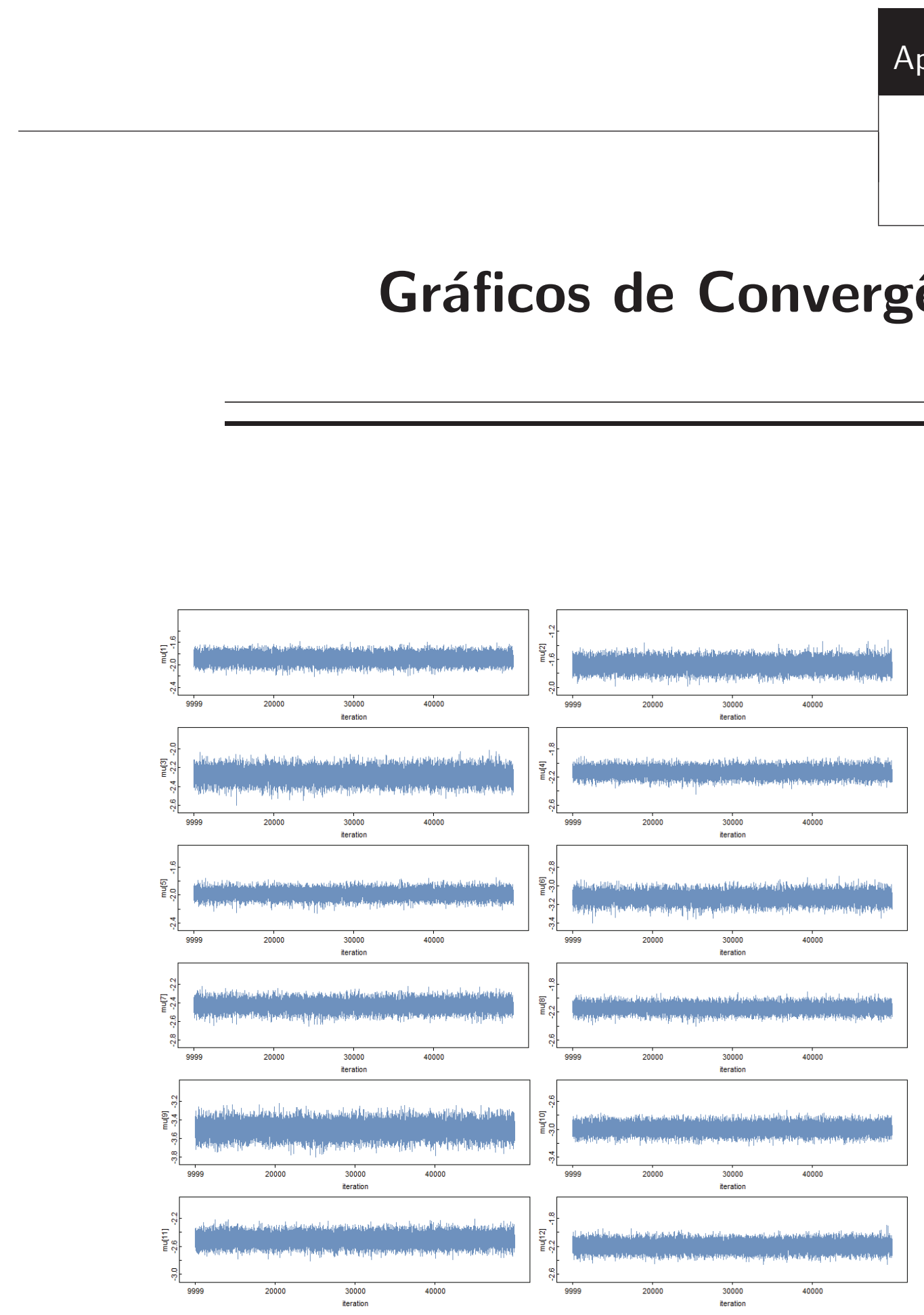

Figura A.1: Convergência de $\mu_{m}, m=1, \ldots, 12$, da usina hidroelétrica de Furnas. 

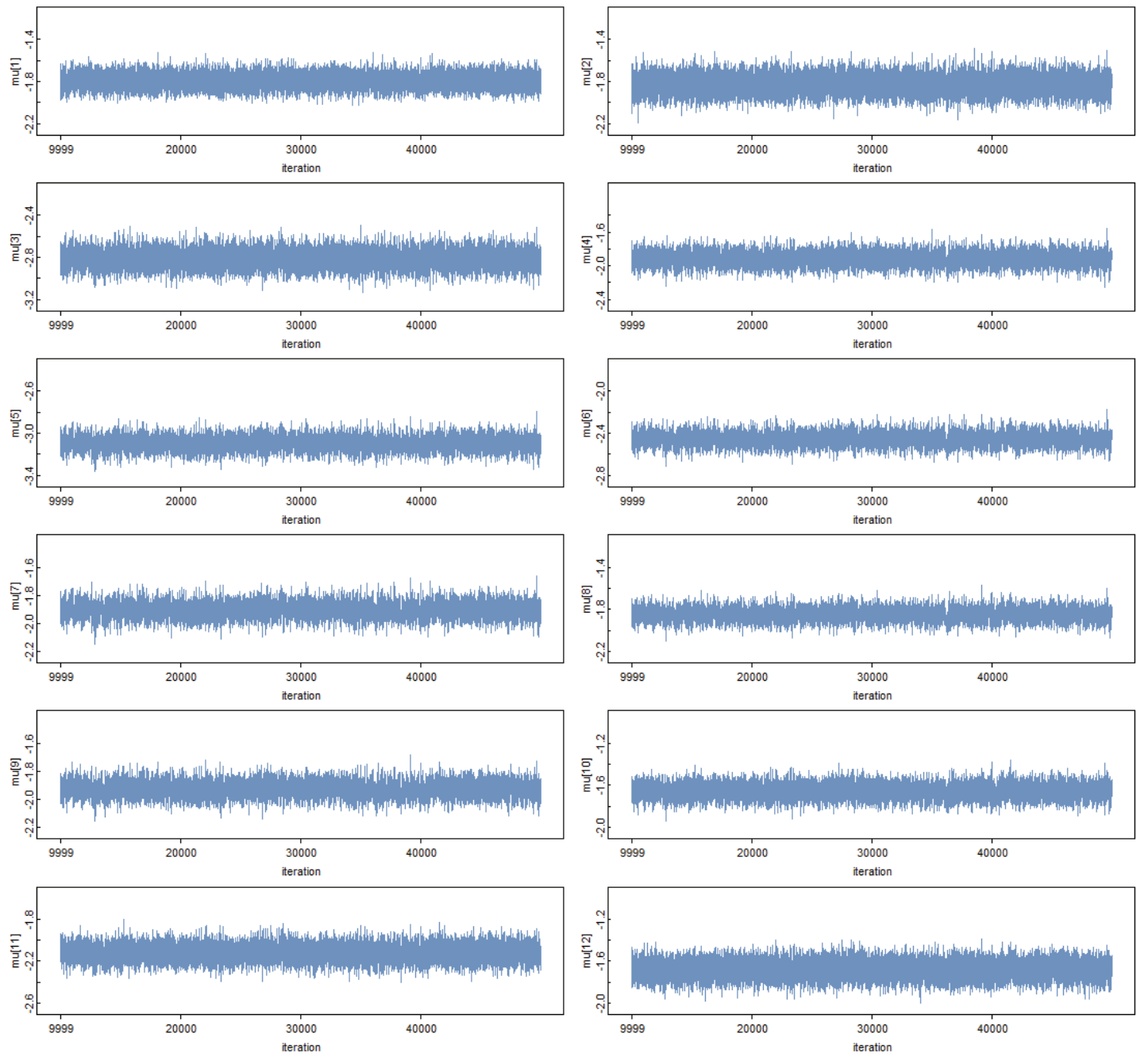

Figura A.2: Convergência de $\mu_{m}, m=1, \ldots, 12$, da usina hidroelétrica de Sobradinho. 

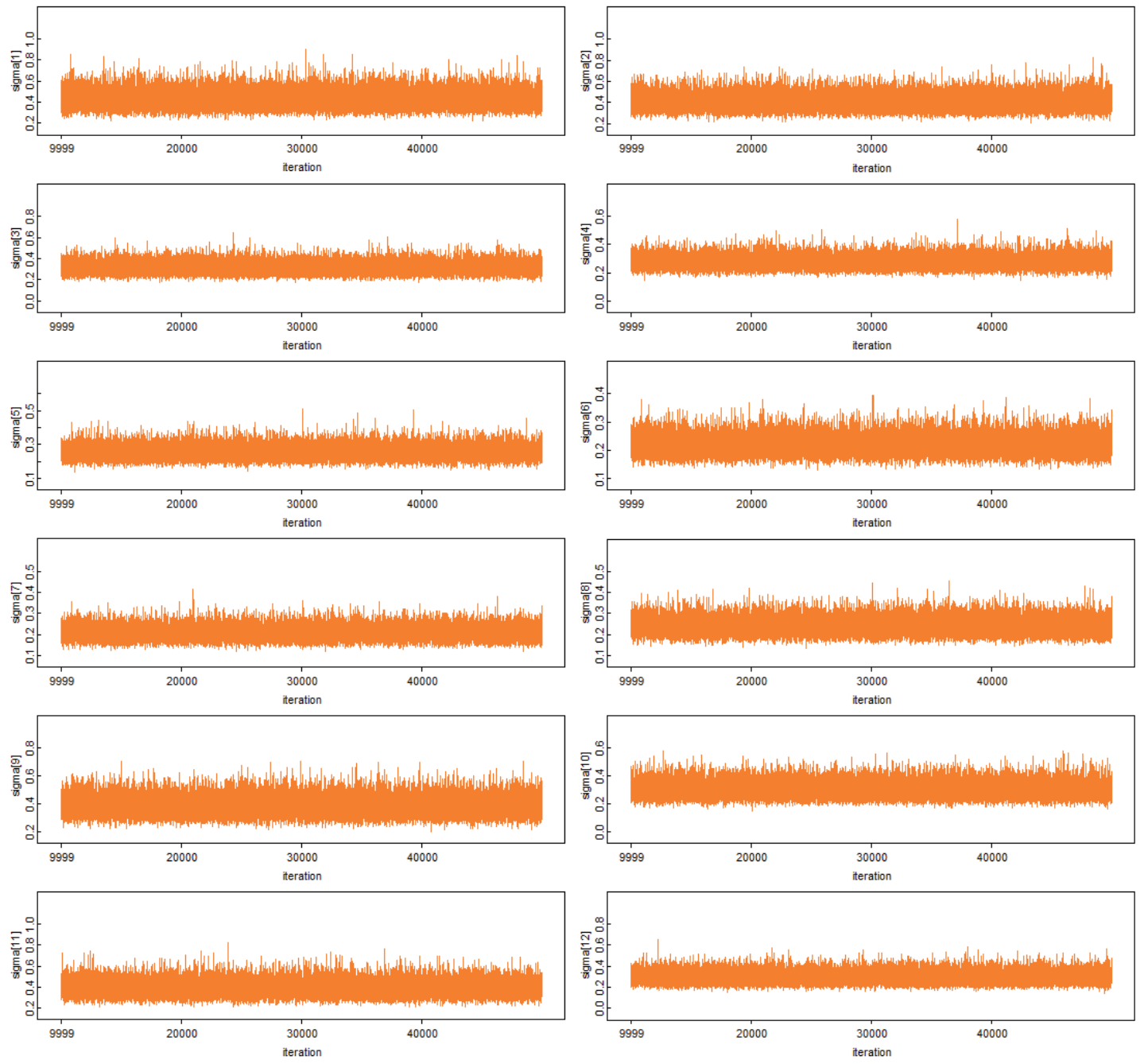

Figura A.3: Convergência de $\sigma_{m}^{2}, m=1, \ldots, 12$, da usina hidroelétrica de Furnas. 

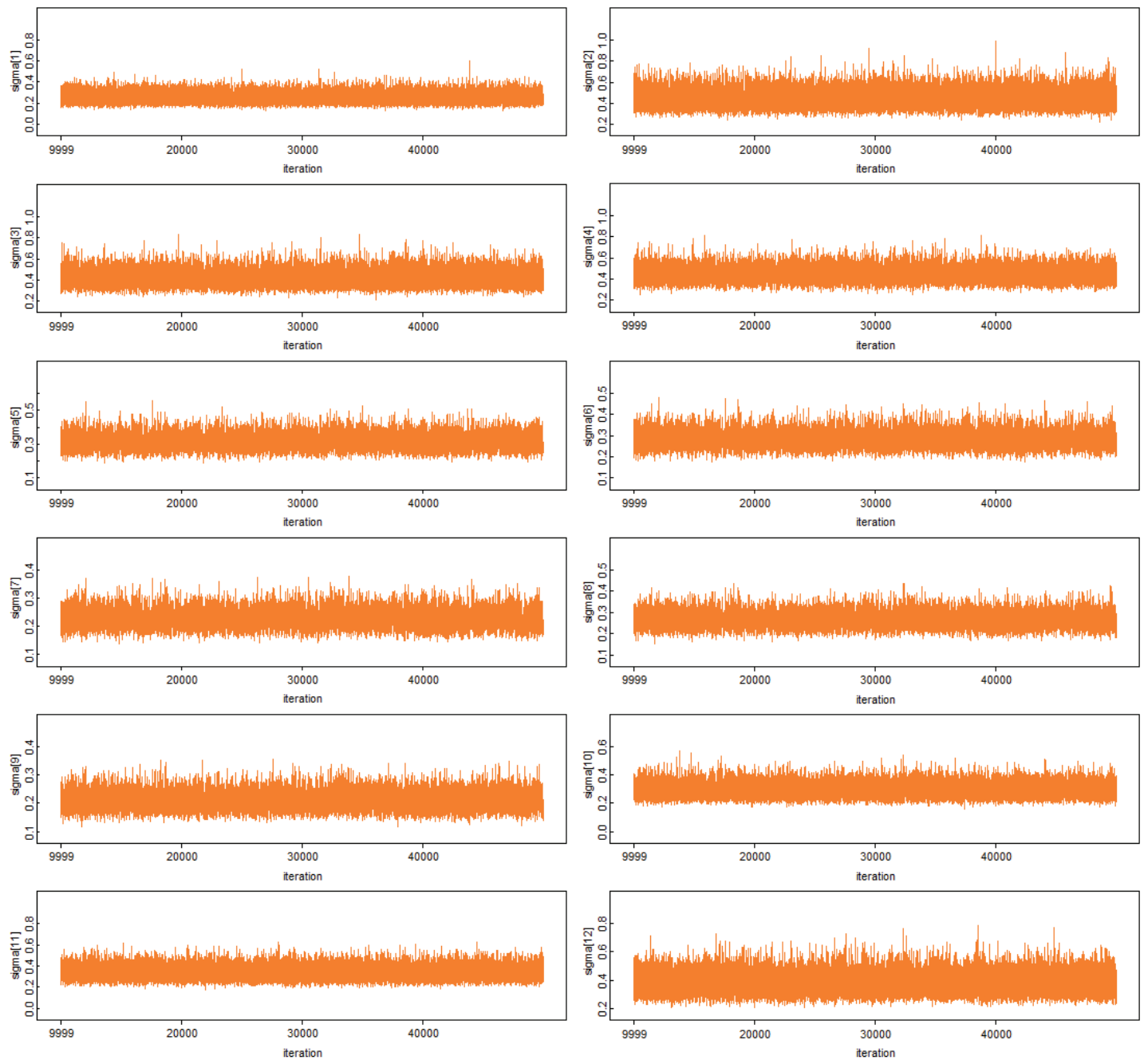

Figura A.4: Convergência de $\sigma_{m}^{2}, m=1, \ldots, 12$, da usina hidroelétrica de Sobradinho. 

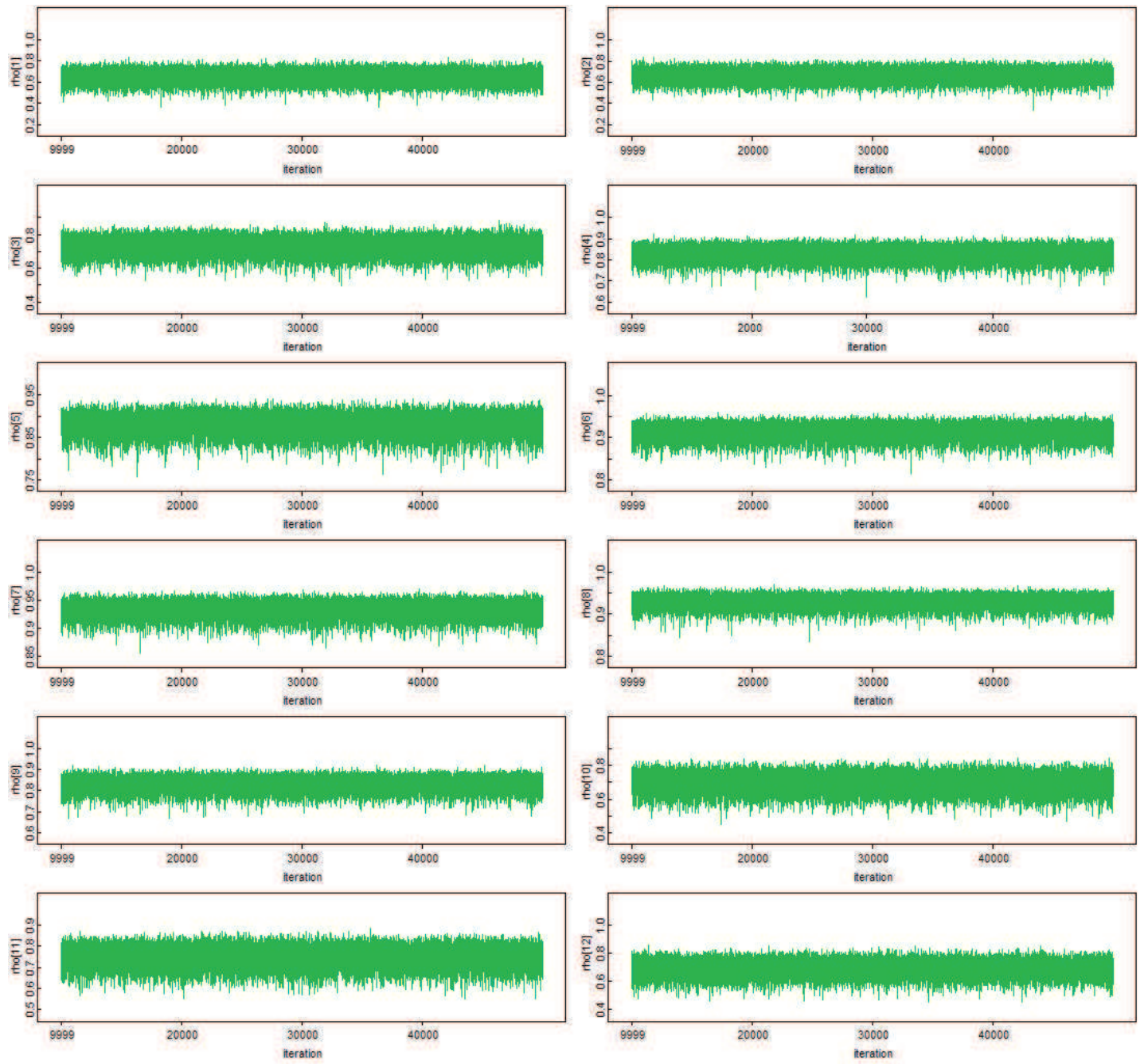

Figura A.5: Convergência de $\rho_{m}, m=1, \ldots, 12$, da usina hidroelétrica de Furnas. 

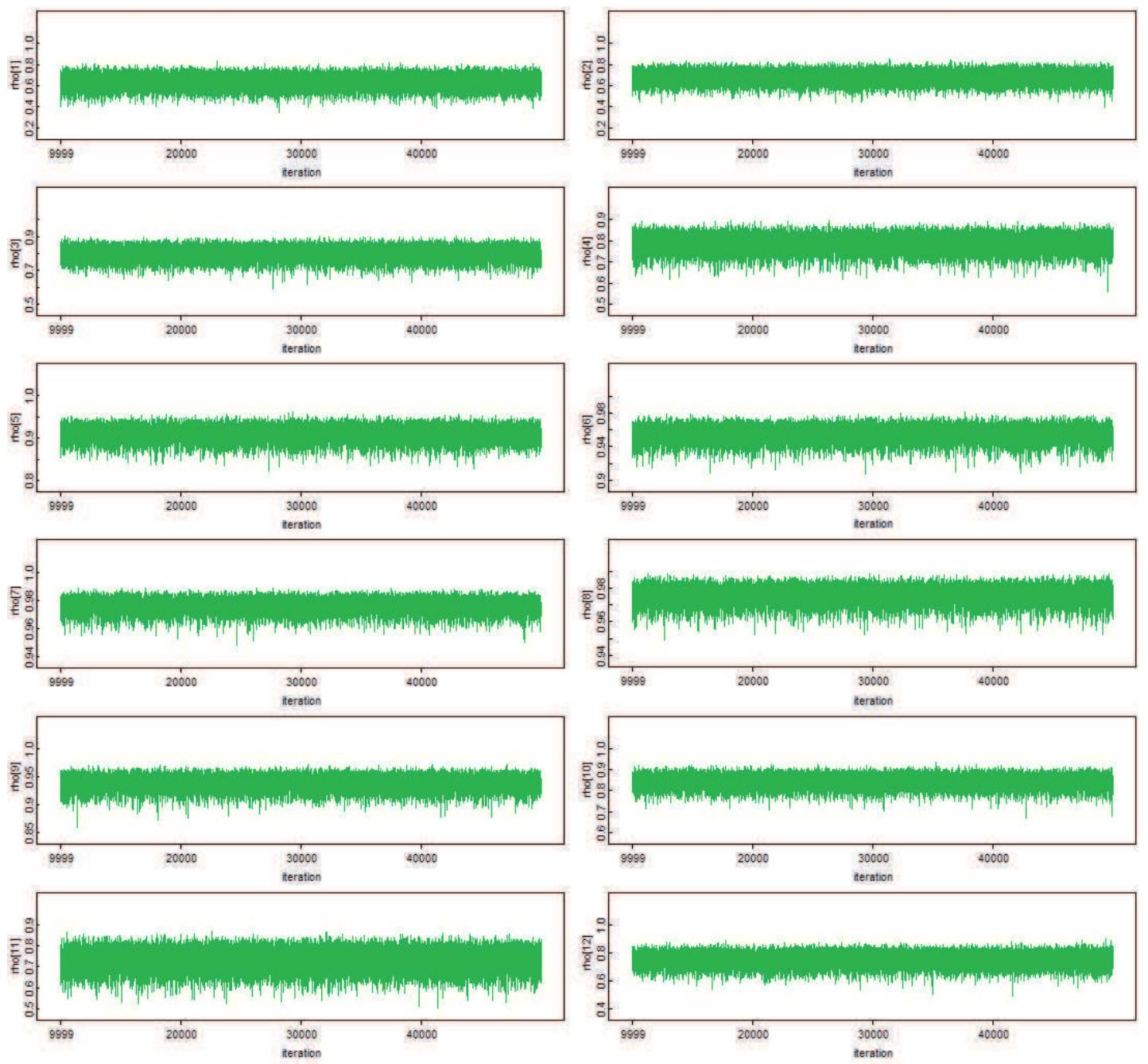

Figura A.6: Convergência de $\rho_{m}, m=1, \ldots, 12$, da usina hidroelétrica de Sobradinho. 


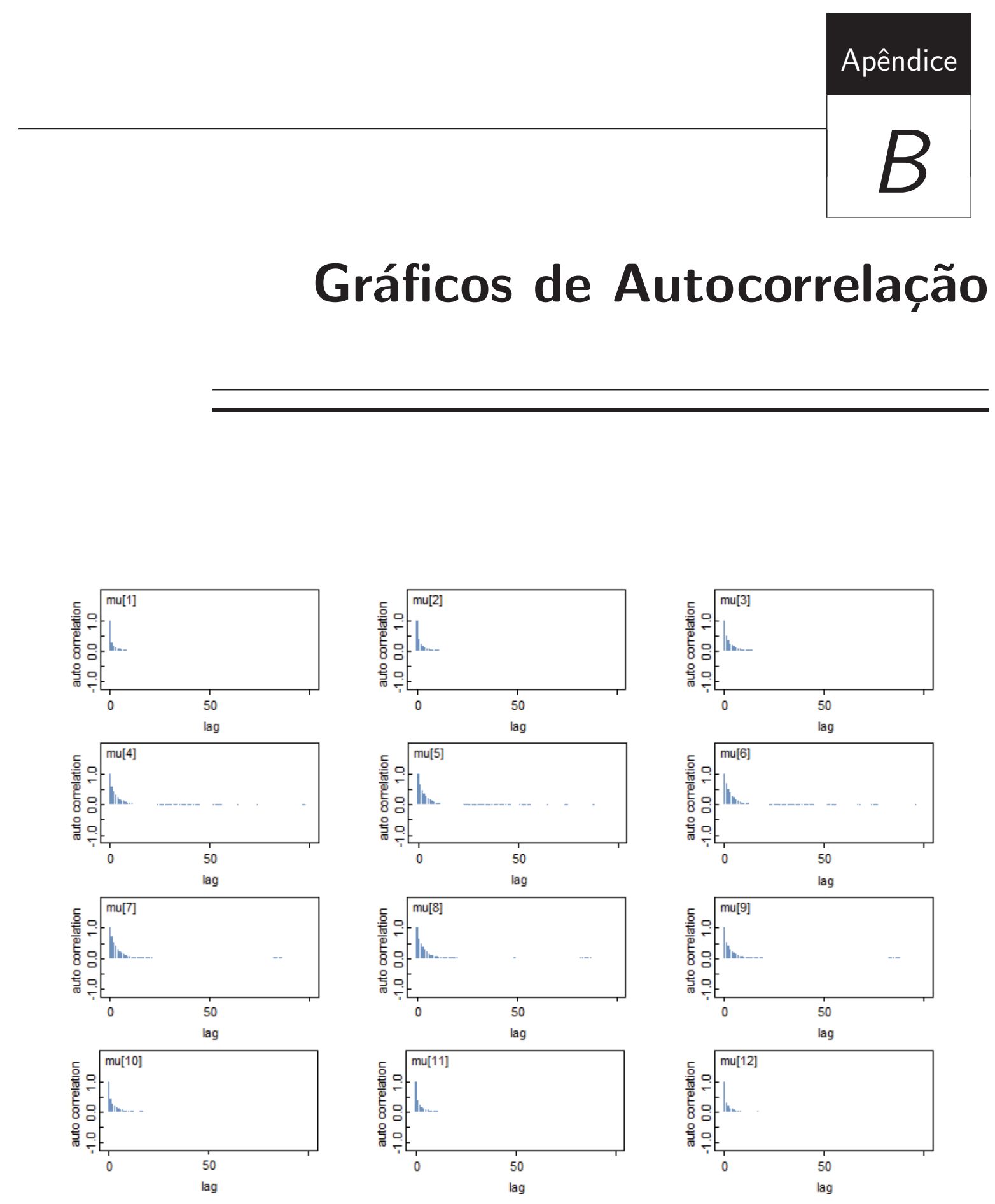

Figura B.1: Autocorrelação de $\mu_{m}, m=1, \ldots, 12$, da usina hidroelétrica de Furnas. 

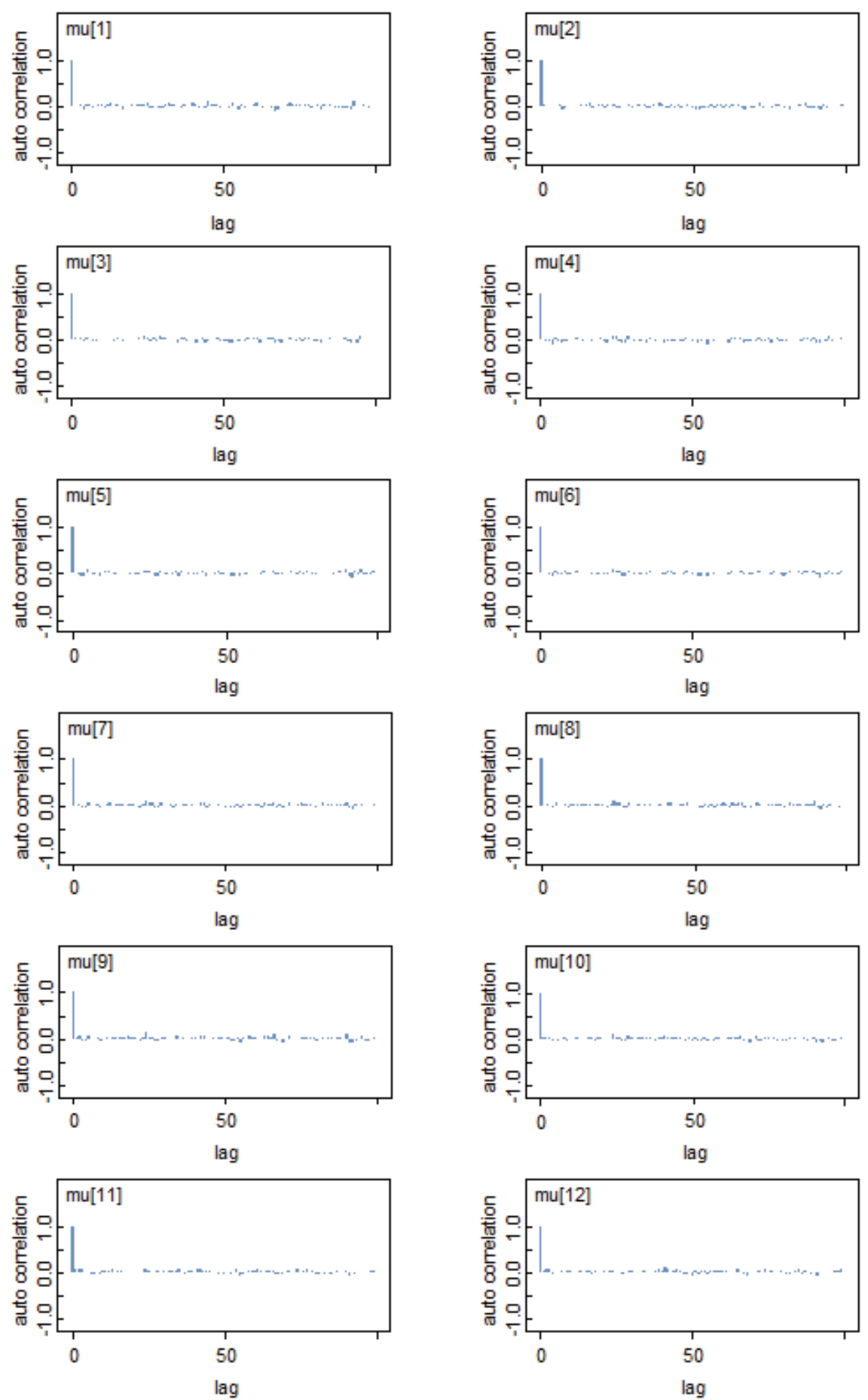

Figura B.2: Autocorrelação de $\mu_{m}, m=1, \ldots, 12$, da usina hidroelétrica de Sobradinho. 

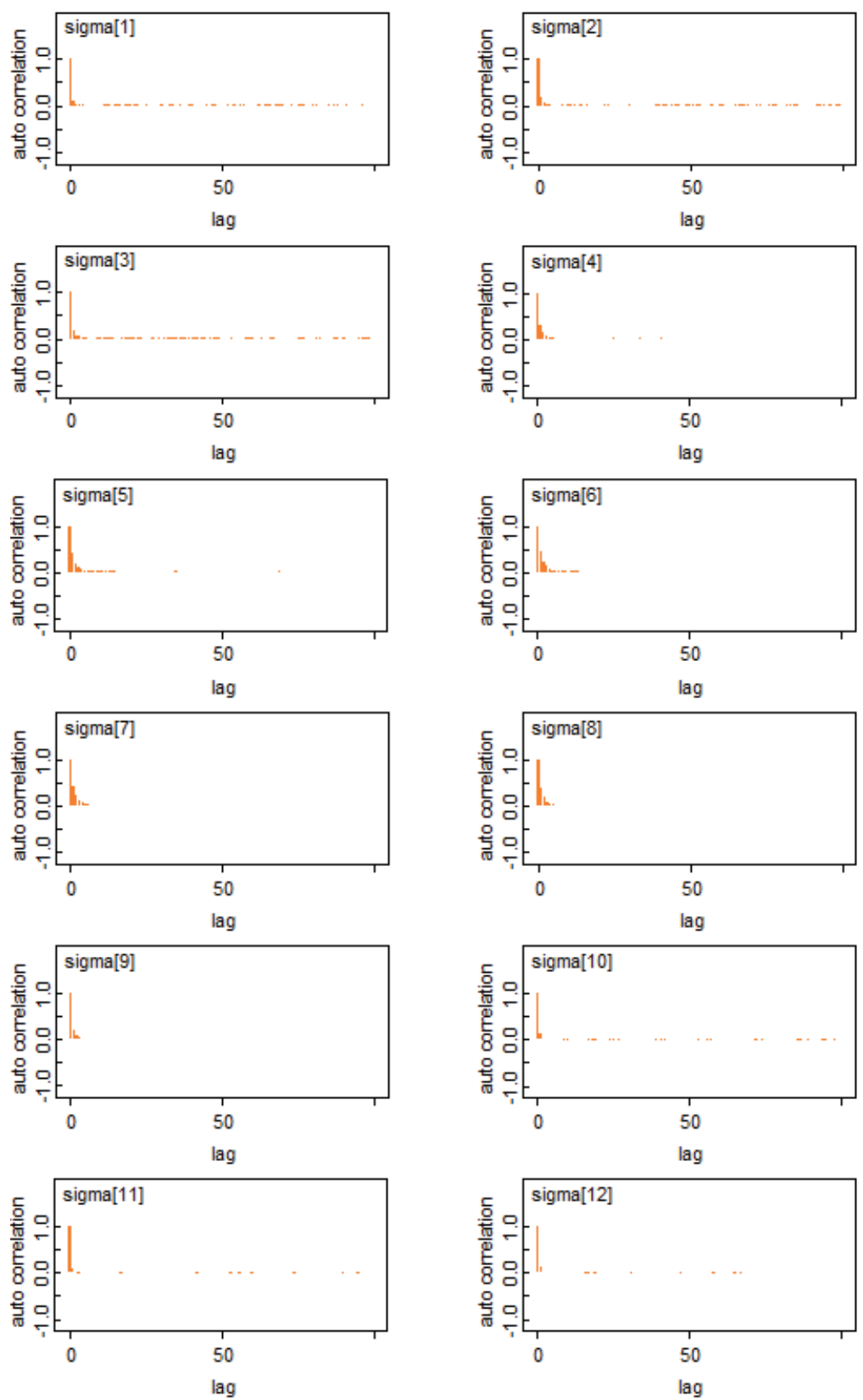

Figura B.3: Autocorrelação de $\sigma_{m}^{2}, m=1, \ldots, 12$, da usina hidroelétrica de Furnas. 

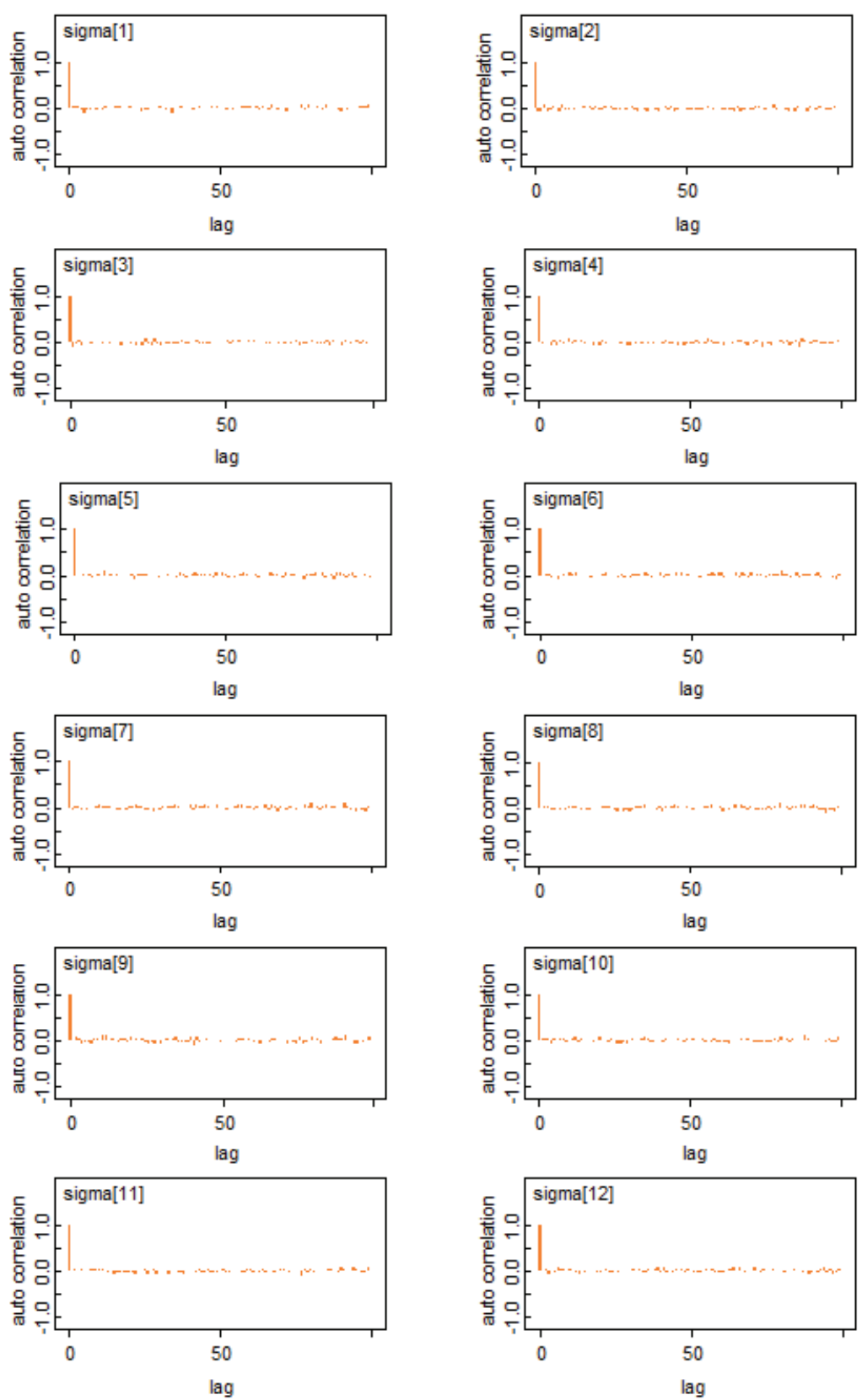

Figura B.4: Autocorrelação de $\sigma_{m}^{2}, m=1, \ldots, 12$, da usina hidroelétrica de Sobradinho. 

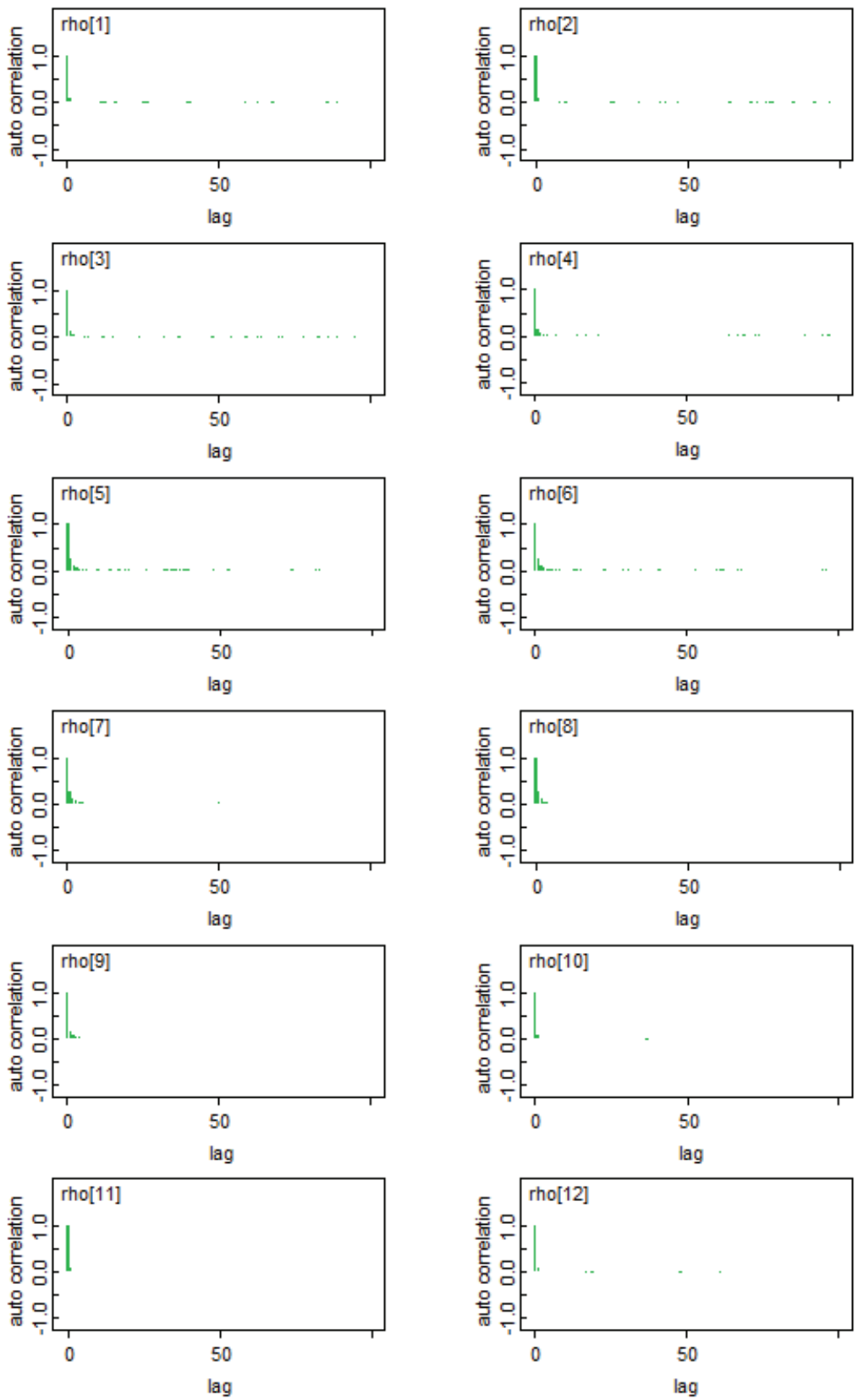

Figura B.5: Autocorrelação de $\rho_{m}, m=1, \ldots, 12$, da usina hidroelétrica de Furnas. 

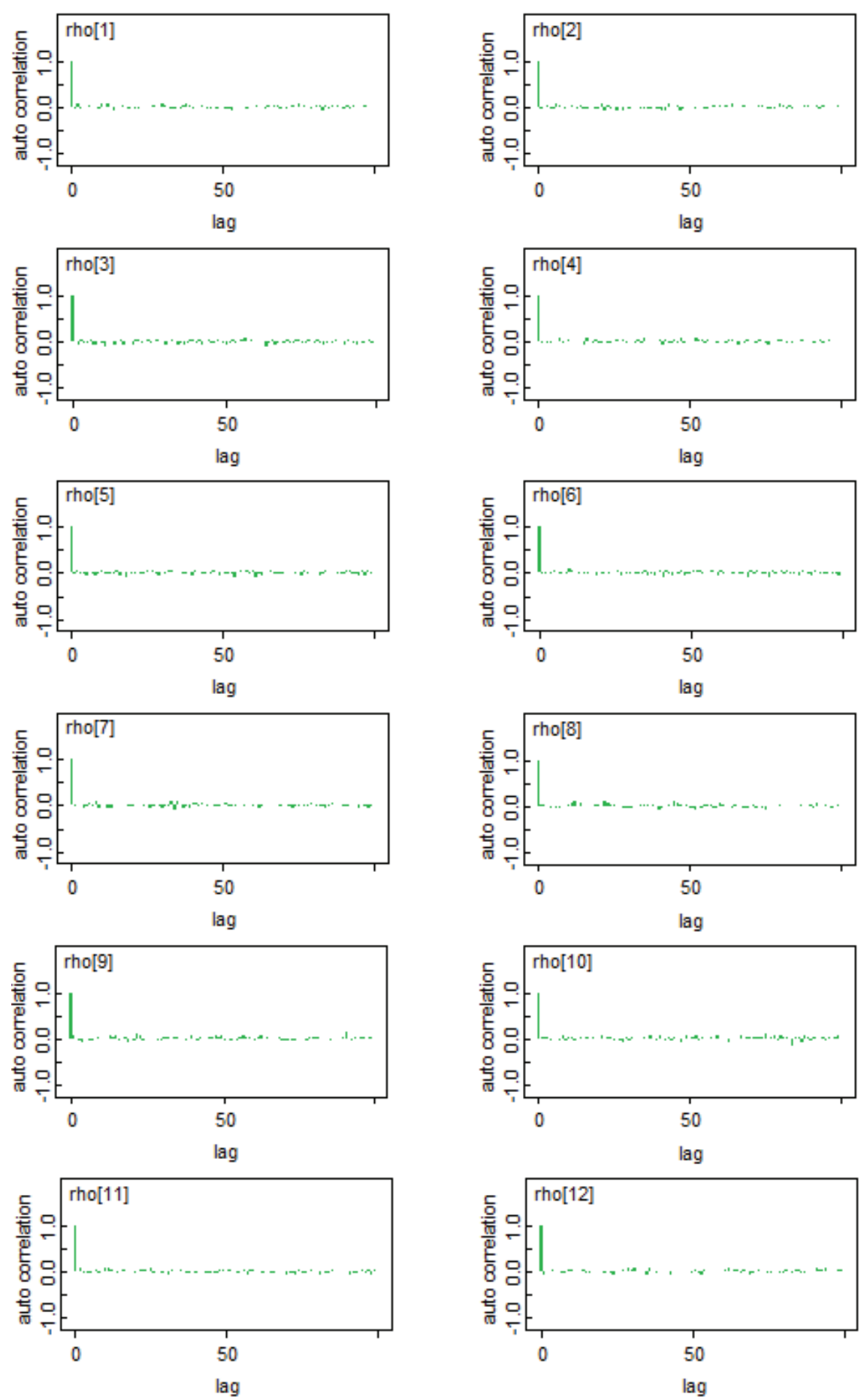

Figura B.6: Autocorrelação de $\rho_{m}, m=1, \ldots, 12$, da usina hidroelétrica de Sobradinho. 